\title{
Analysis of Contact Pressure for Monitoring Body Fluid Distribution
}

by

Madison Cohen-McFarlane, B.Eng.

A thesis submitted to the Faculty of Graduate and Postdoctoral Affairs in partial fulfillment of the requirements for the degree of Master of Applied Science in Biomedical Engineering

Ottawa-Carleton Institute for Biomedical Engineering Department of Systems and Computer Engineering

Carleton University

Ottawa, Ontario, Canada, K1S 5B6

April 2017

C Copyright 2017, Madison Cohen-McFarlane 


\section{Abstract}

Fluid distribution is a key indicator for a variety of diseases that become more prevalent as we age, such as congestive heart failure (CHF) and nocturia. Current methods to monitor fluid distribution rely on infrequent and often self-report measures, which are unreliable. This thesis aims to develop and evaluate a continuous, unobtrusive, and non-invasive alternative method based on the use of pressure sensitive mats (PSM) to accurately measure fluid distribution within a patient. We here detail the design of an algorithmic system to monitor changes in fluid distribution over time.

A series of four increasingly complex experiments were performed using PSMs. The first three experiments established that PSMs are sufficiently sensitive to detect small variations in mass typical of fluid retention observed in CHF patients, where fluid pools in the ankles while the patient is vertical and redistributes to the bladder over night while horizontal. The final experiment and corresponding algorithm aimed to differentiate when an individual exits the bed to: (1) do nothing, (2) void their bladder, or (3) drink as much water as was comfortable. A method to automatically segment a person's pressure image into regions of interest (ROI) was developed. Based on the results from a single participant in three different postures (prone, supine, and side), the system was able to identify bed exits associated with large voids and drinking events $(\mathrm{p}<0.05)$. Small voids were only reliably detectable in the prone positon $(\mathrm{p}<0.01)$. These results suggest that this system is

effective at distinguishing between significant fluid intake and fluid output events, and emphasizes the potential for novel non-invasive fluid distribution monitoring systems to improve traditional healthcare approaches. 


\section{Acknowledgements}

First and foremost, I would like to thank my academic supervisors, Dr. Rafik Goubran and Dr. James Green, for all the support that I received throughout my thesis. I have been lucky enough to not only have two supervisors that were able to effectively guide me through this process, but also two mentors that have pushed me to reach for goals that I previously would not have considered. I would also like to thank my medical supervisor, Dr. Frank Knoefel, for his help with all things clinical and for always taking the time form a busy schedule to offer his expertise on all the written material I sent his way.

Thank you to Stephanie Bennett for having the patience to answer all of my questions and Vilas Joshi for encouraging me to 'reach for the stars'. I would also like to thank all of my fellow graduate students in both the Green Lab and the Goubran Lab for their support and friendship over the last two years.

Finally, I would like to thank my family for their unconditional love, support and encouragement. And to my friends, thank you for being the best excuse to take a break a girl could ever ask for. 


\section{Table of Contents}

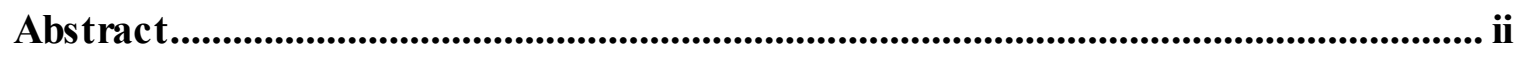

Acknowledge ments ................................................................................................. iii

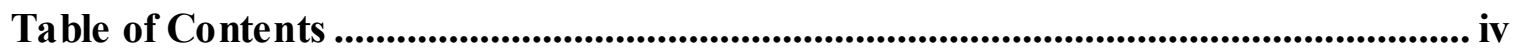

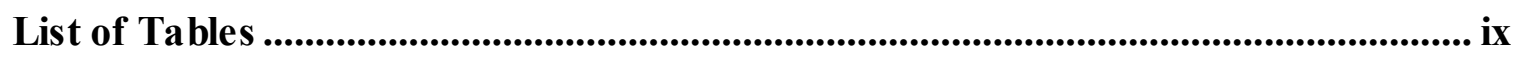

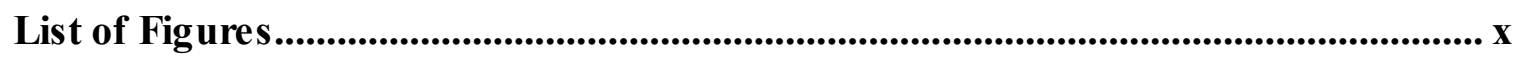

List of Appendices ..................................................................................................................... xiv

1 Introduction ..................................................................................................... 1

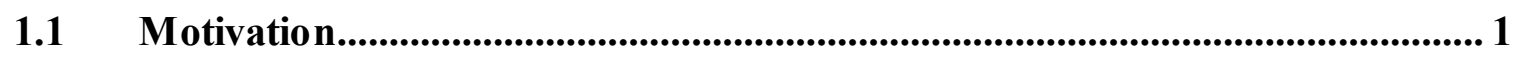

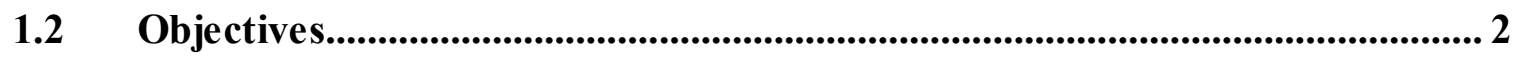

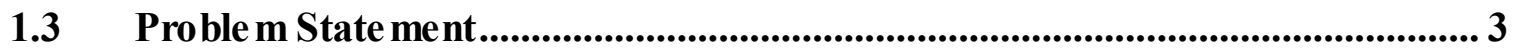

1.4 Summary of Contributions ..................................................................................... 3

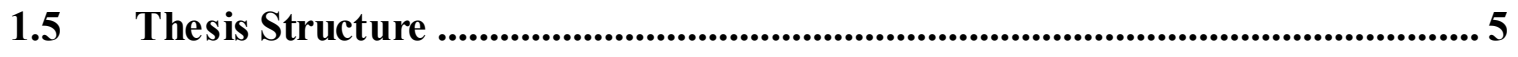

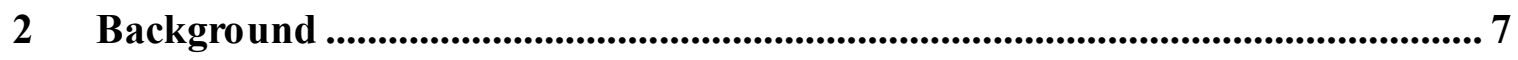

Introduction ............................................................................................................... 7

2.2 Health Conditions of Interest....................................................................................... 7

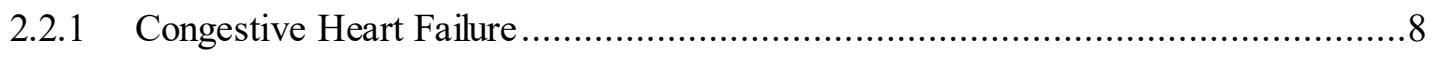

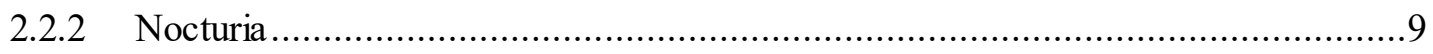

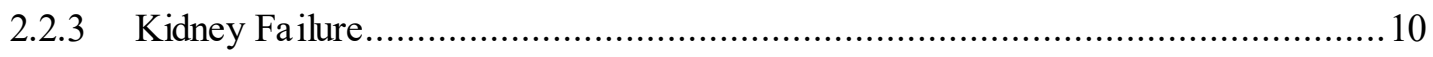

2.3 Patient Monitoring ........................................................................................... 11

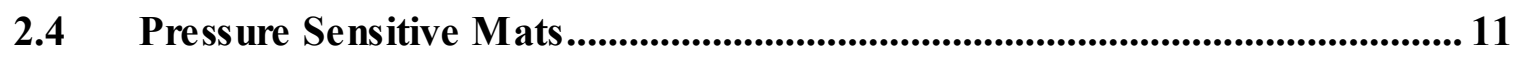

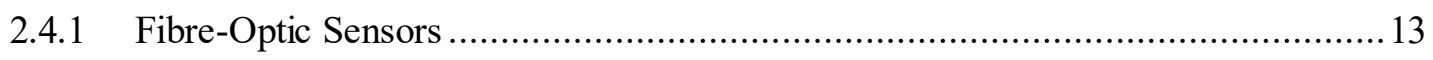

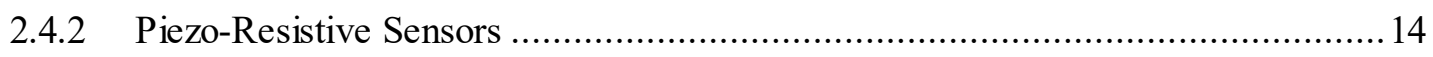


$2.5 \quad$ Related Work.............................................................................................. 15

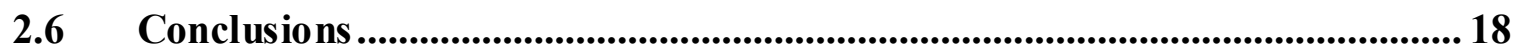

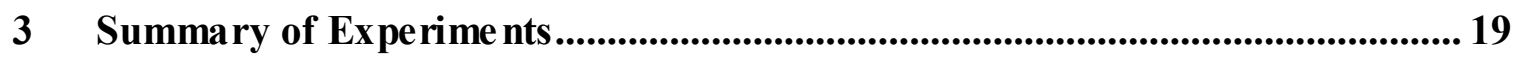

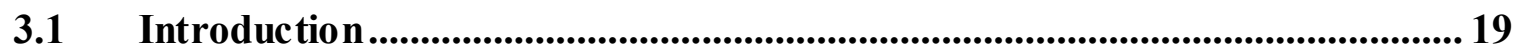

3.2 Preview of Final Experime ntal Results ........................................................ 19

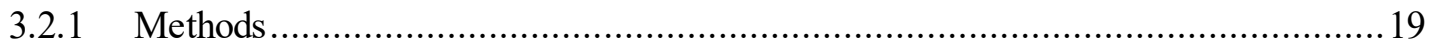

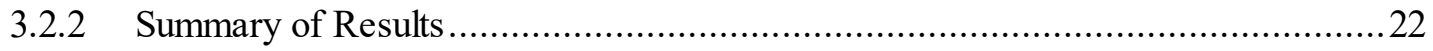

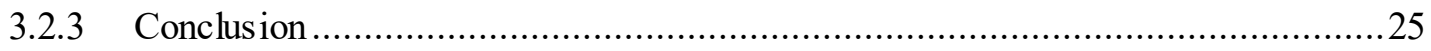

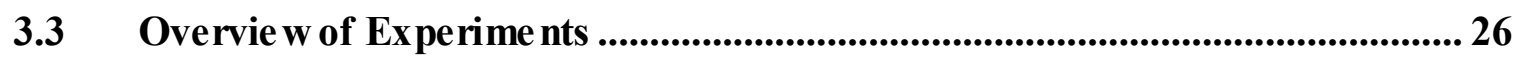

3.3.1 Contribution 1 - Proof-of-concept using Anthropomorphic Model......................26

3.3.1.1 Creation of the Anthropomorphic Human Body Model ..............................26

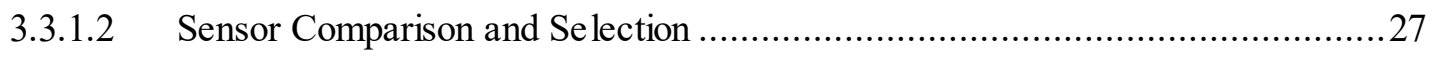

3.3.2 Contribution 2 - System Verification using the Model and External Mass............27

3.3.3 Contribution 3 - System Verification us ing Participants and External Mass ..........28

3.3.4 Contribution 4 - Evaluating Fluid Changes within the Human Body ...................28

4 Contribution 1 - Creating the Anthropomorphic Model and Selecting the PSM Technology ........................................................................................................................ 30

4.1 Creating an Anthropomorphic Human Body Model ................................... 30

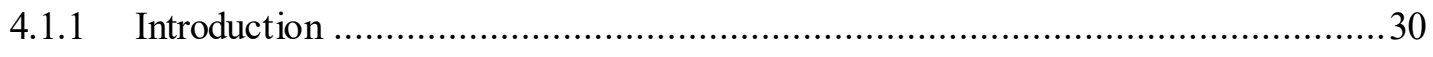

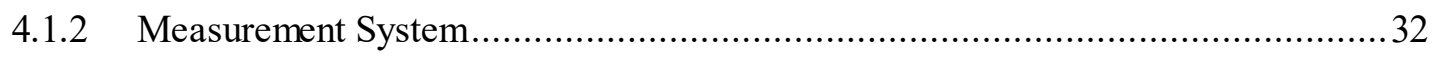

4.1.2.1 Anthropomorphic Measurements for 2D Model ..................................... 32

4.1.2.2 Anthropomorphic Measurements for 3D Model...................................... 34

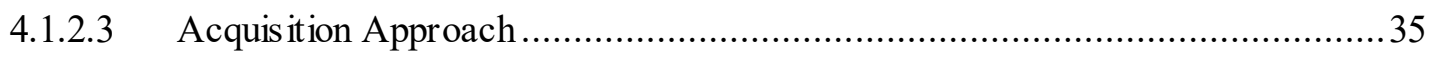

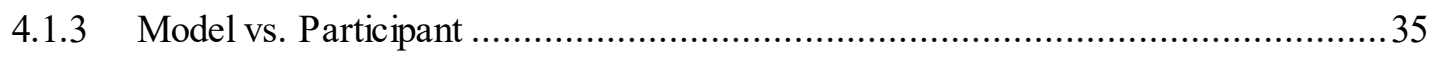




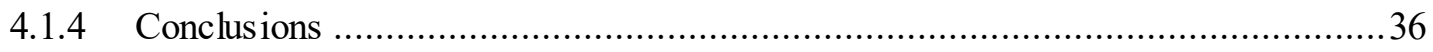

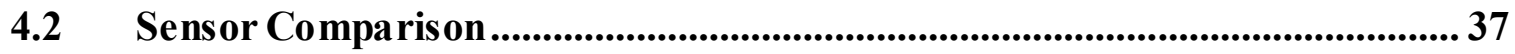

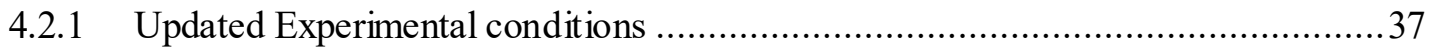

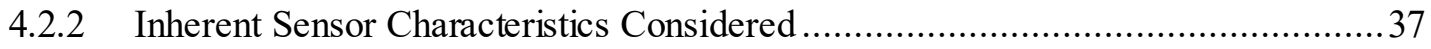

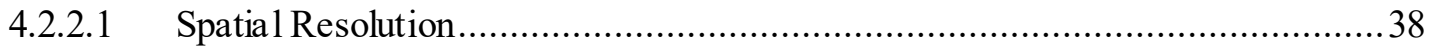

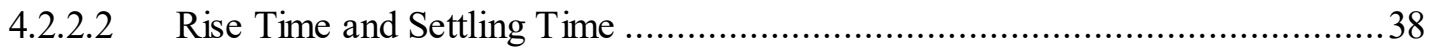

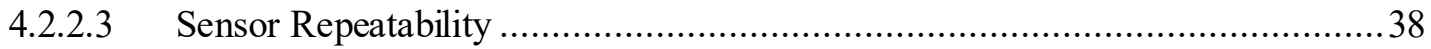

4.2.2.4 Sensor Drift and Creep...................................................................... 39

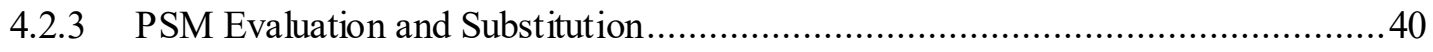

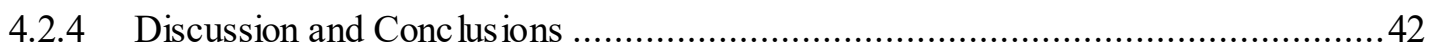

5 Contribution 2 - System Verification using the Model and External Mass....... 44

5.1 Fluid Model Description ................................................................................... 44

5.1.1 External Mass Applied to the Ankle Region ................................................. 45

5.2 External Mass Applied to Multiple Locations using Piezo-electric PSM ...... 46

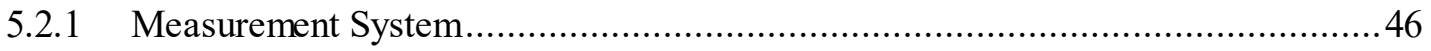

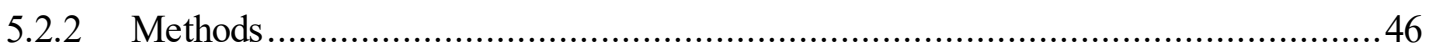

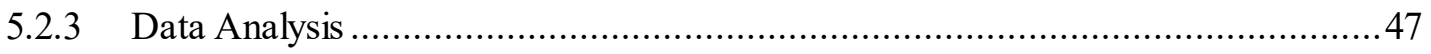

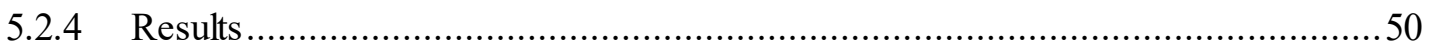

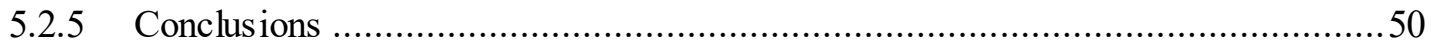

5.3 Dynamic Tracking of External Mass ..................................................................... 50

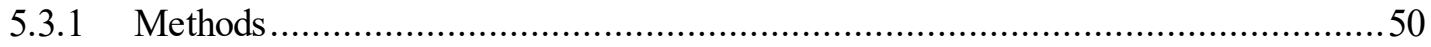

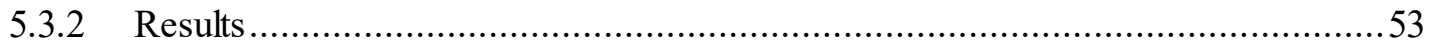

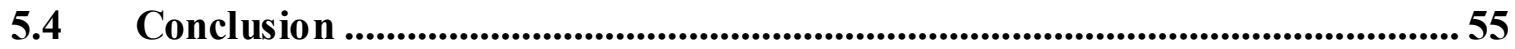


6 Contribution 3 - System Verification using External Mass with Human Subjects 57

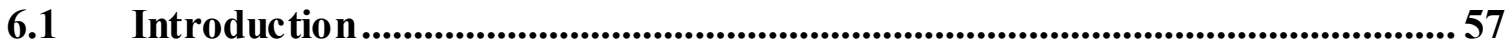

6.2 Measure ment System................................................................................................ 57

6.3 Experimental Procedure..........................................................................................59

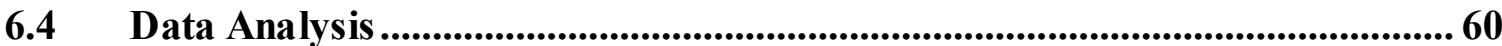

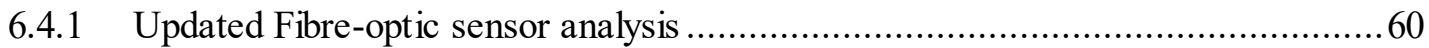

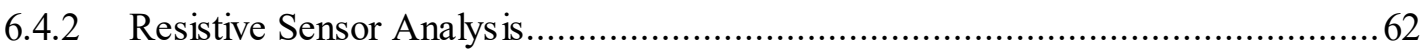

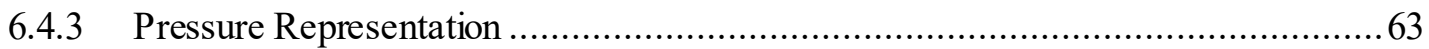

$6.5 \quad$ Results ......................................................................................................................... 63

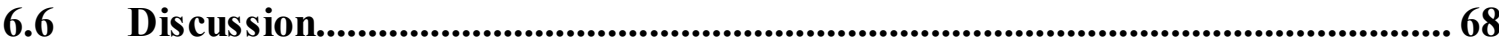

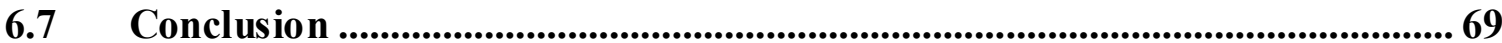

7 Contribution 4 - Evaluating Fluid Changes within the Human Body ................. 71

7.1 Preliminary Experimentation ................................................................................. 71

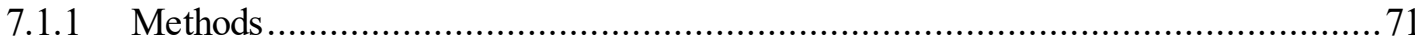

7.1.1.1 Measurement System............................................................................

7.1.1.2 Testing Procedure ..................................................................................... 71

7.1.1.3 Signal Processing ...................................................................................

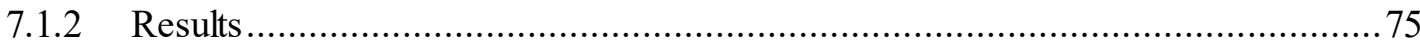

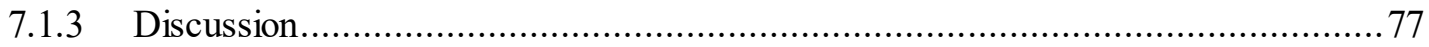

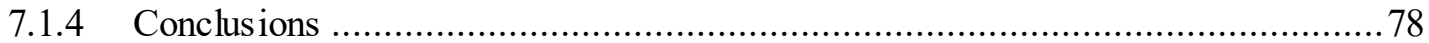

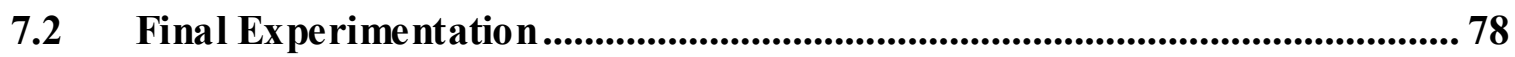

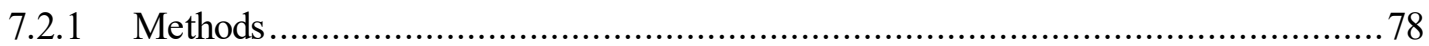

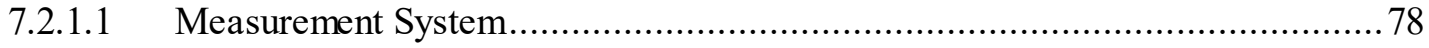

7.2.1.2 Experimental Procedure ……...................................................................79 


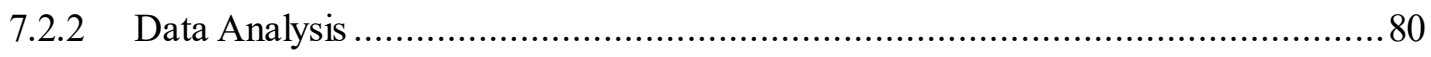

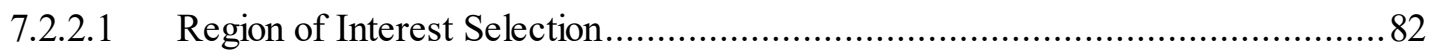

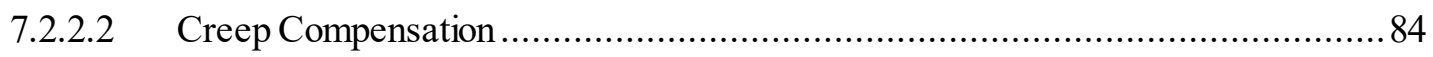

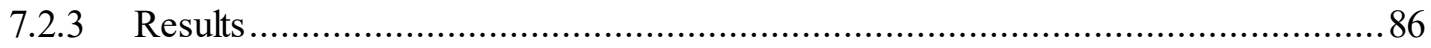

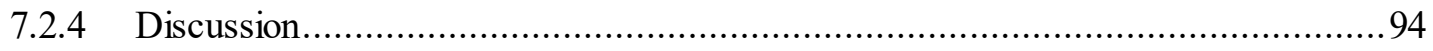

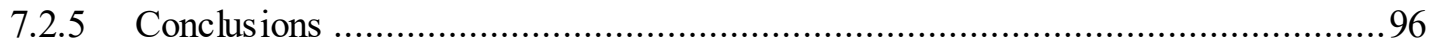

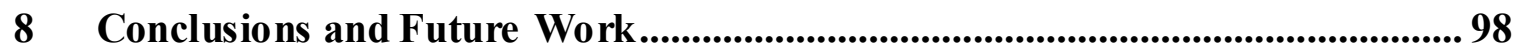

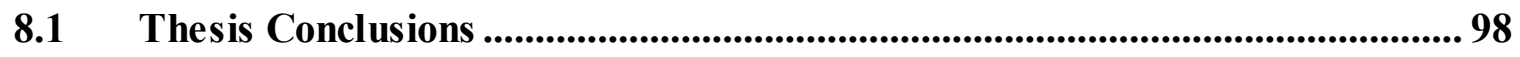

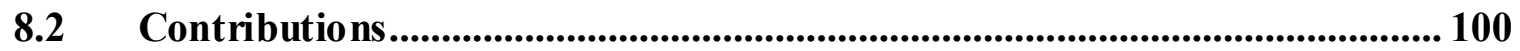

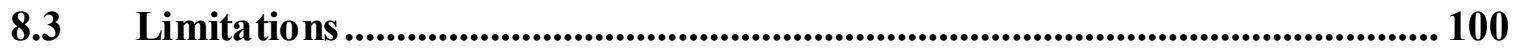

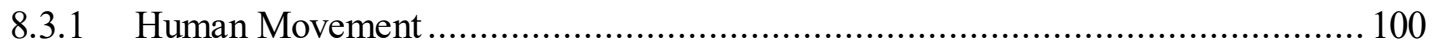

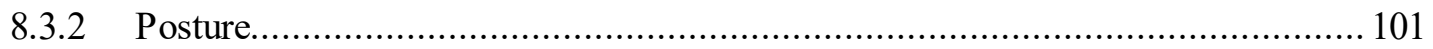

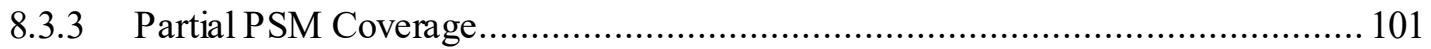

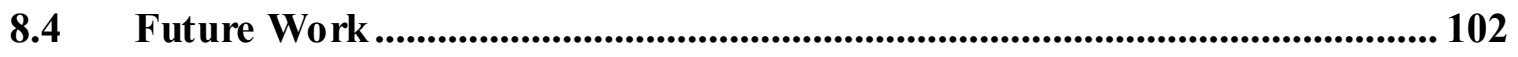

Appendix A: Contribution 2 \& 3 Supplemental Materials .................................... 104

Appendix B Contribution 4 Supple mental Materials ................................................... 108

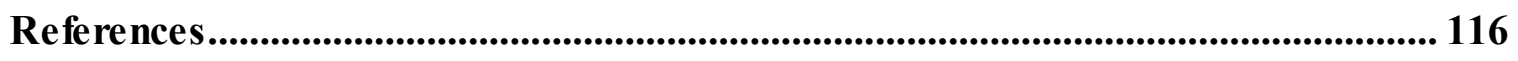




\section{List of Tables}

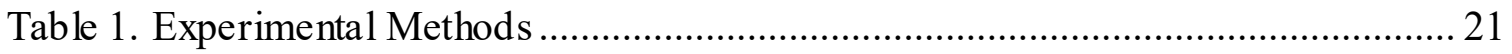

Table 2. Prone positon temporal average pressure response for each sensor-occupied

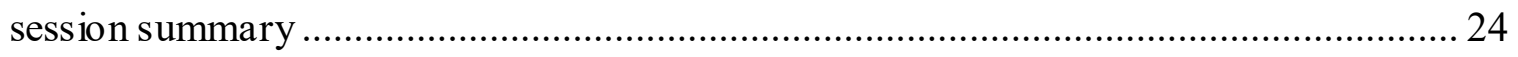

Table 3. Piecewise comparison between each sub-session (Prone - Torso ROI) ............ 25

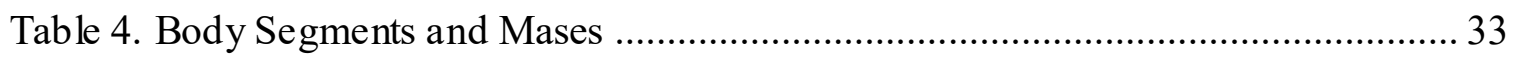

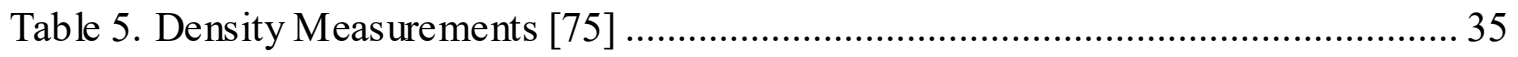

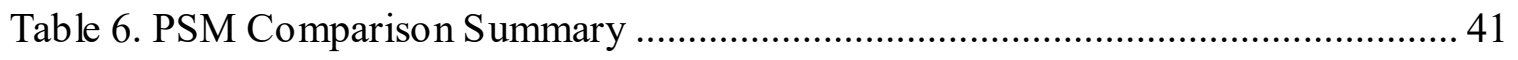

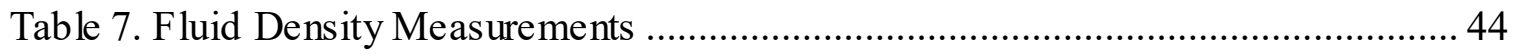

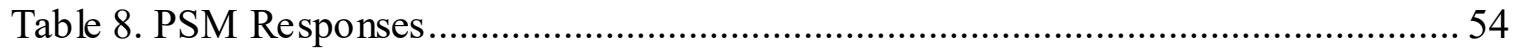

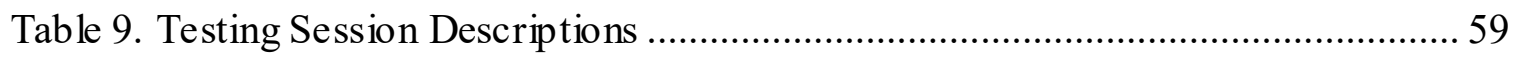

Table 10. Contribution 3 Participant and Model Pressure Responses ............................. 67

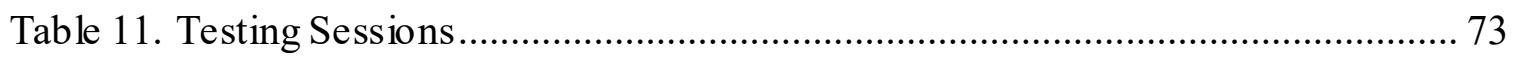

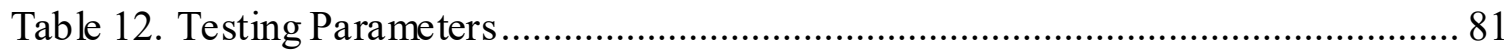

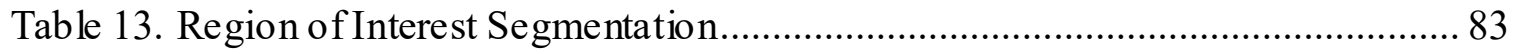

Table 14. Average Pressure Response in PSI (Posture \& Region) ................................ 89

Table 15. Piecewise comparison between each sub-session (Prone - Torso ROI) .......... 92

Table 16. Piecewise comparison between each sub-session (Supine- Torso ROI).......... 93

Table 17. Piecewise comparison between each sub-session (Side- Torso ROI)............. 94 


\section{List of Figures}

Figure 1. PSM overview set up for data acquisition, analys is and visualization .............. 12

Figure 2. Experimental set up (left) and PSM position with respect to the mattress (right)

Figure 3. Prone pressure response for the whole frame; Filtered (Blue) and creep-corrected (Orange). Pressure response for the ROI segments are also shown for Torso Yellow), Hip

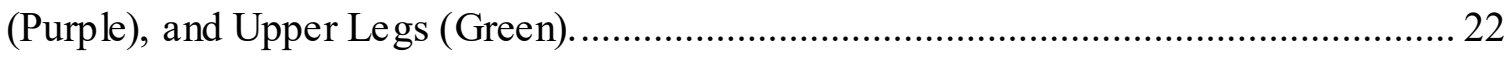

Figure 4. Testing set up for model validation and testing ....................................... 31

Figure 5. Anthropometric 2D (left) and 3D (right) model based on an older female adult 32

Figure 6. Pressure response while lying supine directly on the mat: model (left) and

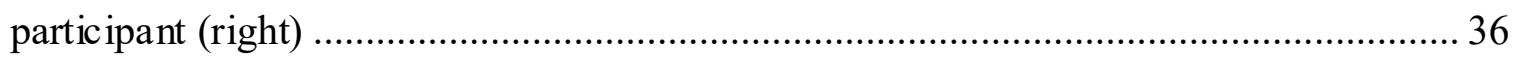

Figure 7. Model alone (A), model with added weight (400g) (B), and pressure difference (C) 45

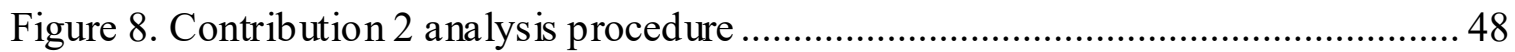

Figure 9. Model alone (A), model with 100g added mass (B) and pressure difference (C) for added mass at the bladder region (1), thigh (2), knee (3), shin (4) and ankle (5) ...... 49 Figure 10. Model alone (A), model with 400g added mass (B) and pressure difference (C) for added mass at the bladder region (1), thigh (2), knee (3), shin (4) and ankle (5) ...... 49 Figure 11. Average pressure response at each region across all testing session, while using

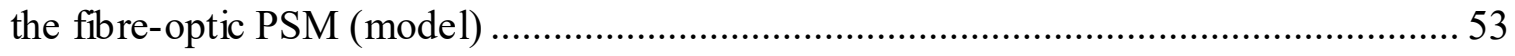


Figure 12. Average pressure response at each region across all testing sessions, while using the piezo-resistive PSM (model) 53

Figure 13. S4 Sensors (fibre-optic) measurement system (left) and Tekscan (resistive) measurement system (right) 57

Figure 14. Contribution 3 analysis procedure

Figure 15. Participant 1 pressure variation at each region over all sessions, while using the fibre-optic based measurement technology

Figure 16. Participant 1 pressure variation at each region over all sessions, while using the piezo-resistive based measurement technology 66

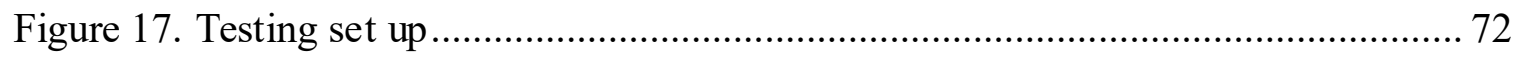

Figure 18. Participant with initial empty bladder (A), immed iately after $700 \mathrm{~mL}$ fluid intake (B), and pressure difference (C) 73

Figure 19. Participant with initial empty bladder (A) 30 minutes after $700 \mathrm{~mL}$ fluid intake (B), and pressure difference (C) 74

Figure 20. Participant with initial empty bladder (A), 60 minutes after $700 \mathrm{~mL}$ fluid intake (B) and pressure difference (C). 74

Figure 21. Participant with final empty bladder (A), 60 minutes after $700 \mathrm{~mL}$ fluid intake immediately prior to emptying the bladder (B), and press ure difference (C). 74

Figure 22. Participant with initial empty bladder (A), final empty bladder after an hour (B), and pressure difference $(\mathrm{C})$. 74

Figure 23. Contribution 4, pre liminary signal processing summary …........................ 75

Figure 24. Piezo-Resistive PSM Testing Set Up ................................................... 79

Figure 25. Contribution 4, final results analys is proced ure ..................................... 80 
Figure 26 Side ROI Extraction Result 82

Figure 27 Supine ROI Extraction Result 82

Figure 28 Prone ROI Extraction Result 82

Figure 29. A single sensel loaded 10 minute session with the filtered pressure response (Blue) and the creep adjusted response (orange)

Figure 30. Prone pressure response of the Whole PSM (blue), the creep adjusted pressure response of the Whole PSM (orange), the Torso(purple), the Hip ROI (yellow), and the Upper Leg ROI (green). 87

Figure 31. Side pressure response of the Whole PSM (blue), the creep adjusted pressure response of the Whole PSM (orange), the Torso ROI (purple), the Hip ROI (yellow), and the Upper Leg ROI (green) 88

Figure 32. Supine pressure response of the Whole PSM (blue), the creep adjusted pressure response of the Whole PSM (orange), the Torso ROI (purple), the Hip ROI (yellow), and the Upper Leg ROI (green)..... 88

Figure 33. Model pressure variation at each region over all sessions, while using the fibre optic based measurement technology 104

Figure 34. Model pressure variation at each region over all sessions, while using the piezoresistive based measurement technology 105 Figure 35. Participant 2 pressure variation at each region over all sessions, while using the fibre-optic based measurement technology 105 Figure 36. Participant 2 pressure variation at each region over all sessions, while using the piezo-resistive based measurement technology 106 
Figure 37. Participant 3 pressure variation at each region over all sessions, while using the

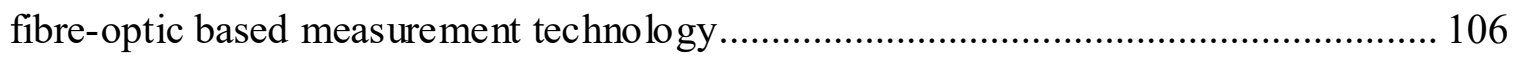

Figure 38. Participant 3 pressure variation at each region over all sessions, while using the piezo-resistive based measurement technology ................................................ 107 


\section{List of Appendices}

Appendix A Contribution $2 \& 3$ Supplemental Materials............................. 104

Appendix B Contribution 4 Supplemental Materials ................................. 108

B.1 Prone....................................................... 108

B.2 Supine........................................................111

B.3 Side......................................................113 


\section{Introduction}

\subsection{Motivation}

In 2011, Statistics Canada reported that the rate of increase in the number of adults over the age of $65(14.1 \%)$ surpassed that of both children aged 14 and under $(0.5 \%)$ and people between the age of 15 and 64 (5.7\%) [1]. Similarly, the United Nations has reported that the number of older adults over 60 is projected to grow by $56 \%$ from 2015 to 2035 resulting in 1.4 billion older adults worldwide [2]. The growing numbers of older adults worldwide is leading to increased prevalence of chronic conditions that cannot be cured but can be controlled via treatment.

Change in fluid distribution within the body is a key indicator for a variety of conditions associated with aging, including kidney failure and congestive heart failure. However, current methods to monitor fluid distribution rely on infrequent and often selfreport measures, which are unreliable. This thesis focuses on the implementation of a noninvasive and unobtrusive pressure measurement system for monitoring fluid distribution within the body. Fluid distribution encompasses both monitoring internal fluid variations that can be caused by swelling as well as the detection of drinking and voiding events.

Kidney disease effects about 3 million Canadians [3] and occurs when the kidneys are unable to filter blood effectively leading to edema (swelling) around the lungs, ankles, legs, and feet [4]. This can be caused by a variety of conditions including heart disease, which affects 22 million worldwide [5]. Specifically, heart failure (HF), results from the heart being unable to sustain the necessary blood flow throughout the body due to damage to the heart tissue [6]. The heart may compensate for the lack of flow by increasing its 
workload to account for the decrease in blood pressure in order to pump blood througho ut the body. Reduction of cardiac effectiveness leads to reduced kidney perfusion and kidney function and hence fluid overload, known as congestive heart failure (CHF) [6].

One consequence of fluid redistribution is nocturia, affecting more than $50 \%$ of individuals over the age of 60 [7]. Nocturia is defined as a person getting up more than two times to void their bladder over the course of a single night [7]. Frequent night-time bedexits can have negative implications on sleep quality, sometimes leading to sleep disorders, and thus negative effects on an individual's overall health [8].

Many of these conditions are manageable by using a combination of medical therapies and monitoring methods. The implementation of long-term non-invasive and unobtrusive monitoring methods has the potential to replace current monitoring technologies. Current methods are invasive/intrusive, time consuming, inaccurate due to patient adoption and compliance, and are only available in hospitals/continuing care facilities. Implementing novel technologies in patients' homes can provide the necessary monitoring measurements to the appropriate health care practitioner while maintaining a person's independence [9].

\section{2 ОВJECTIVES}

The main objective of this work is to evaluate the feasibility of current pressure sensitive mat (PSM) technologies and their ability to detect very small internal changes associated with fluid distribution. The algorithms developed here use image processing techniques to extract regions of interest (ROI) from the pressure response and compare the pressure in corresponding regions before and after fluid distribution changes. A series of increasingly 
complex experiments were designed and conducted, where each experiment more closely approaches an actual deployment of a PSM in a clinical or home environment.

\subsection{ProblemStatement}

Can PSM technology be used to detect and track small internal variations in weight, representative of fluid distributional changes, in the human body? Is it then possible to develop a system based on PSMs to monitor and track fluid distribution as an indicator of chronic health conditions, where current monitoring techniques can be obtrusive and/or inaccurate?

\subsection{SumMARY OF CONTRIBUTIONS}

All human experiments in this thesis were approved by the Carleton University Research Ethics Board (approval \#10343-0230).

This thesis was conducted in several stages of research. As indicated below, many of the contributions made in this thesis have been published. These papers form the basis for the material presented in Chapter 4 to 7 .

1. The first step to evaluate if the PSMs were able to detect small variations in mass was to create an idealized testing environment. This was done by first isolating the pressure mat on a rigid support surface (floor) and then removing all noise that is associated with the human body. This was achieved by creating an anthropomorphically correct human body model based on measurements from an older adult female. This is the first contribution of this thesis. Chapter 4 summarizes the model creation and validation, and was published in the following conference paper and poster presentations: 
- M. Cohen-McFarlane, J. R. Green, R. Goubran, and F. Knoefel, "Characterization of Measurements from Pressure Sensitive Mats using an Anthropomorphic Body Model," in Proc. IEEE Int. Instrum. Meas. Technol. Conf. (I2MTC), 2016, pp. 1-4. [10]

- M. Cohen-McFarlane, J. R. Green, F. Knoefel, and R. Goubran, "Characterization of Fibre-Optic Pressure Mats for Long Term Patient Monitoring." Bruyere Research Institue, Ottawa, 2015. [11]

2. The second contribution (see chapter 5) focused on modeling fluid retention by applying an external mass $(50-600 \mathrm{~g})$ to the model at key locations on the lower body (ankle, shin, knee, thigh and abdomen). This mass represented fluid retention due to CHF. This work was published in the following conference paper and poster presentation:

- M. Cohen-McFarlane, J. R. Green, R. Goubran, and F. Knoefel, "Monitoring Congestive Heart Failure using Pressure-Sensitive Mats," in Proc. IEEE Int. Symp. Med. Meas. Appl. (MeMeA), 2016, pp. 1-6. [12]

- M. Cohen-McFarlane, R. Goubran, F. Knoefel, "Unobtrusive Monitoring of Congestive Heart Failure." AGE-WELL AGM, Montreal, 2016. [13]

3. The third contribution (see chapter 6) has yet to be published, but focuses on the application of an updated processing procedure, including a basic region of interest selection tool. Data were also collected from human participants based on a similar testing protocol used in the second contribution of this thesis.

4. Contribution four (see chapter 7) aimed to determine if the PSM was able to detect internal changes in fluid distribution. This included an investigation of internal fluid 
changes by introducing drinking and bladder voiding events between periods of the participant lying on a mattress placed on top of the PSM. The preliminary results were published in the following conference paper:

- M. Cohen-McFarlane, J. R. Green, R. A. Goubran, and F. Knoefel, "Smart Monitoring of Fluid Intake and Bladder Voiding using Pressure Sensitive Mats," Proc. IEEE Eng. Med. Biol. Soc, pp. 4921-4924, 2016 [14]

5. At the outset of this thesis, fibre-optic PSM were readily available in the lab and were used in contributions one and two (Chapter 4 and 5). While investigating the third contribution (Chapter 6), two new PSMs became available. At this point, it was decided to compare the three different PSM based on their metrological properties. This comparison is summarized in chapter 4 and was published in the following conference paper.

- S. Nizami, M. Cohen-McFarlane, J. R. Green, and R. Goubran, "Comparing Metrological Properties of Pressure-Sensitive Mats for Continuous Patient Monitoring," in Proc. IEEE Sensors Applications Symp. (SAS), 2017, pp. 1-6. [15]

\subsection{Thesis STRUCTURE}

This thesis is organized into eight chapters. Chapter 2 includes a detailed background of a number of health conditions associated with changes in fluid distribution, a description of current pressure sensitive technologies, and a summary of related work. This is followed by an overview of the thesis and a summary of the final experimental results in Chapter 3 . Chapters 4-7 detail the process by which the final experiment was designed through a series of increasingly complex and realistic experiments. Chapter 7 provides a more detailed explanation of the final algorithm, including region-based pressure analysis, pressure 
response creep compensation, results, and discussion. Chapter 8 provides conclusions from this thesis and proposes a number of possible areas for future work. 


\section{Background}

\subsection{INTRODUCTION}

The following sections contain the literature review. A summary of potential health conditions that present with variations in fluid or distribution is provided to illustrate the potential applications of a system that can more accurately monitor these variations. Noninvasive and unobtrusive monitoring is described within the context of health care and related work utilizing PSMs is also described. The underlying principle of the three main PSM technologies considered are also described, as they were each considered for experimentation.

\subsection{Health Conditions OF InTEREST}

A growing concern worldwide is that our populations are ageing, leading to a growing number of older adults in our communities. The United Nations has reported that there were 841 million older adults ( $>65 \mathrm{yrs}$ ) in 2013 and that the older adult population is projected to increase to 2 billion by 2050, the highest it has ever been [16]. In Canada, the older adult population is projected to be $24.5 \%$ of the population by 2036 [17].

As adults age, they become more susceptible to a variety of health conditions. In Canada, the older adult population accounts for $40 \%$ of acute hospital stays, the most common cause being cardiac-related conditions [18]. There are currently 1.3 million Canadians (22 million worldwide) living with heart disease, $23 \%$ of which lead to long term hospitalizations. This costs the Canadian economy approximately 30 billion annually [5], [19]. 


\subsubsection{Congestive Heart Failure}

One of the most common forms of heart disease is heart failure (HF). In this condition, heart tissue is damaged and the heart is therefore unable to pump blood as effectively and maintain blood flow to the body [20]. To compensate and maintain blood pressure, the heart increases its workload which can lead to heart palpitations, increased HR, and further heart tissue damage and death if not treated. Symptoms of long term reduction in cardiac effectiveness include fatigue, nausea, lack of appetite, difficulties breathing and lower extremity edema (fluid accumulation/retention) [21]. Reduction of blood perfusion to the kidneys leads to decreased kidney function causing fluid retention and overload. This fluid retention causes edema around the lungs and in the lower extremities, both of which are indications of congestive heart failure (CHF).

The current method of CHF monitoring in a hospital setting is daily weighing to determine fluid retention. If a person at risk of fluid overload gains more than one to two $\mathrm{kg}$ over one to two days, they are at increased risk of decompensation (i.e. organ failure) [22]. This method is imprecise because the measured weight gain could be from other causes. Furthermore, when weight is due to fluid accumulation this method is unable to identify the location of the moving fluid overload. The gold standard for fluid distribution monitoring uses dilution techniques to measure the total body water and extracellular water [23]. Dilution methods are highly affected by patient compliance, technical limitations and practical implications associated with daily use [23]. Alternatively, the daily weighing at home is fraught with difficulties of compliance, data collection, and remembering to bring the measurements to your next doctor's appointment. Therefore, a portable repeatable and non-invasive method for estimating the body fluid distribution is desired [23]. Due to the 
aforementioned issues, these variations in weight are therefore not always identified early enough, resulting in acute CHF and long hospitalizations. Continuous non-invasive monitoring of fluid distribution may identify changes in fluid distribution earlier and thus reducing hospitalizations.

\subsubsection{NOCTURIA}

The identification of small mass variations and fluid monitoring have applications in other health conditions such as nocturia, when a person needs to urinate (micturition) more than two times over night, thereby interrupting sleep. Nocturia is more common in older adults affecting more than $50 \%$ of individuals over the age of 60 . Interruptions in sleep can lead to poor sleep quality with potential long term negative effects on an individual's overall health [8]. It has also been reported that individuals with nocturia have higher rate of morbidity [24].

There are many potential causes for nocturia, the most relevant to this thesis being the strong connection between CHF and nocturia. In CHF, the fluid that collects in the ankles over the course of the day is distributed back to the trunk when in the horizontal position, where it is detected as fluid overload and filtered by the kidneys. This increased urine production at night is one cause of nocturia. [8]. Other causes include urologic disorders (e.g. prostate or bladder obstructions) and non-urologic disorders (e.g. sleep disorders and drinking water before bed) [24].

Current methods to monitor and identify nocturia for treatment are based on a selfreported questionnaire, where the number of toilet visits are collected [7] [25]. This is most commonly done using a frequency volume chart (FVC) completed by patients at home [24]. The FVC is generally accepted as a method of identifying voiding issues, however 
patient compliance is a tremendous issue, especially with older adults who have conditions affecting memory such as dementia [26]. Furthermore, self-reporting is a participative measure that is entirely dependent on each individual's capability to remember the number of times they exited the bed over the course of a single night, which is difficult for many people [25]. Based on this, a more accurate method of bed exits and toilet visits is needed in order to identify and hopefully minimize the symptoms of nocturnal voiding and therefore improve quality of life for affected patients [8].

\subsubsection{KIDNEY FAILURE}

Kidney failure or acute renal failure occurs when the kidneys are unable to excrete waste, concentrate urine, conserve electrolytes and maintain fluid balance [4]. As mentioned in the CHF section, this leads to edema (swelling) due to the body's inability to excrete excess fluid. The fluid can pool around the lungs, in the ankles, legs and/or feet. There are many causes of kidney failure, CHF being only one of them [4]. The wide variety of causes of kidney failure may lead to more applications of a system that can monitor fluid distribution variations, such as the one discussed here.

Current treatment methods include renal transplants and replacement therapy. The latter can be categorized into two general types [27]. The first is hemodialysis, where blood is passed through a semi-permeable membrane to remove waste products and is then returned to the body [27]. This treatment can't remove fluid, so ultrafiltration is needed (via transmembrane pressure) to remove excess fluid that the kidneys are unable to eliminate. The volume of fluid removed or added is essential in determining if treatments are appropriate and during treatment these measurements are recorded. However, fluid distribution is not known when an individual is not undergoing treatment. The use of a 
PSM system that could monitor fluid distribution when one is not undergoing treatment may be able to provide even more detailed information of when there is too much internal fluid buildup and hence a dialysis treatment is needed.

The second therapy is peritoneal dialysis, which uses the peritoneum (layer of tissue that lines the abdomen and covers all organs) as the semipermeable membrane. Dialys is fluid is infused into the peritoneal space. This method does not need an external blood circuit and therefore can be used for longer periods of time. The long-term application of a PSM during a peritoneal dialysis treatment may allow for mapping between the pressure response and the measured fluid input and output (in liters) [27].

\subsection{Patient Monitoring}

Many of the current methods of diagnosis and remote monitoring can be highly invasive to the patient, time consuming to the medical professional, and costly to the health care system. Unobtrusive and non-invasive measurement technologies aim to supplement and potentially replace some of these invasive methods. Non-invasive remote monitoring techniques have been developed for the collection of a range of physiological data including: breathing rate [28], [29], blood pressure [30], heart rate (HR) [29]-[31], weight [29], activities of daily living [29], mobility [32]-[34], and sleeping patterns [35]. We have also explored the use of sensor networks to instrument a smart apartment for monitoring activities of daily living [36].

\subsection{Pressure Sensitive Mats}

There has been a growing interest in pressure sensor technologies as they apply to noninvasive and unobtrusive patient monitoring. These pressure sensors, called sensels, are 
usually organized into an equally spaced matrix. The resulting PSMs have been used to monitor both long-term continuous measurements and short-term measurements. PSMs have been applied to monitor a variety of clinical conditions in a hospital setting and in the patient's home. Placement of the PSM can be between a mattress and a bedframe for overnight monitoring (Figure 1), on a seat for posture monitoring, or embedded into another technology such as a wheelchair cushion in order to monitor the development of pressure soars. The work described in this thesis focuses on PSM applications associated with in-bed monitoring, as summarized in Figure 1.

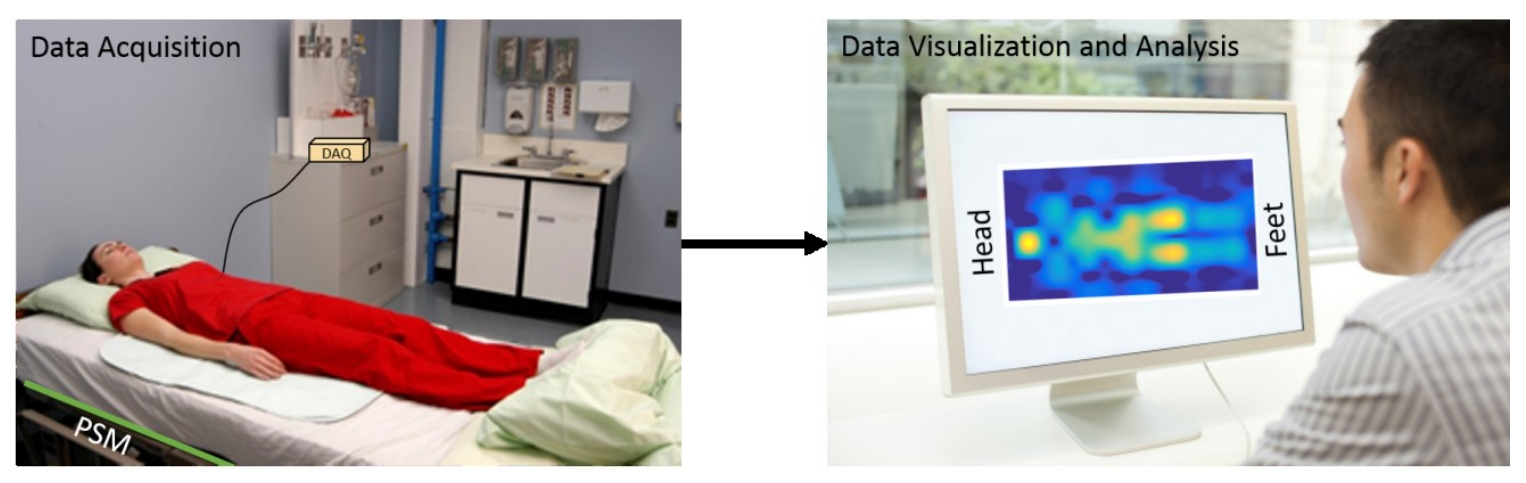

FIGURE 1. PSM OVERVIEW SET UP FOR DAT AACQUISITION, ANALYSISAND VISUALIZATION

Babbs et.al. first described the application of PSMs to health monitoring in 1990, where they described the resulting contact pressure due to a patient lying on a PSM on top of a hospital bed [37]. The basic concept of PSMs is based on the average contact pressure, $\mathcal{P}$, distributed over the contact area of the object, $\mathcal{A}$, on a PSM loaded with a force, $\mathcal{F}$, is defined by the following equation.

$$
\text { (1) } \mathcal{P}=\frac{\mathcal{F}}{\mathcal{A}}
$$


This pressure response at each sensel can be visualized in the form of a heat map highlighting high and low pressure areas associated with the body's position (Figure 1right).

PSMs have been used to monitor patients at home, in continuing care facilities, and in hospitals for a variety of health conditions. Our lab and others have used pressure sensitive measurement technologies to characterize sleep quality [38], [39], older adult mobility [29], sleep apnea detection [38], [40], and bed exit/re-entries over the course of a night [41], [42].

Novel sensors are being developed that are being embedded into fabric. For example, Google's Project Jacquard has partnered with Levis ${ }^{\circledR}$ to weave conductive thread into garments activated by touch and gestures [43], [44]. In another example, a pressure sensitive bed sheet is being developed by studiollabs for monitoring the positional information of neonatal patients [45]. The algorithms developed for this thesis are designed to be compatible with any pressure measurement technology, meaning that new and more sensitive technology could be used in the future.

What follows is a description of the three PSM technologies used in this thesis.

\subsubsection{FIBRE-OPTIC SENSORS}

S4 Sensors Inc. (previously Tactex) PSMs are embedded with Kinotex TM fibre-optic sensors (Nitta Corp., Osaka, Japan) that measure the pressure response to an applied force. Each sensel consists of a sensor-emitter diode pair surrounded by foam. When force is applied, the foam compresses reducing the amount of refracted light that is measured by the sensing diode. This change in detected light is converted to a unitless representation of pressure response, which is then used for analysis. 
The total sensing area comprised nine equally spaced $80 \times 25 \mathrm{~cm}$ PSM containing 24 fibre-optic sensor-emitter pairs each. The sensels were spaced at $10 \times 10 \mathrm{~cm}$, resulting in a spatial resolution of $0.012 \mathrm{sensels} / \mathrm{cm}^{2}$. Each PSM was connected to a computer via Bluetooth using a data acquisition device. All data were sampled at $20 \mathrm{~Hz}$ with a digital resolution of 16 bits.

\subsubsection{Piezo-Resistive SeNSORS}

Tekscan (Tekscan, Boston, USA, tekscan.com) uses piezo-resistive ink in their HUGE MAT 5400N sensor. Their Body Pressure Measurement System (BPMSTM) software suite handles data acquisition and visualization. Tekscan ${ }^{\mathrm{TM}}$ pressure sensors operate based on a decrease in contact resistance when external pressure is applied to a sensel [46], [47]. Specifically, each sensel is composed of two thin sheets of flexible polyester [47], [48]. Electrically conductive silver traces are printed on each sheet, one arranged in rows and the other in columns. A patented semi-conductive material is printed on top of all silver trace columns and rows [47], [49]. The two sheets are then laminated, creating an array of sensing elements at each intersection of rows and columns called sensels [47], [49]. When pressure is applied across the array of sensels, the contact resistance decreases and is converted to a pressure measurement by the Tekscan ${ }^{\mathrm{TM}}$ BPMS software [50], [51].

The HUGE MAT has a $58 \times 88 \mathrm{~cm}$ sensing area that contains 1768 sensels $(0.7 \times 0.7$ $\mathrm{m}$ each) $1 \mathrm{~cm}$ apart on both the $\mathrm{x}$ and $\mathrm{y}$ axes. This results in a spatial resolution of 0.3 sensels $/ \mathrm{cm}^{2}$. The PSM was connected to a computer for data collection via a USB port using the Tekscan ${ }^{\mathrm{TM}}$ 'Evolution Sensor Handle'. All data collection was performed using the BPMS ${ }^{\mathrm{TM}}$ software at an 8 bit digital pressure resolution and sampled at $2 \mathrm{~Hz}$ [50]. 


\subsubsection{CAPACITIVE SENSORS}

XSensor (XSensor Technology Corp. Calgary, Canada, XSensor.com) uses capacitive technology in their LX100:36.36.02 PSM to measure the pressure response to an applied force. The main operating principle is based on increasing and decreasing the conductivity between two conductive elements [52]. Two sheets of parallel conductive strips separated by a thin compressible elastomer are arranged perpendicular to each other to create a grid of capacitive intersections called sensels [52]. The capacitance at each sensel is derived from the surface area of the intersection in conjunction with the separation between the two strips defined by the compression of the elastomer [52]. As the elastomer is compressed, the strips get closer together and cause an increase in capacitance [52]. The resulting capacitive measurements are correlated to pressure measurements via the built-in calibration procedure provided by XSensor [53].

The LX100 has a $45.7 \times 45.7 \mathrm{~cm}$ sensing area that contains 1296 equally spaced sensels, resulting in a spatial resolution of 1.27 sensels $/ \mathrm{cm}^{2}$ [53]. The PSM was connected to a computer via a USB port. All data collection was performed using the XSensor data collection software at a 16 bit resolution and was sampled at $1 \mathrm{~Hz}$, however the sampling rate was adjustable [53].

\subsection{RELATED WORK}

What follows is a discussion of related applications of PSM for patient monitoring and a discussion of current monitoring methods for the clinical conditions introduced earlier in this chapter. Our lab and others have worked with PSMs to evaluate a variety of health related factors. Specifically they have been used to measure balance and mobility [54], [35], [55], risk of pressure ulcers [35], [56], sleeping patterns [57], [32], bed occupancy 
[58] and sit-to-stand movement [59], [60], [55]. The fiber optic based PSMs have been implemented clinically to monitor long term sleeping patterns and health [32], [35], [61][66]. Sleep disordered breathing is another area of research in our lab were the PSM are able to monitor breathing patterns during sleep [64], [65], [67], resulting in an effective algorithm for the detection of central sleep apnea.

Current methods to monitor fluid distribution are generally specific to the condition in question. For patients with CHF, daily weights are taken, at home or in hospital, and then submitted to the health care provider to identify if an intervention is needed [22]. For patients with nocturia, the patient is asked to recall how many times they left the bed to void their bladder every night. This record is then given to the health care provider at their next appointment [25]. For patients with kidney failure, the amount of fluid added and removed from their system is recorded during treatment sessions [27].

More recently, bio-impedance methods have been proposed to monitor fluid distribution. Bio-impedance was developed from electrical impedance therapy (EIT), where electrodes are equally spaced around the area of interest [68]. The resulting current flow is captured based on the impedance of the biological tissue of interest and associated input frequency [68]. When looking at fluid, higher frequency inputs are desired, the current passes through all cell membranes (acting as capacitors) and the current response is dependent on the fluid both inside and outside the cells in the physiological area of interest [68]. This method has been proposed to measure the fluid-build up in the thoracic region for patients with CHF [69]. Though these results are promising, this method of fluid monitoring is not unobtrusive, due to the necessary electrodes. Furthermore, bioimpedance measurements are most commonly available in a hospital or health care setting. 
Both of these factors make long-term bio-impedance measurements difficult and infeasible at this time, especially in the home.

A number of groups have proposed and developed CHF continuous monitoring systems. Fannucci et al have proposed a smart home monitoring system to track the vital signs of CHF patients. The system collects vital signs and sends them to the Hospital Information System to be evaluated by physicians [30]. Vital signs include electrocardiogram, SpO2, blood pressure, and weight [30]. This system aims to reduce the number of in-person visits needed by each patient, while maintaining the necessary health tracking associated with individuals with CHF [30]. While this system represents important progress towards home monitoring of patients with $\mathrm{CHF}$, it requires active patient compliance. Furthermore, a non-contact solution would be preferable.

Telehealth frameworks have also been proposed for use in continuous monitoring. Clark et al. has proposed such a system to monitor CHF patients at home [31]. The system made use of digital scales, which wirelessly communicate the patient's daily weight to a heart failure clinic via computer or fax. This monitoring framework has been shown to improve patient outcomes [31]. However, this technology again relies on patient compliance and is affected by external factors such as clothing.

Huppert et al. have proposed an ambulatory sensor system to monitor bed exits and urination events using a sensor watch (Somnowatch Plus) and a room occupancy monitor (HOBO) located in the bathroom. This is a non-invasive system and the authors reported a false detection rate of $0.33 \pm 0.09$. Based on the two sensor measurements proposed, it is difficult to differentiate between a true urination event after an individual entered the bathroom and, for instance, an individual sitting down and brushing their teeth. 
Additionally, continually wearing the watch sensor can be bothersome and individuals may not be comfortable sleeping with such a device. If the device is removed for the night, the chances of remembering to put it on when woken because of bladder pressure are low. Furthermore, the introduction of non-invasive measurement technologies in the home may be able to reduce health care costs associated with the aforementioned conditions by allowing individuals to safely stay in their own homes.

\subsection{CONCLUSIONS}

This chapter has discussed clinical conditions that are relevant to fluid distribution monitoring (CHF, nocturia and kidney failure). The three PSM technologies that are used in this thesis were described (fibre-optic, piezo-resistive and capacitive). Lastly, a discussion of previous work that utilized PSMs to monitor individuals for a variety of purposes was provided. 


\section{Summary of Experiments}

\subsection{INTRODUCTION}

This chapter provides a preview summary of the experimental protocol and results relating to the final contribution of this thesis. This is done to emphasize the end-goal: to determine if a PSM is able to detect internal fluid distribution variations within a body over time. This chapter details the experimental progression, where each experiment presented in this thesis increases in complexity and realism culminating in the final experiment. A summary of each experiment is provided here, while details are provided in Chapters $4-7$.

\subsection{PreVieW Of Final ExPERIMENTAL Results}

\subsubsection{METHODS}

The Tekscan BRE5400-1 resistive ink PSM was placed directly on the floor and a futon mattress $(15 \mathrm{~cm}$ thick) was placed on the PSM (Figure 2). The Tekscan BPMS system was used for all experimentation under these conditions. The top of the PSM was aligned with the approximate location of the subject's shoulders and the bottom aligned with the upper thigh when the participant was in a prone or supine position. Due to the size $(58 \times 88 \mathrm{~cm})$ of the PSM, the entire body of the participant was not captured. This was deemed to be acceptable since the principle region of interest pertaining to fluids is the abdomen, where both the bladder and the stomach are located. Future work may include data acquisition using a full-body Tekscan PSM to capture the entire human body. For this experiment, a pillow was placed on the mattress for the participant's comfort (outside of the sensing area). 

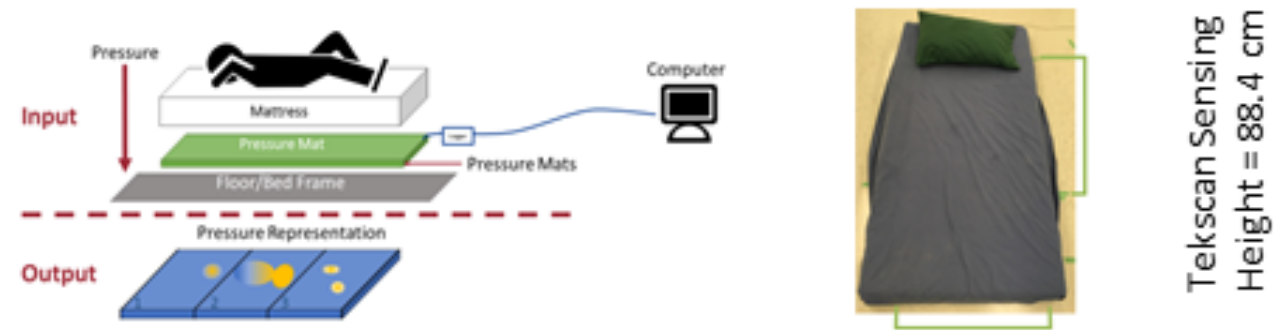

\section{Tekscan Sensing}

Width $=57.8 \mathrm{~cm}$

FIGURE 2. EXPERIMENT AL SET UP (LEFT) AND PSM POSITION WITH RESPECT TO THEMATTRESS (RIGHT)

A single female participant (24yrs, 5'7”, and 130lbs) was asked to participate and vary her internal fluid distribution. The chosen method of inducing internal fluid changes was asking the participant to drink as much water as they were comfortable, followed by lying in a single position on the mattress until they felt the need to void. The participant was asked to get up from the PSM repeatedly throughout the experiment to either: (1) do nothing, (2) void her bladder or (3) drink as much water as was comfortable ( $\sim 1 \mathrm{~L})$. The full testing procedure is outline in Table 1. The PSM was recording throughout the entire experiment at a sampling rate of $2 \mathrm{~Hz}$ with 8 bit digital resolution. This procedure was repeated while the same participant was lying in prone, supine, and side position.

This experiment used the resistive PSM, however preliminary work used the fibreoptic PSM as described in the following chapters. The fibre-optic PSM technology was initially chosen for its ability to cover the entire body and the fact that the fibre-optic PSM had been characterized by previous students in our lab. The resistive mat was chosen for the final experiment due to the substantial increase in spatial resolution (a sensel separation of $1.7 \mathrm{~cm}$ vs. $10 \mathrm{~cm}$ ), at the cost of full body coverage. Because the final experiment was 
most interested in the trunk of the body and the pressure response due to the limbs was not necessary, the resistive PSM with a higher spatial resolution was deemed appropriate under these conditions.

TABLE 1. EXPERIMENT AL METHODS

\begin{tabular}{|c|c|c|}
\hline Participant Status & Duration & Purpose \\
\hline On mattress & 10 minutes & Initial baseline bladder volume. \\
\hline Off mattress & 2 minutes & $\begin{array}{l}\text { Simulates bed exit not involving fluid } \\
\text { distributional changes. }\end{array}$ \\
\hline On mattress & 10 minutes & $\begin{array}{l}\text { Negative control session. No significant } \\
\text { change in pressure should be observed } \\
\text { relative to previous session. }\end{array}$ \\
\hline Off mattress & Approx. 5 minutes & $\begin{array}{l}\text { Participant was asked to void her } \\
\text { bladder. }\end{array}$ \\
\hline On mattress & 10 minutes & $\begin{array}{l}\text { Pressure response associated with empty } \\
\text { bladder after small bladder voiding } \\
\text { event. }\end{array}$ \\
\hline Off mattress & Approx. 5 minutes & $\begin{array}{l}\text { Participant was asked to drink as much } \\
\text { water as she was comfortable }(\sim 1 \mathrm{~L}) .\end{array}$ \\
\hline On mattress & 60 minutes & $\begin{array}{l}\text { Pressure response associated with fluid } \\
\text { distribution from the imbibing event. }\end{array}$ \\
\hline Off mattress & Approx. 2 minutes & $\begin{array}{l}\text { Participant was asked to void her } \\
\text { bladder. }\end{array}$ \\
\hline On mattress & 10 minutes & $\begin{array}{l}\text { Pressure response associated with empty } \\
\text { bladder after large bladder voiding } \\
\text { event. }\end{array}$ \\
\hline Off mattress & 2 minutes & $\begin{array}{l}\text { Simulates bed exit not involving any } \\
\text { fluid distributional changes }\end{array}$ \\
\hline On mattress & 10 minutes & $\begin{array}{l}\text { Negative control session - no change } \\
\text { should be observed from previous } \\
\text { measurement. }\end{array}$ \\
\hline
\end{tabular}




\subsubsection{SUMMARY OF RESULTS}

Pressure data were saved in units of PSI and were exported as CSV files. All data analysis was performed in MATLAB, as described in Chapter 7. Data were smoothed using digital filtering, as detailed in Chapter 7 and thresholding methods were used to identify bed entrances and exits. The pressure data were adjusted based on a first difference creep normalization algorithm, as described in Chapter 7. The results were then spatially averaged across the entire PSM (Figure 3) across regions of interest (ROIs) that were selected based on the ROI identification algorithm described in Chapter 7.

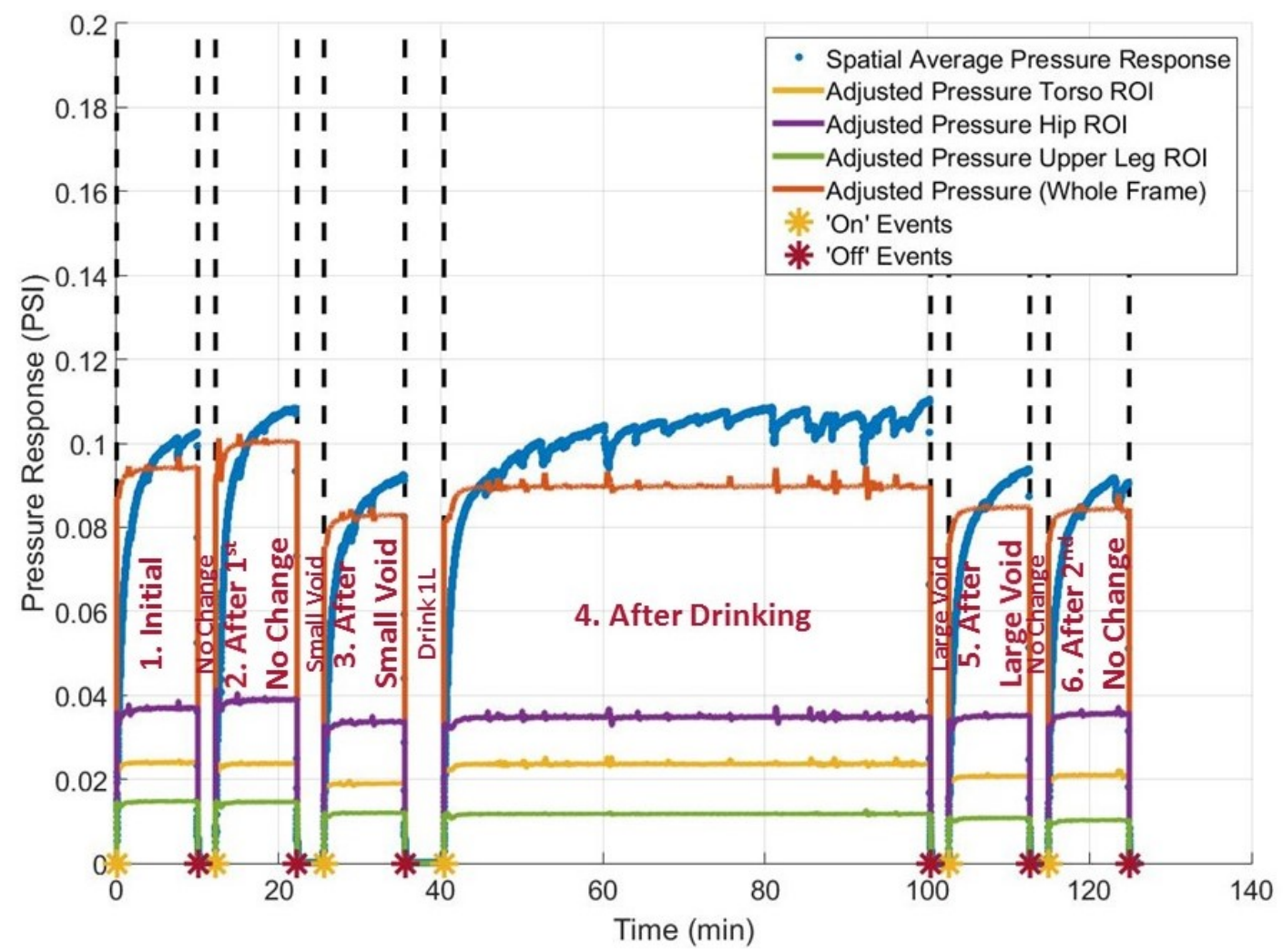

FIGURE 3. PRONE PRESSURE RESP ONSE FOR T HE WHOLE FRAME; FILTERED (BLUE) AND CREEPCORRECTED (ORANGE). PRESSURE RESPONSE FOR THE ROI SEGMENT SARE ALSO SHOWN FOR TORSO YELLOW), HIP (PURPLE), AND UPPER LEGS (GREEN). 
The ROI segmentation identifies two to three of these regions depending on the position of the participant during testing sessions. The subject's pose was recorded here, but pose can also be determined directly from PSM data [32].

Figure 3 displays the filtered spatial average pressure response over the whole frame and the regions of interest for the entire testing procedure when the subject was in the prone position. The small bladder void, water intake and large fluid void are all visually differentiable when looking at the whole frame data (Figure 3-Orange). This is even clearer when looking at the torso region (Figure 3 - Yellow). For each sensor-occupied session (i.e. a period of time when the subject was on the PSM), the temporal average was calculated and the percent difference between the current session and the previous session was calculated based on Equation (2).

$$
\% \Delta=\frac{p(i)+p(i-1)}{p(i-1)} * 100 \%
$$

Where $p(i)$ is the average pressure of the whole frame for each ROI segment for the current sub-session and $p(i-1)$ is the average pressure of the whole frame or for each ROI segment for the previous sub-session, as summarized in Table 2. The summary table and figure were also generated for the supine and side positions which are included in Chapter 7.

In order to determine if these percent changes between consecutive sessions were significant, random sampling was performed over each sensor-occupied session in order to perform an ANOVA statistical analysis with a null hypothesis that the pressure response from each sensor-occupied session was the same. A pairwise comparison was then performed using MATLAB's built in function 'multipcompare' to determine if each 
loading period was statistically different from each other sensor-occupied session. The resulting multi-factor comparison is summarized in Table 3 for the torso region.

TABLE 2. PRONE POSIT ON T EMPORAL AVERAGE PRESSURE RESP ONSE FOR EACH SENSOR-OCCUPIED SESSION SUMMARY

\begin{tabular}{|c|c|c|c|c|c|c|c|c|c|}
\hline \multirow{2}{*}{\multicolumn{2}{|c|}{$\begin{array}{l}\text { Posture } \\
\text { Region }\end{array}$}} & \multicolumn{8}{|c|}{ Prone (Stomach) } \\
\hline & & \multicolumn{2}{|c|}{$\begin{array}{l}\text { Whole } \\
\text { Frame }\end{array}$} & \multicolumn{2}{|c|}{ Torso } & \multicolumn{2}{|c|}{ Hips } & \multicolumn{2}{|c|}{ Upper Legs } \\
\hline \multirow{6}{*}{ 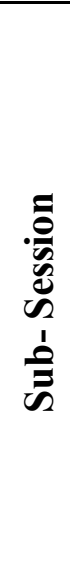 } & Initial & 0.101 & $\% \Delta$ & 0.024 & $\% \Delta$ & 0.037 & $\% \Delta$ & 0.015 & $\% \Delta$ \\
\hline & No-Change & 0.107 & 6.07 & 0.024 & -0.01 & 0.039 & 0.05 & 0.015 & -0.01 \\
\hline & Small Void & 0.091 & -21.0 & 0.019 & -0.25 & 0.034 & -0.16 & 0.012 & -0.22 \\
\hline & Drank 1L & 0.103 & 8.57 & 0.024 & 0.21 & 0.035 & 0.04 & 0.012 & -0.01 \\
\hline & Large Void & 0.092 & -7.92 & 0.021 & -0.15 & 0.035 & -0.00 & 0.011 & -0.10 \\
\hline & No-Change & 0.088 & -0.41 & 0.021 & 0.01 & 0.036 & 0.01 & 0.010 & -0.05 \\
\hline
\end{tabular}

For each combination of sensor-occupied sessions, a p-value was calculated to quantify the significance of their observed difference in mean pressure. The comparisons of consecutive sessions are highlighted to emphasize that corresponding sessions with no change were not statistically different $(p>0.05)$ and the corresponding sessions when fluid changes did occur are significantly different $(\mathrm{p}<0.05)$ (Table 3 ). This table was created for each position and each pressure region of interest (whole PSM, and each segmented ROI) and is included in Chapter 7. 
TABLE 3. PIECEWISE COMPARISON BETWEEN EACH SUB-SESSION (PRONE - TORSO ROI)

\begin{tabular}{|c|c|c|c|c|c|}
\hline \multicolumn{6}{|c|}{ Prone - Torso ROI } \\
\hline 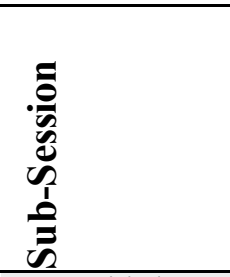 & 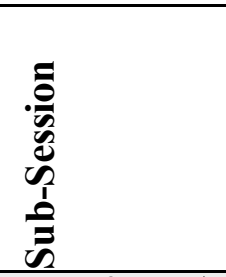 & 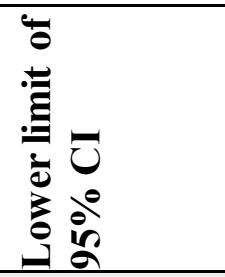 & 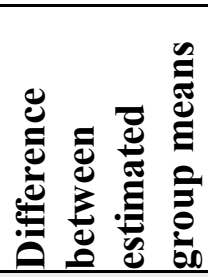 & 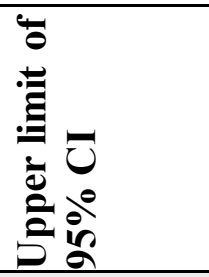 & 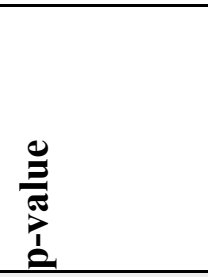 \\
\hline 1 - Initial & $\begin{array}{l}2 \text { - After } 1^{\text {st }} \\
\text { No Change }\end{array}$ & -0.00 & 0.00 & 0.00 & 0.93 \\
\hline 1 & 3 & 0.00 & 0.01 & 0.01 & 0.00 \\
\hline 1 & 4 & -0.00 & 0.00 & 0.00 & 0.99 \\
\hline 1 & 5 & 0.00 & 0.00 & 0.00 & 0.00 \\
\hline 1 & 6 & 0.00 & 0.00 & 0.00 & 0.00 \\
\hline $\begin{array}{l}2 \text { - After 1st } \\
\text { No Change }\end{array}$ & $\begin{array}{l}\text { 3- After } \\
\text { Small Void }\end{array}$ & 0.00 & 0.01 & 0.01 & 0.00 \\
\hline 2 & 4 & -0.00 & -0.00 & 0.00 & 0.99 \\
\hline 2 & 5 & 0.00 & 0.003 & 0.00 & 0.00 \\
\hline 2 & 6 & 0.00 & 0.00 & 0.00 & 0.00 \\
\hline $\begin{array}{l}3 \text { - After } \\
\text { Small Void }\end{array}$ & $\begin{array}{l}4 \text { - After } \\
\text { Drinking }\end{array}$ & -0.01 & -0.01 & -0.00 & 0.00 \\
\hline 3 & 5 & -0.00 & -0.002 & -0.00 & 0.00 \\
\hline 3 & 6 & -0.00 & -0.00 & -0.00 & 0.00 \\
\hline $\begin{array}{l}4 \text { - After } \\
\text { Drinking }\end{array}$ & $\begin{array}{l}5 \text { - After } \\
\text { Large Void }\end{array}$ & 0.00 & 0.00 & 0.00 & 0.00 \\
\hline 4 & 6 & 0.00 & 0.00 & 0.00 & 0.00 \\
\hline $\begin{array}{l}5 \text { - After } \\
\text { Large Void }\end{array}$ & $\begin{array}{l}6 \text { - After } 2^{\text {nd }} \\
\text { No Change }\end{array}$ & -0.00 & -0.00 & 0.00 & 0.27 \\
\hline
\end{tabular}

\subsubsection{CONCLUSION}

As can be seen above, we were successfully able to detect changes in fluid status associated with drinking and bladder voiding when the participant was in a prone positon. The results from testing when the participant was in the supine and side positions are summarized and discussed in Chapter 7. A description of the first difference creep compensation algorithm and the ROI segmentation algorithm is also detailed in Chapter 7. 
The ability to detect small internal fluid changes has obvious implications in monitoring of conditions such as nocturia, where it would be possible to keep count of how many bed exits and entries were associated with bladder voiding events. Applying our algorithm to monitor fluid distribution as an indicator of fluid retention that occurs with many individuals presenting with CHF would be a possible next step for this research.

\subsection{OVERVIEW OF EXPERIMENTS}

What follows a brief description of the series of experiments conducted during this thesis research. Each experiment increases in both complexity and realism, ultimately culminating in the results described above.

\subsubsection{CONTRIBUtion 1 - PROOF-OF-CONCEPT USING ANTHROPOMORPHIC MODEL}

Contribution 1 is detailed in Chapter 4. This chapter describes the development of an anthropomorphic human body model and the evaluation of three different PSM technologies for the purpose of patient monitoring.

\subsubsection{CREATION OF THE ANTHROPOMORPHIC HuMAN BODY MODEL}

In order to reduce the impact of external factors known to effect pressure sensors, ideal conditions were established as a baseline for all subsequent experimentation. The PSM was placed directly on the floor to eliminate the effect of non-uniform bed frames. The mattress was removed to eliminate the spatial distribution of contact pressure. With a real human subject, we expect to observe both large movements (shifting on the PSM) and minute movements (e.g. breathing, twitching). These movements could impact observed contact pressure. It is also difficult to recruit human subjects for prolonged experiments. Therefore, an anthropomorphic human body model was created in order to eliminate all movements. 


\subsubsection{SENSOR COMPARISON AND SELECTION}

A sensor comparison between three pressure sensitive technologies was performed to determine which underlying technology would be the most appropriate for this thesis. The meteorological properties of each PSM were characterized. Although the results of this comparison suggest that the XSensor capacitive PSM may be optimal, was not used for further evaluation, since it was only available for a short period in November 2016. Ultimately, we made use of the best available PSM system at any given time. Hence, the PSM used changed as research progressed.

\subsubsection{CONTRIBUTION 2 - SySTEM VERIFICATION USING THE MODEL AND EXTERNAL MASS}

Contribution 2 is detailed in Chapter 5 and involved the first experiment that was designed to evaluate the ability of a PSM to detect small changes in fluid mass. The anthropometric human body model was placed directly on the fibre-optic PSM, which was placed directly on the floor. A model of the excess fluid typical of that retained by patients suffering from CHF was created with a mass of $400 \mathrm{~g}$. This external mass was placed at key locations (ankle, shin, knee, thigh and abdomen) on the lower body of the model while in a supine position. A clear pressure increase was detectable for each location when performing a simple 1:1 pressure subtraction across each sensel. The external mass was then decreased until a minimum threshold was identified, representing the point at which external mass was undetectable $(\sim 100 \mathrm{~g})$. This procedure was then repeated after the application of a mattress, resulting in a higher minimum detectable mass $(\sim 400 \mathrm{~g})$. This procedure was recreated when the piezo-resistive PSM became available, resulting in similar minimum detectable masses. 


\subsubsection{CONTRIBution 3 - System Verification using Participants and EXTERNAL MASS}

Contribution 3 is detailed in Chapter 6 , and summarizes a similar experiment to the one detailed in Contribution 2, however human participants were used. This represented a step towards our ultimate goal, where the realities of human movements were now included. $600 \mathrm{~g}$ was chosen as the external mass for all participant experiments. This experiment also coincided with the acquisition of the new piezo-resistive PSM from Tekscan ${ }^{\mathrm{TM}}$ therefore both this new PSM and the original fibre-optic PSM (S4 Sensors) were evaluated. Participants were asked to lie in a supine position and remain as still as possible for two minute periods when the external weight was applied to the key locations on the lower body (ankle, shin, knee, thigh, and abdomen). A manual ROI extraction algorithm was used. For each ROI, the pressure observed with the applied external mass was compared to those sessions where the mass was applied elsewhere. Classification was considered to be correct when the location of applied mass matched either the highest and second highest increase in pressure region. The resulting accuracy was $90 \%$ for the fibre-optic technology and $95 \%$ for the piezo-resistive technology.

\subsubsection{Contribution 4 - Evaluating Fluid Changes within the Human Body}

The final contribution in this thesis is detailed in Chapter 7. In this experiment, the fluid changes being observed now represented internal, rather than external processes. As described above, a single participant was asked to lie on a mixed density foam mattress that was placed directly on the piezo-electric PSM, which was placed on the floor. During the experiment, the participant was asked to exit the bed to either (1) do nothing, (2) void their bladder or (3) drink as much water as was comfortable. This procedure was repeated 
with the participant in a prone, supine and side positions. The algorithm was updated to include an automatic ROI segmentation tool that utilized image processing methods in combination with anthropometric measurement data.

Additionally, it was observed that the pressures response associated with the piezoresistive technology experienced a continual creep over time (reported by the manufacturer as a $<=5 \%$ logarithmic pressure increase). A creep compensation algorithm was created to account for this metrological property.

The results show clear increases across all positions and all regions (including the entire pressure image) when the participant drank water and when they had a large bladder void. The smaller bladder voids were detectable after ROI segmentation in most positions, but were not always significantly different from those pressure changes associated with two consecutive sessions of no change in some positions. 


\section{Contribution 1 - Creating the Anthropomorphic Model and Selecting the PSM Technology}

The following chapter summarizes the materials used across all experiments within each contribution. The first section outlines the evaluation and creation of an anthropomorphically correct human body model. The second section describes the evaluation and selection of the most appropriate sensor for each experimental step from the three types of PSMs.

\subsection{Creating an ANThropomorphic Human Body Model}

The content of this sub-chapter was originally published in I2MTC 2016 [10]. I was the lead author on this paper.

\subsubsection{INTRODUCTION}

Accurate characterization of the underlying measurement system is essential prior to the development of robust monitoring and diagnostic systems. This chapter summarizes an anthropomorphically correct model to characterize and test pressure sensitive mats (PSMs). Such a model has several potential applications. First, it is useful in studying the impact of long-term deployment of the PSM system, including sensor drift and long-term compression of bedding. For example, a detailed understanding of these long-term system characteristics could lead to novel adaptive calibration systems. Second, understanding how different PSM technologies respond to small variations in mass. Such small changes in mass and mass distribution can indicate a variety of disorders from frailty in older adults to an early marker of congestive heart failure (CHF) [30]. Additional mass can be added at specific locations, such as the bladder region, that are difficult to implement with human 
participants. Identification of these changes using PSMs may lead to early detection and intervention for these and other conditions where small changes in mass and/or mass distribution are expected. Third, such a model would facilitate the evaluation of novel pressure sensor technologies prior to formal assessment using human participants.

A number of models of the human body currently exist, including both physical and digital simulations. However, each model was created with a specific goal in mind [70], [71]. Several advanced crash test dummies have been developed, but the goal of these models was to measure dynamic movement typical of vehicle collisions while the model is in an upright or semi-upright position [70], [72]. The cost of these crash test dummies is also prohibitive because of the embedded dynamic sensors, which are not required for our purposes. Based on these confounding goals, it was determined that a new model was needed to address static measurements in a constant position over a long period of time based on published anthropomorphic information for the older adult population.

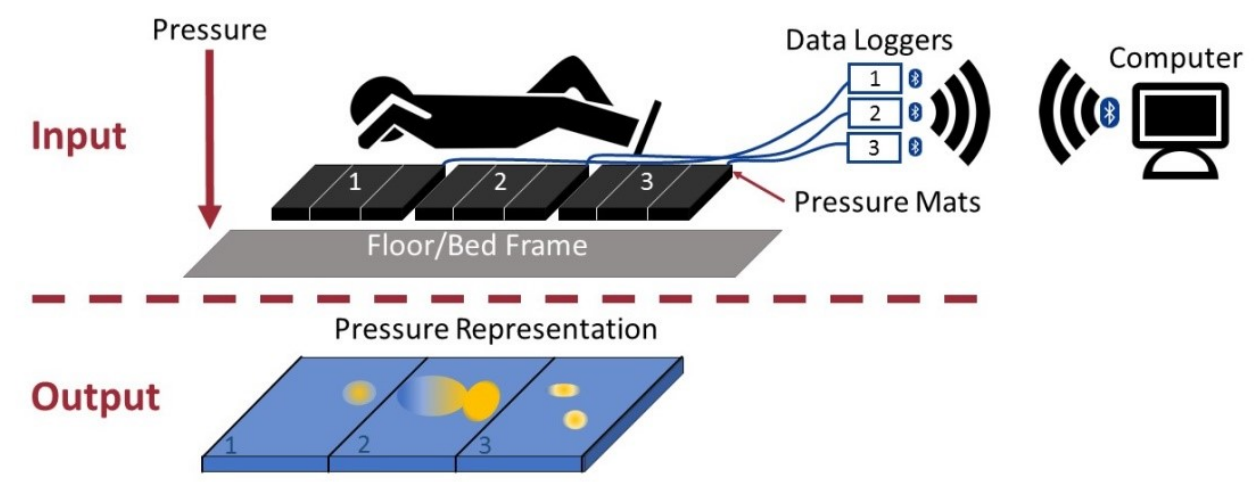

FIGURE 4. TEST INGSET UP FOR MODEL VALIDATIONAND TESTING 


\subsubsection{MEASUREMENT SYSTEM}

The measurement system is composed of the fibre-optic PSM from S4 Sensors, the data acquisition system (including data loggers paired with a data collection computer), the 2D model and the 3D model. This system is summarized in Figure 4.

\subsubsection{ANTHROPOMORPHIC MEASUREMENTS FOR 2D MODEL}

In order to ensure that the model is placed in exactly the same locations on the PSMs or mattress a 2D model consisting of segment perimeters and centroids was created on a flat sheet. For maximum accuracy, average anthropometric measurements were taken and interpolated from data originally gathered by NASA [73]. The majority of the research associated with the PSMs focuses on the growing population of older adults. Therefore, the overall height (length) of the model was based on the measurements obtained from

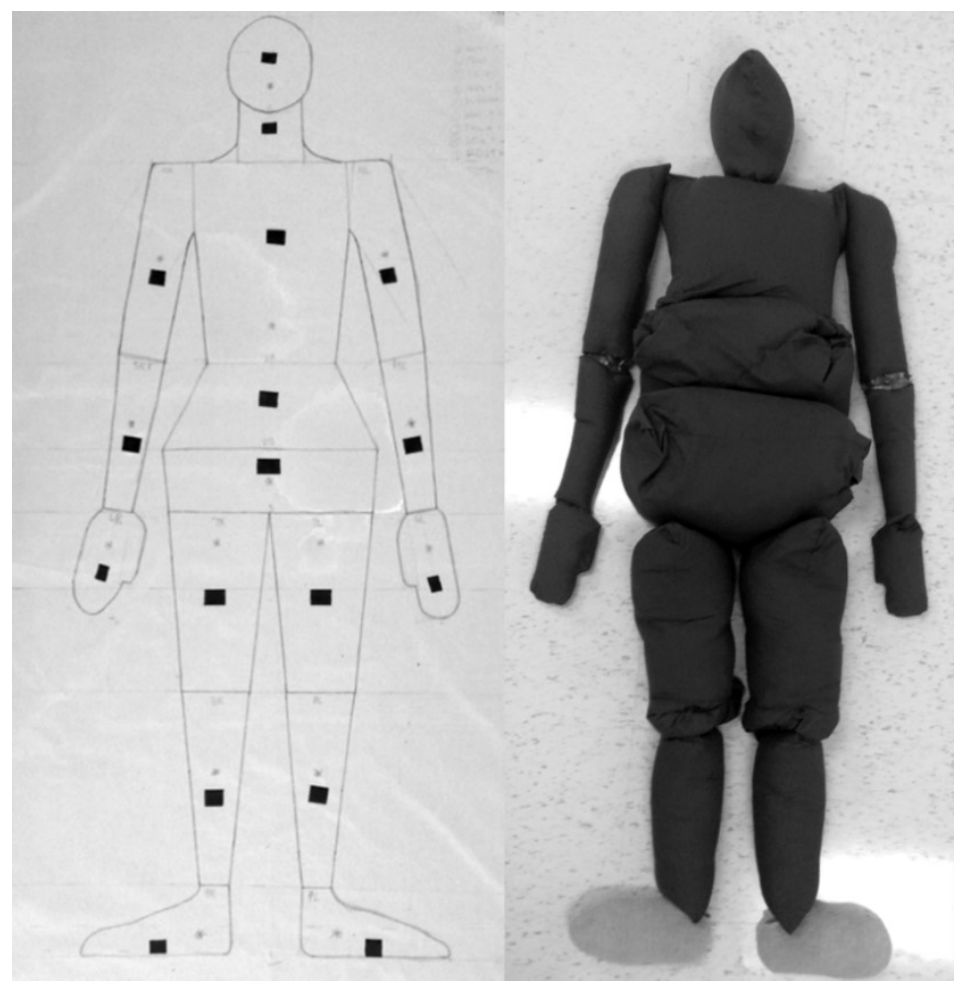

FIGURE 5. ANT HROPOMETRIC 2D (LEFT) AND 3D (RIGHT) MODEL BASED ON AN OLDER FEMALE ADULT 
Pavol et al. for an older female, 1.59 meters [74]. All measurements were marked on the flat sheet and lines were interpolated between the measurements to complete the outline (Figure 5).

The body was segmented into 14 areas (Table 4). The centre of mass locations for each segment relative to the proximal joint and segment masses were provided by Pavol et $a l$. The centre of mass was then marked on the 2D model with an asterisk. Segments chosen were those suggested by Pavol et al. with the exception of the torso segment. The torso was split into two segments at the waist in order to accurately find the location of the hips on the 2D model. The centre of mass proposed by Pavol et al. for the torso segment was used as an indicator of how much mass should be applied to the chest and abdomen section.

TABLE 4. BODY SEGMENT SAND MASES

\begin{tabular}{|c|c|c|}
\hline Segment & Mass (\% of Total) & Mass (kg) \\
\hline Head & 7.4 & 5.3 \\
\hline Torso & 29.2 & 13.4 \\
\hline Pelvis & 18.7 & $2.0(\mathrm{x} 2)$ \\
\hline Upper Arms & $3.0(\mathrm{x} 2)$ & $1.0(\mathrm{x} 2)$ \\
\hline Forearms & $1.4(\mathrm{x} 2)$ & $0.4(\mathrm{x} 2)$ \\
\hline Hands & $0.5(\mathrm{x} 2)$ & $8.5(\mathrm{x} 2)$ \\
\hline Thighs & $11.6(\mathrm{x} 2)$ & $3.2(\mathrm{x} 2)$ \\
\hline Lower Legs & $4.6(\mathrm{x} 2)$ & $0.9(\mathrm{x} 2)$ \\
\hline Feet & $1.2(\mathrm{x} 2)$ & $\mathbf{7 1 . 6 k g}$ \\
\hline Totals & $\mathbf{1 0 0} \%$ & \\
\hline
\end{tabular}


The center of mass for the torso segment was given as $42 \%$ of the length between the top of the shoulders and waist. This equated to $21.2 \mathrm{~cm}$ from the top of the shoulders. It was then decided that, based on this percentage, $42 \%$ of the total segment mass $(21 \mathrm{~kg})$ would be assigned to the chest $(8.82 \mathrm{~kg})$ and the remaining mass would be assigned to the abdomen $(12.18 \mathrm{~kg})$.

\subsubsection{ANTHROPOMORPHIC MEASUREMENTS FOR 3D MODEL}

The total mass of an average $\left(50^{\text {th }}\right.$ percentile, North American) older female is $71 \mathrm{~kg}$ [74]. This mass formed the basis for calculating the mass of each body segment. For each body segment, Pavol et al. defined a mass factor, capturing the proportion of total mass accounted for by each body segment. The following equation was used to determine the mass of each segment:

$$
W_{\text {segment }}=M_{\text {total }} * P_{n}
$$

Where $P_{n}$ is the Pavol factor for segment $n$ (Table 4).

In order to represent this mass as a model of human tissue, materials of similar density to human soft and hard tissue were required. Hydrated potassium acrylate (AgSAP, 800-150um dry) crystals (M2Polymer, West Dundee, IL) were chosen for soft tissue and wet gravel (4-7mm) was chosen for bone tissue (Table 5). For each segment, a combination of both materials was used in order to match the previously calculated mass values. After all segments were measured and placed in their corresponding segment pockets the overall mass of the model was determined and found to be $71.6 \mathrm{~kg}$, well within the range associated with the average mass for an older female, $71.2 \pm 12.2 \mathrm{~kg}[74]$. 
TABLE 5. DENSITY MEASUREMENTS [75]

\begin{tabular}{|c|l|l|l|l|}
\hline \multirow{2}{*}{} & \multicolumn{2}{|c|}{ Soft Tissue } & \multicolumn{2}{c|}{ Hard Tissue } \\
\cline { 2 - 5 } & \multicolumn{1}{|c|}{ Actual } & \multicolumn{1}{c|}{ Model } & Actual & Model \\
\hline Material & $\begin{array}{l}\text { Fat and } \\
\text { Muscle } \\
\text { Tissue }\end{array}$ & $\begin{array}{l}\text { Hydrated } \\
\text { AgSAP }\end{array}$ & Bone Tissue & Wet Gravel \\
\hline $\begin{array}{c}\text { Density }(\rho) \\
\mathbf{k g} / \mathbf{m}^{3}\end{array}$ & $982.5^{a}$ & 1000 & 1950 & 2000 \\
\hline
\end{tabular}

${ }^{a}$ Average density of fat $\left(940 \mathrm{~kg} / \mathrm{m}^{3}\right)$ and muscle tissue $\left(1025 \mathrm{~kg} / \mathrm{m}^{3}\right)$

\subsubsection{ACQUISITION APPROACH}

For both the $3 \mathrm{D}$ model and the participant, the flat $2 \mathrm{D}$ model was placed directly on three sets of three $80 \times 25 \mathrm{~cm}$ PSMs on top of the surface being evaluated (Figure 4). The 3D model was aligned with the corresponding body segment sections on the $2 \mathrm{D}$ model and data were collected at $20 \mathrm{~Hz}$ over a 5-minute period. The participant, a healthy female (23yrs, 5'7', 130lbs), was asked to lie in a supine positon aligned with the top of the head segment on the $2 \mathrm{D}$ model and was instructed to move as little as possible. A five-minute calibration data set was taken without the model/participant present to account for the intermat variability and the mass of the $2 \mathrm{D}$ flat model.

Before further evaluation, each set of three mats was calibrated using the (unloaded) calibration data. The mean pressure responses were then calculated for each sensor. The measurements taken from the model and from the participant were then compared.

\subsubsection{MODEL VS. PARTICIPANT}

The pressure responses from the model and participant are highly consistent (Figure 6). There are a few discrepancies, which can be explained by the morphology of the human body when lying in the supine position. For instance, the participant's lower back was not touching the PSM due to the curvature of the spine. The participant's thighs are also not 


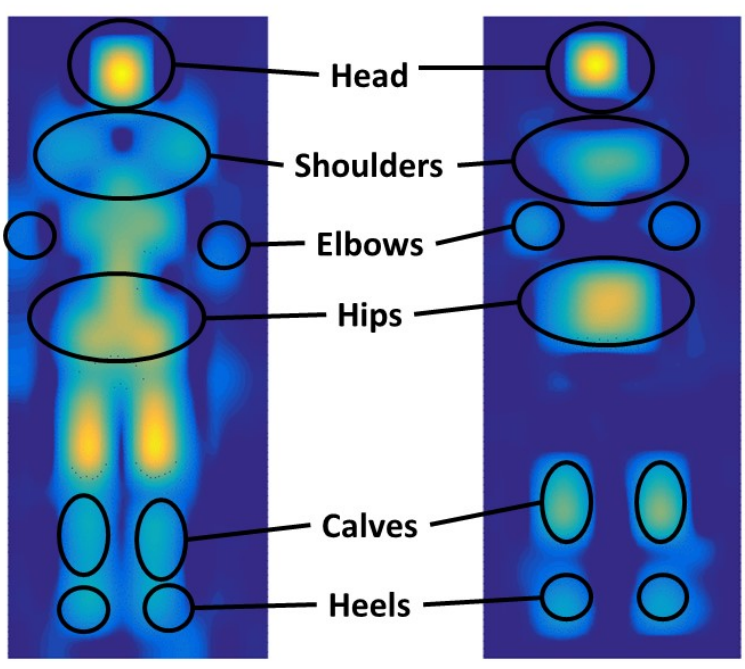

FIGURE 6. PRESSURE RESPONSE WHILE LYING SUPINE DIRECTLY ON THE MAT: MODEL (LEFT) AND PARTICIPANT (RIGHT)

visible due to the weight distribution through the femurs to the back of the calves. The model does not contain a skeletal structure, making it unable to accurately represent these variations.

There is a defined area for the head, shoulders, elbows, calves, heels and the general outline of the human body is visible (Figure 6). The resolution of the PSM used in this study is relatively low (sensors were equally spaced $10 \mathrm{~cm}$ apart). Therefore, the small variations due to the skeletal structure do not change the measurements from the fibre-optic sensors.

\subsubsection{CONCLusions}

This section summarized the creation and validation of an anthropomorphically correct human body model. The next step is to identify if the PSM is able to detect changes in pressure that are associated with the application of external mass. Future work that may harness this model includes; the characterization of long term mass applied to PSMs as a 
model for people susceptible to bed ulcers and the characterization of long-term mass loading of novel pressure sensing technologies prior to human participation.

\subsection{SENSOR COMPARISON}

The following section is a summary of work published in the 2017 Sensor Applications Symposium [15].

\subsubsection{UPDATED EXPERIMENTAL CONDITIONS}

Preliminary work in this thesis (contribution 1-3) was done to identify if small variations in weight, modeling fluid variation, was identifiable using PSMs. This work was done using the fibre-optic PSMs that were readily available in the lab. These PSM have been used for a variety of investigations prior to this thesis (e.g. [32], [35], [67] ). There were also many fibre-optic PSMs available in the lab, allowing for full coverage of a human body. This was essential in preliminary investigations, due to the uncertainty associated with where fluid variations would be detectable.

After establishing that these small variations were detectable, other PSMs were identified and evaluated to establish which PSM would be most appropriate for subsequent experiments.

\subsubsection{INHERENT SENSOR CHARACTERISTICS CONSIDERED}

There is some variability in PSMs due to the inherent properties associated with the sensing technology used and the way the PSMs were constructed. This section discusses some of the most relevant inherent characteristics associated with PSMs. The factors addressed here have been used to determine which PSM is the most appropriate for this thesis work [15]. The characteristics described below are summarized for each PSM considered in Table 6 . 


\subsubsection{SPATIAL RESOLUTION}

Spatial resolution refers to the physical orientation of the sensels within the PSM. All sensels in PSMs are equidistant, however the spacing between each sensor can vary depending on the intended purpose. Higher spatial resolution, meaning sensels are closer together, is desired for monitoring fluid distribution changes presented in this thesis. The more sensors in a given area, the more spatial information available and the more precisely we can identify the physical location of fluid changes or accumulation. When there is a lower spatial resolution, the physical location of loading may lead to varying pressure responses despite loading under the same conditions; the more directly centered a load is over a sensel, the higher the measured pressure response will be when compared to loading in between two sensels.

\subsubsection{Rise TIME AND SETTLING TIME}

Rise time is defined as the time it takes for a sensor response to rise from $10 \%$ to $90 \%$ of the steady state response after a step input load has been applied. Settling time is defined as the time it takes for a sensor to reach its steady state value after a step input load has been applied. Recovery time is the time it takes for a PSM to return to zero after removal of the load. These metrics are a measure of a sensors responsiveness to load variations (i.e. movement).

\subsubsection{SENSOR REPEATABILITY}

Sensor repeatability is defined as a sensors ability to produce the same output in response to the same input under the same conditions for a short time period, irrespective of the time 
of application. Nizami et. al. uses the coefficient of variation $\left(C_{0} \mathcal{V}\right)$ as a measure of repeatability as described in the following equation.

$$
\operatorname{CoV}(\%)=\frac{\text { Standard deviation }}{\mathcal{M} \text { ean }} * 100 \%
$$

Here, Standard deviation and Mean are computed from a set of repeated applications and removals of the same load on the PSM. Co $V$ is a measure of data dispersion around its mean. The smaller the dispersion, i.e. the closer the samples are to one another, the more reliable a sensor is and therefore the higher the repeatability measure [76].

\subsubsection{SENSOR DRIFT AND CREEP}

For the purposes of this thesis, sensor creep and sensor drift are defined as follows. Sensor creep is caused by its inherent elasticity. Pressure sensors, no matter the underlying technology, measure pressure based on the 'spring balancing principle'. When a force is applied, there is an elastic deflection in the sensor. This deflection is translated into an electric output for analysis. When the sensor is loaded abruptly, i.e. a step input, the sensor produces an immediate elastic or 'spring' response. The sensor will then produce a time dependent continual increase associated with sustained loading conditions. This effect is what we perceive to be the unwanted creep response, where the apparent pressure continues to increase over time while the true load is kept constant [77]. In other words, when a constant load is applied to a PSM, the output pressure response will increase with time. Creep can be accounted for using calibration curves [76], [78]. There is also a hysteresis response when a load is removed from a PSM, the sensor will continue to measure pressure due to its elasticity before eventually returning to zero. 
Nizami et. al. further defined percent change in creep $(\Delta C(\%))$ as the change in pressure response due to a constant applied force from $\mathcal{P}_{1}$ to $\mathcal{P}_{2}$ over time $\mathcal{T}_{1}$ to $\mathcal{T}_{2}$ divided by the average pressure over that time duration, $\mathcal{M}$ ean $\mathcal{P}_{12}$. Percent change in creep is defined as:

$$
\Delta \mathcal{C}(\%)=\frac{\mathcal{P}_{1}-\mathcal{P}_{2}}{\text { Mean } \mathcal{P}_{12}}
$$

Creep and drift have been used interchangeably in the literature [33], [79]-[81]. For this thesis, the term drift follows the definition originally proposed by Shelton et.al., where drift is defined as the tendency of a system's output to float higher or lower over continuo us measurements due to fluctuations in the zero point [76]. Based on this, changes occurring under a continuous load after a sensor has reached steady state are the result of system drift noise, or from systematic changes associated with creep.

\subsubsection{PSM EVALUATION AND SUbSTITUTION}

Meteorological measurements were evaluated based on two main experiments conducted on the three available PSMs (as described in Chapter 3), all sampled at $1 \mathrm{~Hz}$. An anthropometrically correct adult torso model (chosen due to the limited size of the PSM) and an infant full-body model were used based on measurements obtained in [10]. Long term experiments were evaluated for a minimum of 14.5 hours for both the adult and infant models applied to each PSM. The drift, rise time, total creep and percent change in creep $(\% \Delta C)$, as described in the previous section, were then calculated for both the adult and infant model. It was assumed that all PSM reached steady state after 30 minutes and percent creep and drift response were calculated based on data beyond this point. Percent drift is based on a non-overlapping sliding window of one minute in duration. The average drift 
reported is computed based on the percent drift response over the 14.5 hours. Percent creep was calculated based on using a sliding window of 60 minutes with an overlap of 30 minutes.

TABLE 6. PSM COMPARISON SUMMARY

\begin{tabular}{|c|c|c|c|}
\hline $\begin{array}{l}\text { Pressure } \\
\text { Technology }\end{array}$ & $\begin{array}{c}\text { Fibre-Optic } \\
\text { S4 Sensors Inc. }\end{array}$ & $\begin{array}{c}\text { Piezo-Resistive Ink } \\
\text { Tekscan TM }\end{array}$ & $\begin{array}{l}\text { Capacitive } \\
\text { XSensor }^{\mathrm{TM}}\end{array}$ \\
\hline $\begin{array}{l}\text { Spatial } \\
\text { Resolution }\end{array}$ & $\begin{array}{c}\text { Low }=0.012 \\
2 \\
\text { sensels } / \mathrm{cm}^{2}\end{array}$ & $\begin{array}{l}\text { High }=0.3 \\
\text { sensels } / \mathrm{cm}^{2}\end{array}$ & $\begin{array}{c}\text { High }=1.27 \\
{ }^{2} \\
\text { sensels } / \mathrm{cm}^{2}\end{array}$ \\
\hline $\begin{array}{l}\text { Digital } \\
\text { Resolution }\end{array}$ & $16 \mathrm{Bit}$ & 8 Bit & $16 \mathrm{Bit}$ \\
\hline Physical Size & Large $=80 \times 225 \mathrm{~cm}$ & Medium $=58 \times 88 \mathrm{~cm}$ & Small $=45.7 \times 45.7 \mathrm{~cm}$ \\
\hline $\begin{array}{l}\text { Creep Response } \\
(\%)\end{array}$ & 12.86 & 9.64 & 7.58 \\
\hline $\begin{array}{l}\text { Drift Response } \\
(\%)\end{array}$ & 0.32 & 0.11 & 0.27 \\
\hline $\begin{array}{l}\text { Repeatability } \\
(C \circ \vee \%)\end{array}$ & 7.83 & 3.30 & 2.33 \\
\hline Rise Time (min.) & 1.28 & 2.15 & 0.21 \\
\hline Availability & Since May 2015 & Since Nov. 2016 & $\begin{array}{l}\text { Only available for one } \\
\text { week in October } 2016\end{array}$ \\
\hline
\end{tabular}

The second set of experiments were short-term and were conducted to evaluate repeatability measures for both the adult and infant models for each PSM. Each model was applied to each PSM four times for one minute each. The length of removal before reapplication was increased from 1,2, and 5 minutes. For each application, the average pressure was computed and repeatability was assessed using the coefficient of variation $(\% \mathrm{Co} V)$ as described in equation 5. For each PSM, the meteorological properties from each model were averaged and reported in Table 6.

The piezo-resistive PSM and the capacitive PSM both had a much higher spatial resolution ( 0.3 sensels $/ \mathrm{cm}^{2}$ and 1.27 sensels $/ \mathrm{cm}^{2}$, respectively). Unfortunately, the 
capacitive PSM was physically very small, at only $45.7 \times 45.7 \mathrm{~cm}$, thus eliminating it as a possibility. The piezo-resistive PSM was $58 \times 88 \mathrm{~cm}$ and was much closer to being able to cover the entire human body. The most relevant factors associated with this thesis work are highlighted in Table 6, which lead to the decision to change the PSM used for the final experiment.

After evaluating the metrics described and summarized in Table 6, it was decided to use the piezo-resistive PSM for further testing in order to attain the necessary spatial resolution needed to fully capture fluid distribution changes. Therefore, the final experimental results associated with contribution 4 of this thesis were based on using the piezo-resistive PSM.

\subsubsection{Discussion AND CONCLUSIONS}

The original decision to use the fibre-optic PSM was based on two main factors. The fibreoptic technology had been used in many experiments in our lab and was very well documented. The second and arguably more important factor was that the fibre-optic PSM was large enough to cover the entire length of a human body. All other PSMs evaluated were not large enough to do so. However, it was noted on many occasions that the poor spatial resolution of the fibre-optic PSM $(10 \mathrm{~cm} \times 10 \mathrm{~cm})$ did lead to some inconsistent data.

The experiments conducted here indicate that both the piezo-resistive and capacitive sensors outperform the fibre-optic PSM, particularly in the drift response and creep response. Furthermore, the settling and recovery time of the XSensor mat makes it preferable to the piezo-electric PSM, especially for the purpose of capturing rapid dynamic behavior. Ultimately, the piezo-resistive PSM was selected for the remaining experiments for several reasons including sensor size, availability, and cost. 
Regarding sensor size, the sensor comparison was done in collaboration with another project that focused on the PSM application in neonatal environments. Due to this, the PSM used were smaller in size and were unable to cover an entire adult human body. For the purposes of a neonatal monitoring, this was not an issue and this condition was not addressed in the original paper [15]. For the purposes of this thesis, however, the size of each PSM was included as a selection criteria based on the versions of each PSM that were currently available. All three PSM were available in larger sizes, at higher prices, any of which would be applicable to the algorithm developed in this thesis. Future work may include the acquisition of the recommended PSM from Nizami et. al. in a larger size.

A second important factor for this thesis was PSMavailability. Only fibre-optic and piezo-resistive sensors PSM were available on an ongoing basis. Once the new piezoresistive PSM was available, it was chosen for all further testing due to its higher spatial resolution at the cost of covering the entire human body area. The capacitive PSM was only available for a short period, during which sensor comparison testing was performed, and was therefore eliminated at the onset of sensor selection for all other experiments.

The final consideration was cost. The XSensor capacitive PSM is approximately $50 \%$ more expensive than the Tekscan system for the same sensor size and sensel density. Following the PSM comparison, the piezo-electric PSM was selected for the final experimentation in Chapter 7. Future work may involve the application the final algorithm to novel PSM and is discussed further in (section 8.4). It is important to note that all algorithms developed in this thesis can be easily generalized to other current and future PSM technologies. 


\section{Contribution 2 - System Verification using the Model and External Mass}

Some of the content of this chapter was originally published in MeMeA 2016 [12]. I was the lead author on this paper.

This chapter describes experiments where fluid mass is applied externally to the anthropomorphically correct human model. First, various masses are applied to the ankle to determine the minimum detectable mass change. Second, external masses are applied at various positions on the leg and abdomen to simulate overnight fluid redistribution typical of CHF patients.

\subsection{FLUID MODEL DESCRIPTION}

Hydrated potassium acrylate (AgSAP, 800-150um dry) crystals (M2Polymer West Dundee, IL) were chosen to model internal fluid (Table 7), based on their similar densities. Hydrated AgSAP solution was placed in Ziploc bags. The initial weight chosen was 400g, as this was representative of the mass of fluid expected to be caused by fluid retention associated with $\mathrm{CHF}(<2 \mathrm{~kg}[82])$. Several other bags of AgSAP solution were also

\begin{tabular}{|c|c|c|}
\hline \multirow{2}{*}{} & \multicolumn{2}{|c|}{ Internal Fluid Meas urements } \\
\cline { 2 - 3 } & Actual & Model \\
\hline Material & Water & Hydrated AgSAP \\
\hline Density $(\rho) \mathbf{k g} / \mathbf{m}^{3}$ & 997 & 1000 \\
\hline
\end{tabular}


prepared $(300 \mathrm{~g}, 200 \mathrm{~g}, 100 \mathrm{~g}, 50 \mathrm{~g}$ and $30 \mathrm{~g})$ in order to evaluate the smallest detectable fluid model addition detectable by the PSM.

\subsubsection{EXTERNAl Mass APPLIED TO THE ANKLE REgION}

The model was placed directly on the PSM (Figure 4), and a 400g bag of hydrated AgSAP was placed directly on the left ankle. A five-minute data set was collected, calibrated, and filtered temporally (Figure 7(B)). A separate five-minute data set was

A

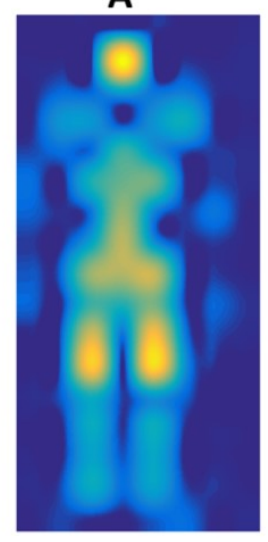

B

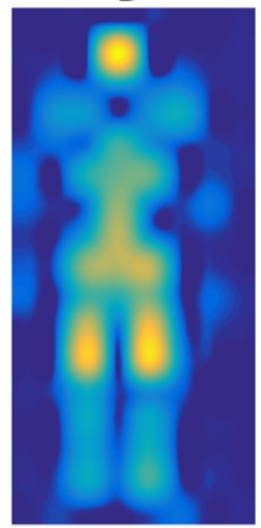

C

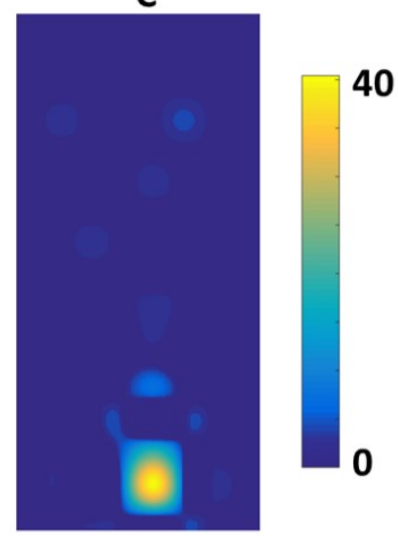

FIGURE 7. MODEL ALONE (A), MODEL WITH ADDED WEIGHT (400G) (B), AND PRESSURE DIFFERENCE (C)

collected without the addition of mass, which was also calibrated and filtered temporally (Figure $7(\mathrm{~A})$ ). The two testing sessions were compared via 1:1 sensel subtraction, resulting in a clear mass addition as seen in Figure 7 (C). After this successful result, decreasing masses $(300 \mathrm{~g}, 200 \mathrm{~g}, 100 \mathrm{~g}, 50 \mathrm{~g}$, and $30 \mathrm{~g}$ ) were applied to the model on the ankle region. The static mass changes that were distinguishable were $300 \mathrm{~g}, 200 \mathrm{~g}, 100 \mathrm{~g}$ and $50 \mathrm{~g}$. The PSM was unable to accurately detect the addition of $30 \mathrm{~g}$. Therefore, the minimum possible detectable mass change is approximately $50 \mathrm{~g}$ in the region of the ankle under idealized conditions. The minimum detectable mass may change if testing conditions were non-ideal, specifically if the model was removed and replaced on the PSM between mass additions. 
It is also expected that the minimum detectable mass change would be larger after the introduction of human participants.

Fluctuations in weight may be indicative of fluid retention associated with CHF. Typically, during daily activities when patients are upright, fluid tends to settle in the ankles. Over the course of the night during sleep this fluid distributes throughout the body, is collected by the kidneys, and passes to the bladder to be expelled. Previous studies have recommended alarm thresholds be set for weight gains of $1 \mathrm{~kg}$ in a day, $2 \mathrm{~kg}$ in three days or $3 \mathrm{~kg}$ in a week [30], [82]. The identification of $50 \mathrm{~g}$ to $400 \mathrm{~g}$ mass variations (Figure 7) by the PSM suggests that PSMs may be able to not only detect overall weight gain, but also track this retained fluid over the course of the night.

\subsection{External Mass Applied to Multiple Locations Using Piezo- ELECTRIC PSM}

\subsubsection{MEASUREMENT SySTEM}

The measurement system included the Anthropometric Human Body Model placed directly on three PSMs (S4 Sensors Inc.) (Figure 4) [10]. The fibre-optic PSM was used for all testing for this experiment, as described in section 2.4.1. Data were recorded at a rate of $20 \mathrm{~Hz}$ and saved as a CSV file for each session.

\subsubsection{METHODS}

A two-minute calibration session was recorded initially with only the $2 \mathrm{D}$ model directly placed on the mats. The $3 \mathrm{D}$ model was then placed directly on the $2 \mathrm{D}$ model with each body segment aligned to its equivalent $2 \mathrm{D}$ outline and data were recorded for a period of two minutes. To model fluid retention experienced by CHF patients, a $400 \mathrm{~g}$ bag of hydrated 
potassium acrylate (AgSAP, 800-150um dry) crystals (M2Polymer, West Dundee, IL) was used $(<2 \mathrm{~kg}[82])$. Five 2-minute data sessions were recorded with the addition of the AgSAP 400g bag placed at the (1) left ankle, (2) shin, (3) knee, (4) thigh, and (5) bladder region. This resulted in seven CSV files in total. This method was repeated using progressively lower weights. The results indicated that, for the sensors used in this study, $100 \mathrm{~g}$ was the lowest reliably detectable weight when considering all measured locations.

All calibration and temporal filtering (averaging over the two minute samples) was completed in MATLAB. Each file representing the addition of weight to the aforementioned body regions was then compared to when the model was directly on the mat without additional mass. The resulting pressure measurements were plotted in Figure $10(400 \mathrm{~g})$ and Figure $9(100 \mathrm{~g})$ using a heatmap where higher pressures are indicated using hotter colours (e.g. yellow vs. dark blue).

\subsubsection{Data ANalysis}

Calibration data were recorded for a period of two minutes when the 2D model was the only thing present on the PSM. These calibration data were used to zero the pressure response data under each testing condition. Adjusted data were the absolute difference between the calibration data from the various testing sessions at each sensor position as described in Equation (6).

$$
\left.\operatorname{Pcal}_{i, j, k}=\left|P_{i, j, k}-\operatorname{mean}\left(\operatorname{Cal}_{i, j}\right)\right|\right)
$$

Where $P_{i, j, k}$ is the pressure responses of the sensor located in row $i$, column $j$ and sample $k$ for the testing session in question. The variable mean $\left(\mathrm{Cal}_{i, j}\right)$ is the sample average for the 
sensor located in row $i$ and column $j$. The resulting variable Pcali,j was then used in all other processing.

Each file representing the addition of mass $(400 \mathrm{~g})$ to the aforementioned body regions were then compared to when the model was directly on the PSM without additional mass. The resulting pressure measurements were interpolated bi-linearly and plotted in Figure 9 and Figure 10. The higher pressures are indicated by the hotter colours (e.g. yellow). This was done by directly subtracting the pressure response of each individual sensor from its counterpart in the comparative testing session. The analysis procedure is summarized in the block diagram in Figure 8.

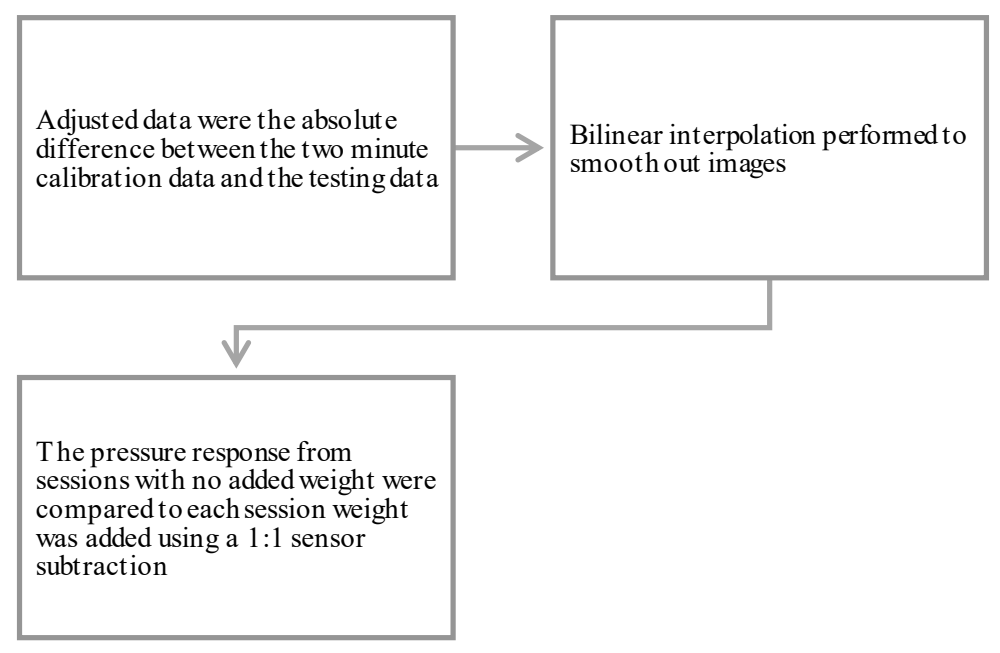

FIGURE 8. CONT RIBUTION 2 ANALYSISPROCEDURE 


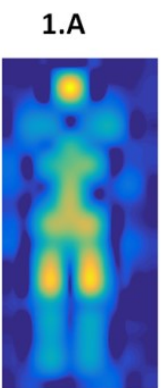

2.A

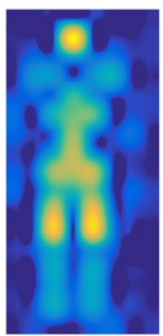

3.A

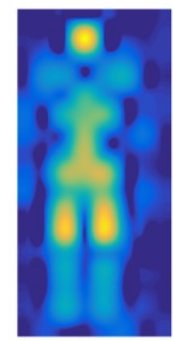

4.A

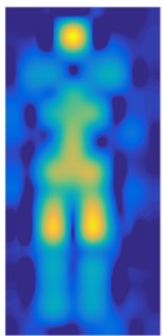

5.A
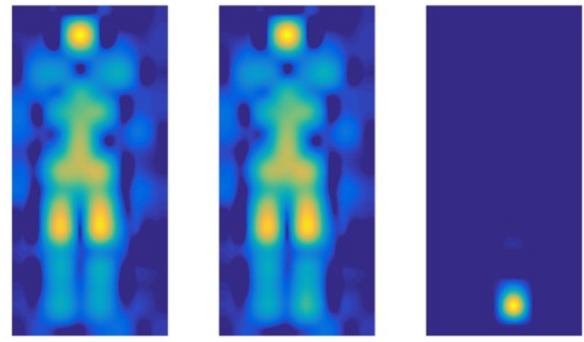

FigurE 10. MODEL ALONE (A), MODEL WIT H 400G ADDED MASS (B) AND PRESSURE DIFFERENCE (C) FOR ADDED MASS AT THEBLADDER REGION (1), THIGH (2), KNEE (3), SHIN (4) AND ANKLE (5)

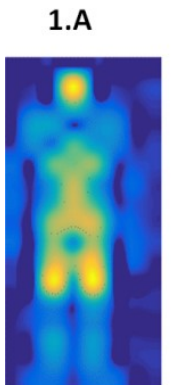

2.A

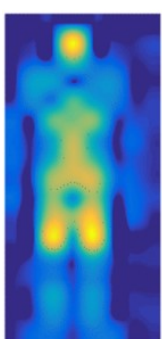

3.A

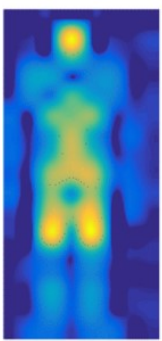

4.A

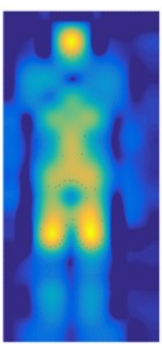

5.A
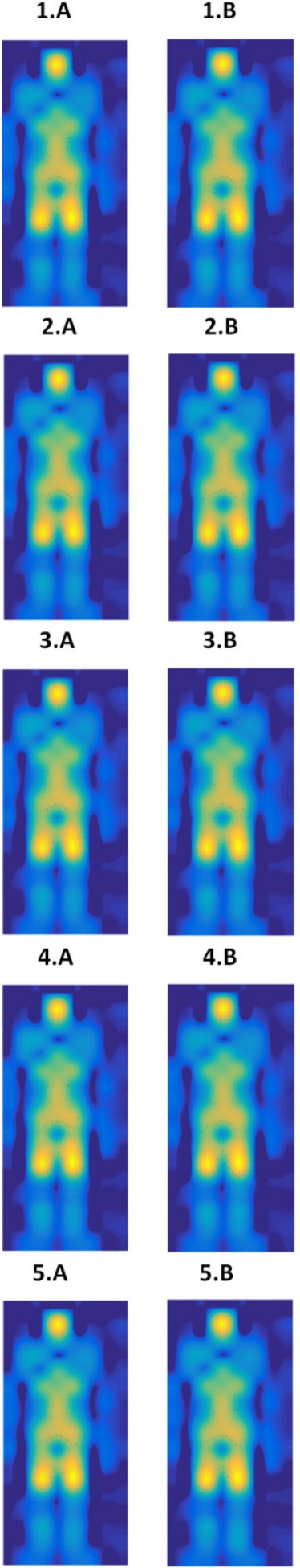

2.B

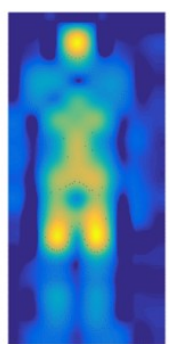

3.B

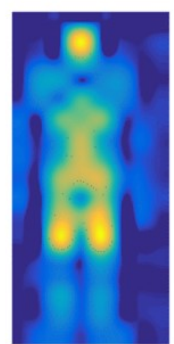

4.B

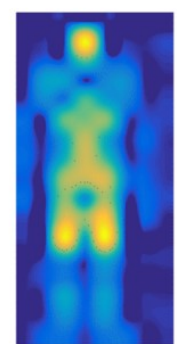

5.B
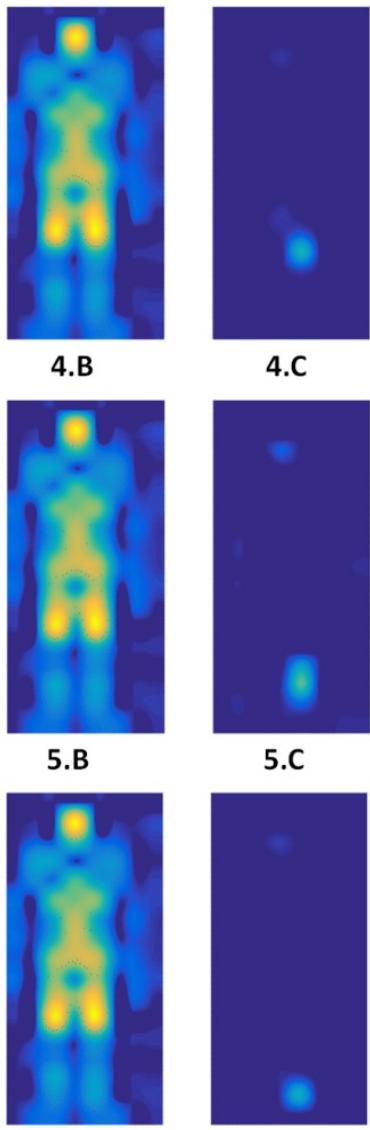

4.C

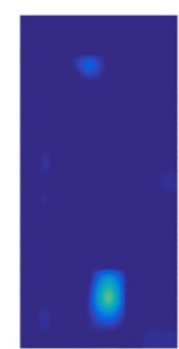

5.C

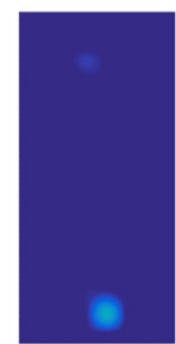

FigURE 9. MODEL ALONE (A), MODEL WITH 100G ADDED MASS (B) AND PRESSURE DIFFERENCE (C) FOR ADDED MASS AT THEBLADDER REGION (1), THIGH (2), KNEE (3), SHIN (4) AND ANKLE (5) 


\subsubsection{RESULTS}

As can be seen in Figure 9 and Figure 10, the 400g and 100g masses are clearly detectable at all positions. Considering that the thigh and abdomen regions are much larger than the ankles, it was not clear a priori whether such a small percent change in mass would be discernable by the PSM. Therefore, it appears possible to track a minimum of $100 \mathrm{~g}$ addition from the ankle to the bladder region. Under ideal conditions, a calibration session was collected and accurate identification of when/where the addition of mass was applied was also achieved.

\subsubsection{CONCLUSIONS}

From this experiment, the minimum mass reliably detectable at all locations was found to be $100 \mathrm{~g}$ for the model on the PSM under idealized conditions. After introducing a thin mattress, mass additions were still detectable.

\subsection{Dynamic Tracking OF EXTernal Mass}

The experiments above demonstrated that it is possible to qualitatively observe an increase in contact pressure when an external mass is applied to the lower limb and abdomen. In this section, it is shown that the location of a moving mass can be tracked quantitatively. This experiment coincided with the acquisition of the piezo-resistive PSM from Tekscan $^{\mathrm{TM}}$. Therefore, the experiments described here were performed using both the fibreoptic and the piezo-resistive PSM.

\subsubsection{METHODS}

Despite being able to accurately track $400 \mathrm{~g}$ on the model, it was decided to increase the mass addition to $600 \mathrm{~g}$, which is still less than $2 \mathrm{~kg}$ identified as a relevant increase in weight 
for CHF patients [82]. This increase in mass was to ensure that the mass would still be detectible when applied to human subjects, as done in Chapter 6. It was suspected that the skeletal structure of human subjects would distribute mass additions to adjacent regions. A brief test was performed to confirm this hypothesis by applying the $400 \mathrm{~g}$ and $600 \mathrm{~g}$ masse s to the abdominal region (most difficult region to identify as noted in Figure 9) of a single participant. Though, the $400 \mathrm{~g}$ was detectable, the $600 \mathrm{~g}$ was more clear and thus chosen for all further experiments.

The application of this $600 \mathrm{~g}$ mass to the aforementioned body regions was performed based on the same testing procedure as above, with the addition of a thin mattress, to allow for result comparisons between the model and human participants described in Chapter 6. The testing protocol was performed with the 600g mass on both the fibre-optic PSM (Figure 11) and the piezo-resistive PSM (Figure 12).

Regions of interest were defined corresponding to the ankle, the shin, the knee, thigh, and abdomen. Details of the ROI extraction method are presented in section 6.4. For each session, and each technology, the temporal average $\left(P_{\text {avg }}\right)$ was calculated for each ROI $(r)$ to provide a single pressure representation for each session $(s)$ (Equation 7)

$$
\text { (7) } P_{\text {avg }}(r)=\frac{\operatorname{mean}\left(P_{a d j}(r)\right)}{\operatorname{mean}\left(S_{\text {act }}(r)\right)}
$$

Where, $S_{a c t}(r)$ is the average number of active sensors in each ROI. These results are illustrated in Figure 11 and Figure 12 for the fibre-optic and piezo-resistive PSM respectively.

Finally, a rule-based algorithm was developed to identify when the mass has been added to each ROI. Here, the weighted difference was calculated to determine the 
relationship between the two highest pressures across all sessions for each ROI. Ideally the highest pressure in a given ROI would be when the $600 \mathrm{~g}$ mass was added to that region. However, depending on the ROI and its proximity to other regions, the session when the $600 \mathrm{~g}$ mass was added may be identified as the second highest pressure. In order to evaluate if it was possible for the second highest pressure to be associated with the $600 \mathrm{~g}$ addition to the selected ROI, the highest pressure identified for each region was compared to the second highest pressure as defined in Equation 8 and 9. The updated analysis procedure is summarized in Figure 14 in Chapter 6 for this experiment.

$$
\begin{gathered}
\text { (8) } L(r, 2)=\operatorname{largest}\left(P_{\text {avg }}(r,:), 2\right) \\
\text { (9) } D_{w}(r)=\frac{L(r, 1)-L(r, 2)}{\text { mean }\left(P_{\text {avg }}(r,:)\right)}
\end{gathered}
$$

Where largest is a function created to identify the $n$ ( 2 in this case) largest values in $P_{a v g}$ and both are stored in $L(r, 2)$. The difference between the two largest pressures, $L(r, 1)$ and $L(r, 2)$, is divided by the average pressure response at region $r$ to create the weighted difference $D_{w}(r)$. 

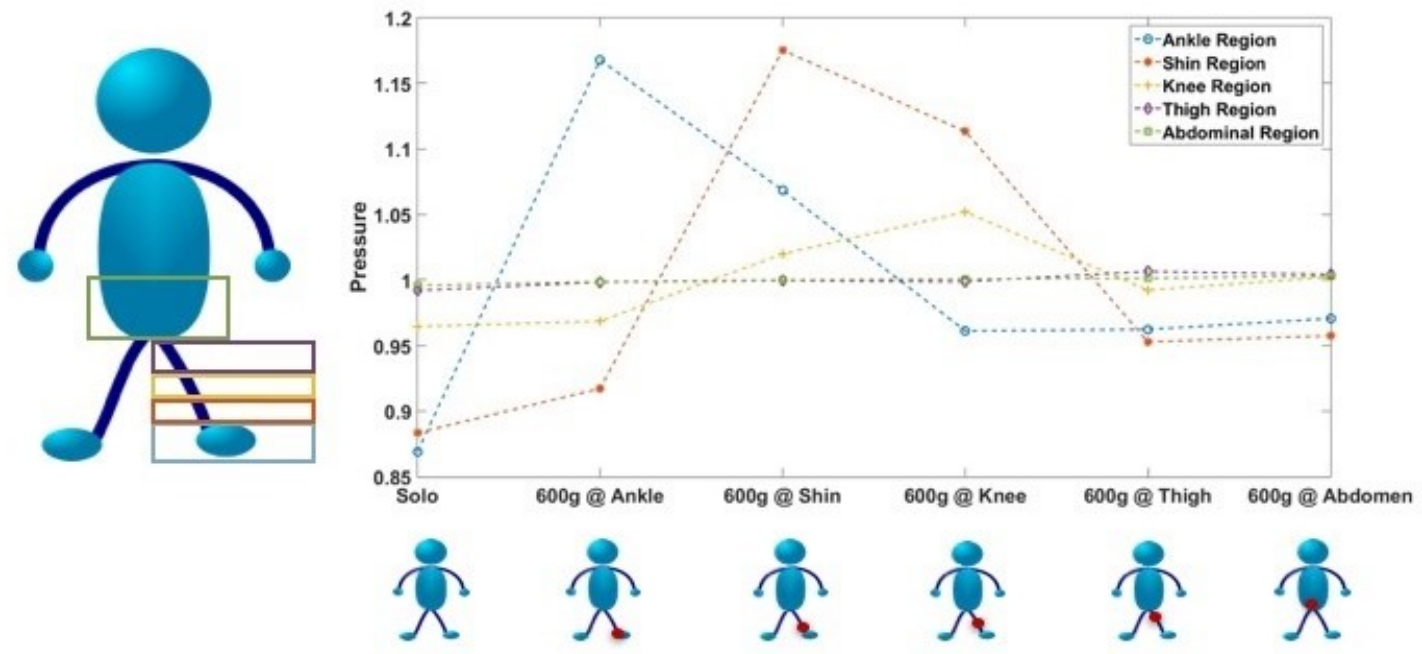

FIGURE 11. AVERAGE PRESSURE RESP ONSE AT EACH REGION ACROSS ALL TEST ING SESSION, WHILE USING THE FIBRE-OPTIC PSM (MODEL)
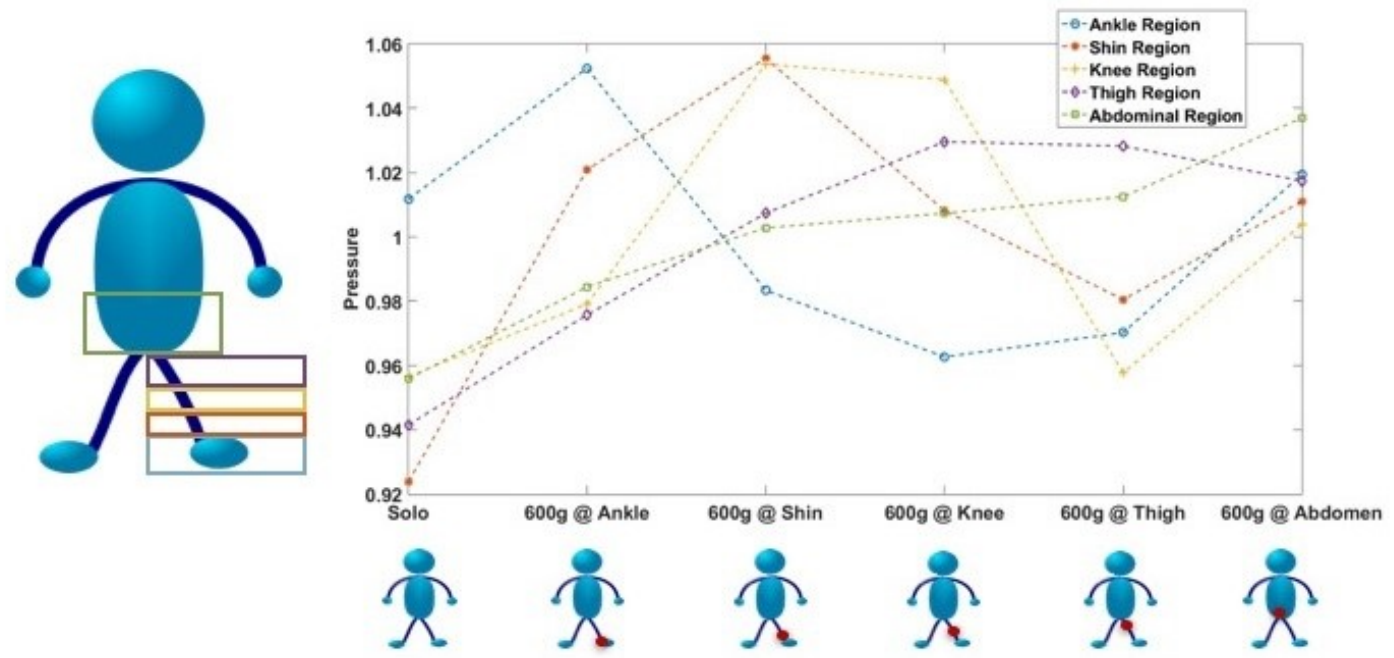

FIGURE 12. AVERAGE PRESSURE RESP ONSE AT EACH REGION ACROSS ALL TEST INGSESSIONS, WHILE USING THE PIEZO-RESIST IVE PSM (MODEL)

\subsubsection{RESULTS}

The addition of mass with respect to each ROI for the model is plotted in Figure 11 when using the fibre-optic PSM and in Figure 12 when using the piezo-resistive PSM. The stick figure directly to the left of each plot illustrates the ROIs selected by the user 
during data analysis. The colour surrounding each ROI corresponds with each of the average pressure responses identified in the plot (Green - abdominal region; Purple - thigh region; Yellow - knee region; Orange - shin region; Blue - ankle region). The $\mathrm{x}$-axis of each figure corresponds to consecutive two-minute testing sessions when the external mass (600g) was placed at each region of interest (from ankle to abdomen). The stick figure located below each testing session on the $\mathrm{x}$-axis visually identifies the location of the mass application (represented by a red dot). The y-axis of each figure highlights the average pressure response during each session, as described in Equation 9.

TABLE 8. PSM RESPONSES

\begin{tabular}{|l|l|l|l|l|l|}
\hline \multicolumn{7}{|c|}{ highest, 2nd highest and, weighted difference ( $\boldsymbol{D}_{w}$ ) } \\
\hline Region & Ank. & Shi. & Kne. & Thi. & Abd. \\
\hline Model & S2 (Ank.) & S3 (Shi.) & S3 (Shi.) & S4 (Kne.) & S6 (Abd.) \\
& S6 (Abd.) & S2 (Ank.) & S4 (Kne.) & S5 (Thi.) & S5 (Thi.) \\
\cline { 2 - 6 } & $D_{w}=0.033$ & $D_{w}=0.035$ & $D_{w}=0.005$ & $D_{w}=0.001$ & $D_{w}=0.024$ \\
\hline \multirow{2}{*}{ Region } & Ank. & Shi. & Kne. & Thi. & Abd. \\
\hline Model & S2 (Ank.) & S3 (Shi.) & S4 (Kne.) & S5 (Thi.) & S6 (Abd.) \\
\cline { 2 - 6 } & S3 (Shi.) & S4 (Kne.) & S3 (Shi.) & S6 (Abd.) & S5 (Thi.) \\
\cline { 2 - 6 } & $D_{w}=0.099$ & $D_{w}=0.062$ & $D_{w}=0.032$ & $D_{w}=0.002$ & $D_{w}=0.001$ \\
\hline
\end{tabular}

Table 8 summarizes the region demonstrating peak pressure for each session and for each PSM technology. The weighted difference, $\mathrm{D}_{\mathrm{W}}$, is also provided for each. $\mathrm{D}_{\mathrm{W}}$ 
captures the normalized difference between the highest and second-highest observed contact pressure within each session.

In Figure 11, for each ROI, the peak pressure was observed during the two-minute session when the external $600 \mathrm{~g}$ mass was applied to that region. As expected, when examining the difference between the highest observed pressure and the second largest pressure at each ROI, we note a smaller change in pressure for regions that are more massive (e.g. abdomen vs. ankle).

Figure 12 presents the addition of mass with respect to ROI when using the piezoresistive PSM. The ankle and shin respond similarly to the fibre-optic results, where the highest pressures occurred during the sessions when the $600 \mathrm{~g}$ was actually added to the corresponding ROIs. When observing the knee ROI, the session when $600 \mathrm{~g}$ was added to knee (session four) was identified as the second highest pressure. Session three $(600 \mathrm{~g} @$ shin) was identified as the highest pressure, however the observed $D_{w}$ was quite small, 0.005, indicating that the second highest pressure may be correct. For the thigh ROI, the session with the highest pressure was when mass was added to the knee (S4) and the second highest pressure was during session five, when $600 \mathrm{~g}$ was added to the thigh. Again, the $\mathrm{DW}_{\mathrm{w}}$ between these two pressures was only 0.001, indicating that there was some mass distributed to the knee from the thigh during session four that surpassed the thigh measurement during session five.

\subsection{Conclusion}

The results presented in this section demonstrate that we are able to track an externallyapplied mass using an anthropometrically correct human model. The piezo-resistive PSM outperformed the fibre-optic PSM most importantly due to the large increase in spatial 
resolution. The creep and drift responses were also better for the piezo-resistive PSM. The next chapter explores the application of external masses to actual human test subjects. 


\section{Contribution 3 - System Verification using External Mass with Human Subjects}

\subsection{INTRODUCTION}

We have previously demonstrated that it is possible to identify changes in mass applied to an anthropomorphically correct human body model placed directly on the PSM [10]. This chapter builds on our work originally published in MeMeA 2016 [12] by introducing human participants, examining two different PSM technologies (fibre-optic and piezoresistive), developing more robust sensor data preprocessing and analytics, and the addition of a mattress between the patient and the PSM

\subsection{MeASUREMENT SYSTEM}

Two different pressure measurement technologies were used for data collection, resulting in two different testing set-ups. The first measurement system was based on fibre-optic pressure sensors manufactured by S4 sensors (previously Tactex Sensors, Victoria, BC, Canada) and the associated software. These PSMs have been used in a variety of studies to identify and/or monitor various physiological signals including weight changes (e.g. [10], [12], [14], mobility assessments [62], [83], and sleep analysis [35], [39], [84]). As
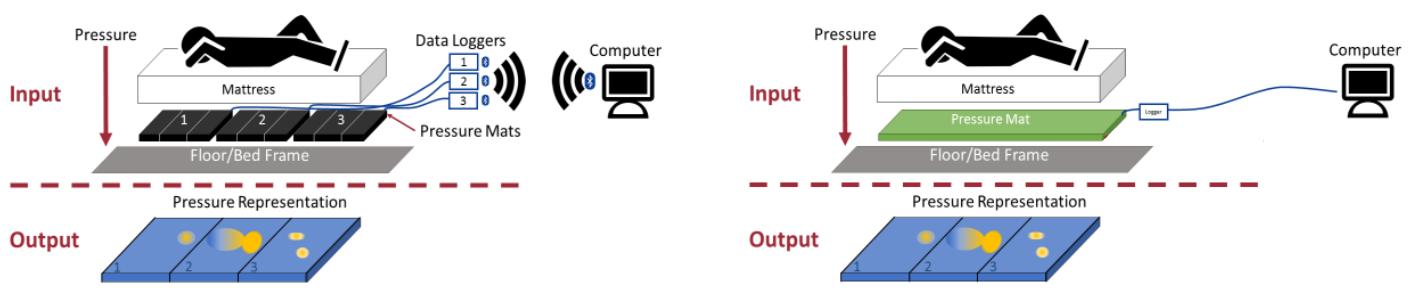

FIGURE 13. S4 SENSORS (FIBRE-OPTIC) MEASUREMENT SYSTEM (LEFT) AND TEKSCAN (RESIST IVE) MEASUREMENT SYST EM (RIGHT) 
mentioned, the entire pressure array consisted of three separate PSMs each $95 \times 80 \mathrm{~cm}$ and containing 72 equally spaced $(10 \mathrm{~cm} \times 10 \mathrm{~cm})$ fibre-optic emitter-sensor pairs. The three PSMs were connected to three separate wireless data loggers and transmitted to a computer via Bluetooth where data were recorded at a sampling rate of $20 \mathrm{~Hz}$ and saved as CSV files for analysis (Figure 13, left). This same configuration was used in all previous experimentations, however, a thin mattress has now been added between the participant and the PSM to better reflect expected data collection conditions.

The second measurement system was a PSM that uses piezo-resistive pressure sensors manufactured by Tekscan (Boston, USA) and the associated BPMS ${ }^{\mathrm{TM}}$ software. The entire pressure array in this case was made up of a single PSM (106 x 64cm) containing 1,768 equally spaced $(0.35 \times 0.35 \mathrm{~cm})$ sensing elements. The PSM was connected to a computer for data collection via a USB port using a Tekscan "Evolution Sensor Handle" (Figure 13, right). All data collection was performed using the BPMS ${ }^{\mathrm{TM}}$ software and sampled at $20 \mathrm{~Hz}$.

For a given testing session, each PSM was placed on a rigid support surface (floor) and a thin mattress (3/8"thick) was placed directly on top (Figure 13). The 2D anthropomorphic body model was then placed on top of the mattress in order to ensure body alignment while testing [10]. Depending on the testing parameters (described in the following section), either the 3D anthropomorphic body model was placed on the 2D model in a supine position or a human participant was asked to lie down with their head aligned with the 2D model in a supine position. Due to the fact that the Tekscan PSM was not long enough to measure the entirety of a person, only the pressure response from the lower body (from abdomen to ankles) was used for data analysis for both measurement systems. 


\subsection{EXPERimental Procedure}

Approximately $1 \%(600 \mathrm{~g})$ of the mass of the model was added at the locations identified

by Table 9. This mass was chosen based on current thresholds used by physicians to monitor CHF; if a person gains more $2 \mathrm{~kg}$ in a three day period, their medication may need to be adjusted [82]. A mass of $600 \mathrm{~g}$ was used for all experiments due to the expected difficulty in detecting the added mass in the presence of 1) spatial averaging, due to the mattress, and 2) non-uniform pressure distribution, due to the human skeletal system.

TABLE 9. TEST ING SESSION DESCRIPTIONS

\begin{tabular}{|c|c|}
\hline Session Number $(\boldsymbol{k})$ & Testing Sessions \\
\hline S1 & Participant Alone (Solo) \\
\hline S2 & $400 / 600 \mathrm{~g}$ placed on Ankle (Ank.) \\
\hline S3 & $400 / 600 \mathrm{~g}$ placed on Shin (Shi.) \\
\hline S4 & $400 / 600 \mathrm{~g}$ placed on Knee (Kne.) \\
\hline S5 & $400 / 600 \mathrm{~g}$ placed on Thigh (Thi.) \\
\hline S6 & $400 / 600 \mathrm{~g}$ placed on Abdomen (Abd.) \\
\hline
\end{tabular}

When using the fibre-optic sensors, a two-minute calibration session was performed when only the mattress and 2D model were present on the mat. This calibration session was used to account for the effect of the mattress and 2D model on the pressure measurements during data analysis. The calibration session was not necessary when using the Tekscan technology, due to their built-in calibration procedure that was performed prior to testing on a participant. Initially, baseline data were collected for two-minutes with only the model present with no additional mass using the fibre-optic PSM. Two minute data 
collection was then performed using the same PSM when the 600g AgSAP was added sequentially to each location identified in Table 9. The six testing sessions then were repeated using the resistive PSM, immediately afterwards.

The experimental procedure was repeated for the three human participants (2M: $61 \pm 1$ yrs, $1.68 \mathrm{~m}, 73 \pm 1 \mathrm{~kg} ; \mathrm{F}: 23 \mathrm{yrs}, 1.74 \mathrm{~m}, 59 \mathrm{~kg}$ ) on both technologies and measurements were saved for data analysis. During each two-minute data collection session, the participants were asked to move as little as possible in order to simulate idealized conditions.

\subsection{Data Analysis}

A summary of the analysis procedure for this experiment is shown in Figure 14.

\subsubsection{UPDATED FIBRE-OPTIC SENSOR ANALYSIS}

Considering that we were now using a mattress between the PSM and the subject, the fibre optic PSM calibration procedure was modified from the original methods above to ensure that sensor to sensor comparisons were more accurate. Rather than a direct subtraction of the temporal average of the calibration data, as used above, instead the ratio of pressure response with respect to the resting (calibration) response was used as described in Equation 10 .

$$
P_{c a l}{ }_{i, j, k}=\frac{P_{i, j, k}}{\operatorname{mean}\left(\operatorname{cal}_{i, j}\right)}
$$

In addition to updating the calibration procedure, the method for computing the difference in observed pressure between two recording sessions was also improved to use spatial averaging across ROIs. Previously, a 1:1 signal subtraction was performed to highlight mass addition. This method tended to introduce large amounts of noise if the 

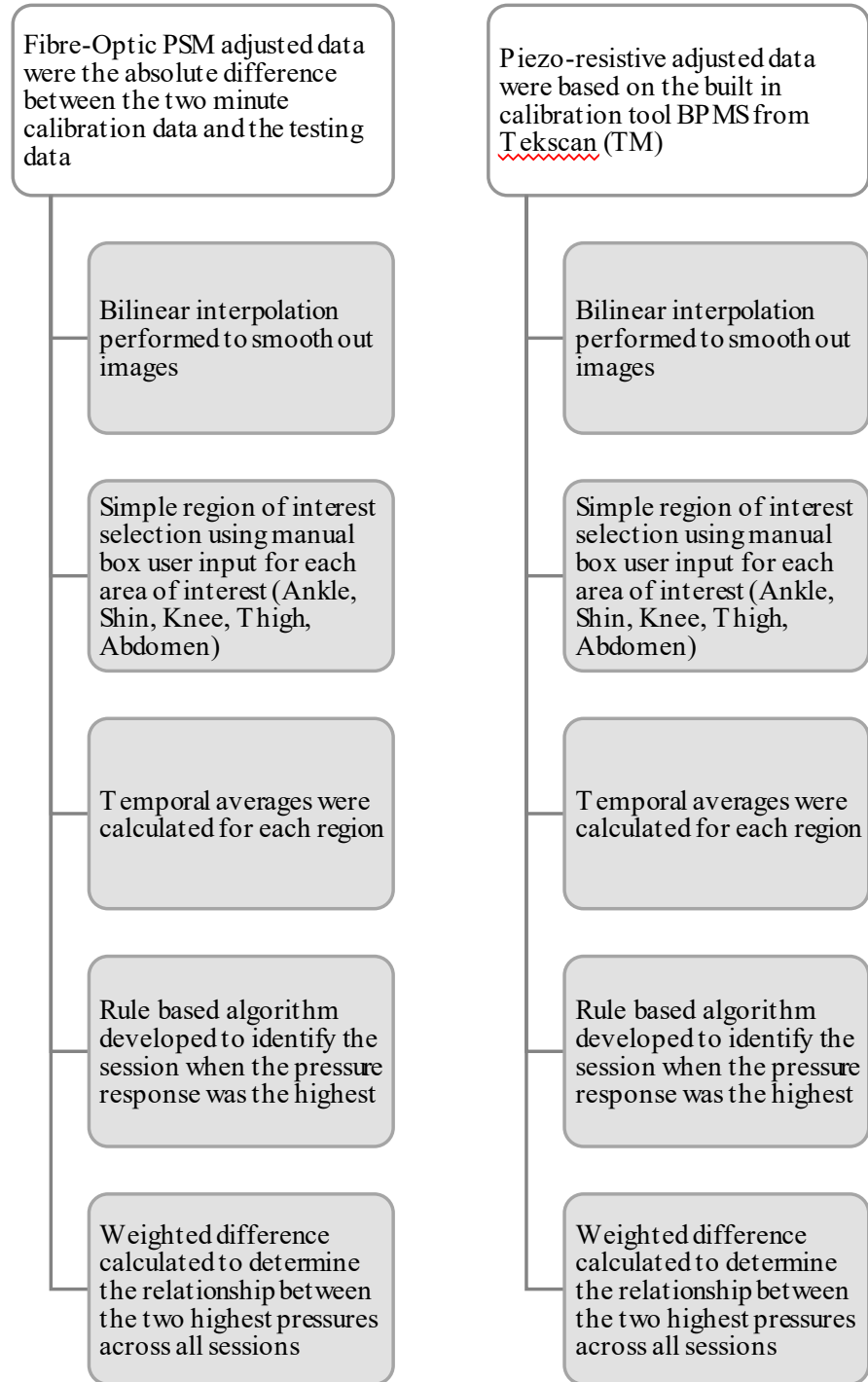

FIGURE 14. CONT RIBUTION 3 ANALYSISPROCEDURE

model was not in exactly the same location across all sessions. To account for this, we propose a semi-automated region of interest (ROI) method that requires user input. The user is prompted to select the total number of regions. They are then prompted to manually select the bounding boxes from a pressure images similar to those in Figure 15. For the purposes of this research, the user was specifically asked to select the region of the left ankle, left shin, left knee, left thigh, and abdominal area using a built in box selection tool 
in MATLAB. ROIs were only selected once for each participant/model, and were applied across all sessions to maintain consistency. For each selected region $(r)$, the sum of pressure $\left(P_{\text {sum }}\right)$ was calculated for each sample $(k)$, as described in Equation (11). A five-second moving average filter was applied to $P_{\text {sum }}$ for each testing session (Equation 11) and the results were visualized in the pressure representation analysis step.

$$
\begin{gathered}
P_{\text {sum }}(k)=\sum_{i} \sum_{j} P_{c a l}(i, j, k) \\
P_{\text {adj }}(k)=\frac{1}{M} \sum_{l=0}^{M-1} P_{\text {sum }}(k-l)
\end{gathered}
$$

Where $P_{c a l}(i, j, k)$ is the pressure response of all sensors in the ROI $(r)$ for each sample $(k)$.

For Equation (12), $M$ is the number of points used in the moving average filter. For all experimentation a five-second moving average filter was chosen resulting in $M=100$ due to the $20 \mathrm{~Hz}$ sampling frequency.

\subsubsection{RESISTIVE SENSOR ANALYSIS}

When using the Tekscan resistive sensors, all data collection was done using the provided BPMS $^{\mathrm{TM}}$ software. The built-in ROI selection tool allows the user to specify multiple ROIs by manually defining bounding boxes on the pressure image. For each participant/model, a single ROI file containing the definition of all ROIs for each region (right ankle, shin, knee, thigh, and abdomen) was created and applied across all successive sessions. Two CSV files were exported from the $\mathrm{BPMS}^{\mathrm{TM}}$ software. The first file contained the summation of raw data for each ROI at each time point and the second contained the overall contact area $\left(\mathrm{cm}^{2}\right)$ for each ROI. The effective contact area of a single sensor, constant across all experiments, was also noted in order to calculate the number of active sensors for each ROI. 
The two files were transferred to MATLAB for further processing. The contact area of each region was divided by the contact area of a single sensor to determine the number of active sensors. The five-second moving average filter from the fibre-optic analysis was applied to the raw data (Equation 12). The number of active sensors and the filtered raw output were then exported to the pressure representation step. Figure 14 summarizes the analysis procedure for data from the piezo-resistive PSM.

\subsubsection{Pressure RePRESENTATION}

As defined in section 5.3.1, for each session, and each technology, the temporal average $\left(P_{\text {avg }}\right)$ was calculated for each ROI $(r)$ to provide a single pressure representation for each session $(s)$. The resulting pressures at each region were sorted in chronological order based on session number, $s$ (Table 9). The weighted difference, $D_{w}$, is also reported, that represents the normalized difference in pressure between the highest and second-highest observed contact pressures among all ROI.

\subsection{ReSUlts}

Testing sessions for all participants are summarized in Table 10, with the results from the model session, as described in 5.3.1, included for reference. Additionally, data from participant one are illustrated for both the fibre-optic and resistive technologies in Figure 15 and Figure 16, respectively. The same trends observed when using the model are also seen during these human participant sessions. However, redistribution to adjacent regions appears to be more common, likely due to the skeletal structure. As with the model results in Chapter 5, the stick figure directly to the left of each plot demonstrates the ROIs selected by the user during data analysis. The colour surrounding each ROI matches each of the 
average pressure responses identified in the plot (Green - abdominal region; Purple - thigh region; Yellow - knee region; Orange - shin region; Blue - ankle region). The $\mathrm{x}$-axis of each figure corresponds to consecutive two-minute testing sessions when the external mass (600g) was placed at each region of interest (from ankle to abdomen). The stick figure located below each testing session on the $\mathrm{x}$-axis visually identifies the location of the mass application (represented by a red dot). The y-axis of each figure highlights the time- and spatial-average pressure response for each ROI, during each session.

For the fibre-optic based PSM, mass addition to the ankle, knee and thigh regions are quite clear. The highest pressure responses were observed during their expected sessions (S1, S3 and S4 respectively). When observing the shin ROI (Figure 15, orange *), the session of highest pressure occurred when the $600 \mathrm{~g}$ mass was applied to the knee (S4) and the second highest pressure occurred during session 3 when $600 \mathrm{~g}$ was applied to the shin. The weighted difference between the two pressures is quite small $(0.02)$ when compared to other weighted differences (Table 10), indicating that the highest pressure session may not be accurate. Based on Figure 15, the abdominal ROI (green, $\square$ ) appears

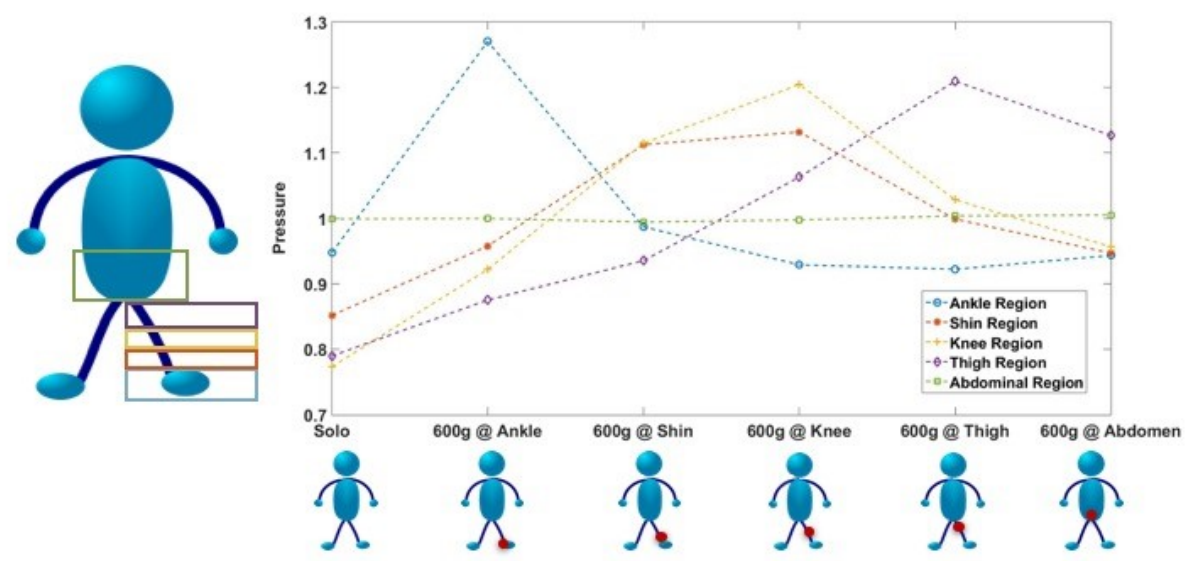

FIGURE 15. PART ICIPANT 1 PRESSURE VARIATION AT EACH REGION OVER ALL SESSIONS, WHILE USINGT HE FIBRE-OPT IC BASED MEASUREMENT TECHNOLOGY 
to be steady across all sessions. Numerically, the highest pressure response in this area is when the $600 \mathrm{~g}$ was applied to the abdomen (S6), however there is a small weighted difference (0.001) between the highest (S6) and second highest (S5), highlighting the minimal relative impact of $600 \mathrm{~g}$ in more massive regions (Table 10).

The pressure response using the piezo-resistive PSM for participant one correctly shows increases in the ankle, shin, thigh, and abdominal regions during sessions when external mass was added to the corresponding regions (Figure 16). During data collection, it was noted that the back of the knees were not consistently touching the mattress. Due to this, mass additions at the knee and shin were distributed to the thigh region through the skeletal structure. This resulted in sessions of highest pressure for both the shin and knee ROIs to occur during S5, when $600 \mathrm{~g}$ was added to the thigh. Figure 16 shows that the pressure associated with the correct sessions ( $\mathrm{S} 3$ for the shin ROI and S4 for the knee ROI) were very close to the sessions of highest pressure for both the shin (orange ${ }^{*}$ ) and knee (yellow + ) regions with weighted differences of 0.003 and 0.012 respectively.

A summary of all participants across all sessions for both fibre-optic and resistive technologies are reported in Table 10. For each region, the sessions in which the highest and second highest pressures were observed are reported. Below each session identifier, the weighted difference between the two highest pressures is also reported. Looking at the $D_{w}$ values for the correctly and incorrectly classified samples for each region, it is clear that $D_{w}$ values are consistently lower for incorrectly classified samples, suggesting some kind of decision rule may be possible in a future fully autonomous monitoring system. 
The accuracy of detecting the correct session for each region is evaluated using two different conditions. The first accuracy is defined as correct identification of highest pressure during the session of corresponding weight addition for each ROI. The second accuracy is based on correct identification of the highest or second highest pressure during the session of corresponding weight addition for each ROI. For instance, when looking at the resistive PSM results based on participant three (P3) in Table 10, the highest pressure for the shin ROI occurred during S4 when the $600 \mathrm{~g}$ was added to the knee. However, S3 (when $600 \mathrm{~g}$ as added to the shin) was identified as the second highest pressure. In this case, the correct session was not identified by the highest pressure but it was by the second highest pressure. Therefore, this ROI was not considered accurate based on the first accuracy constraints, but it was considered accurate based on the second accuracy constraints of $95 \%$ for the piezo-resistive PSM and 90\% for the fibre-optic PSM.

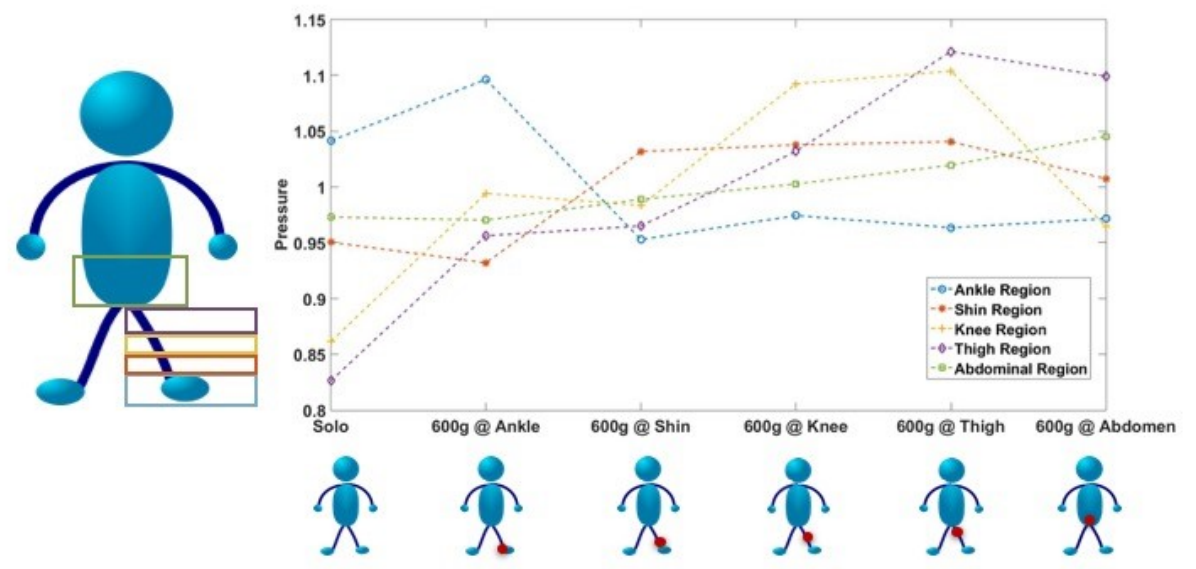

FIGURE 16. PART ICIP ANT 1 PRESSURE VARIATION AT EACH REGION OVER ALL SESSIONS, WHILE USINGT HE PIEZO-RESIST IVE BASED MEASUREMENT TECHNOLOGY 
TABle 10. CONTRIBUtion3 PARTICIPANT AND MODEL PRESSURE RESPONSES

\begin{tabular}{|c|c|c|c|c|c|c|c|c|c|c|}
\hline \multicolumn{11}{|c|}{$\begin{array}{c}\text { Session with highe st pressure: } \\
\left.\text { highest, } 2^{\text {nd }} \text { highest and, weighted diffe re nce ( } D_{w}\right)\end{array}$} \\
\hline \multicolumn{6}{|c|}{ Resistive PSM Responses } & \multicolumn{5}{|c|}{ Fibre-Optic PSM Responses } \\
\hline $\begin{array}{r}\text { Region } \\
\text { Participant }\end{array}$ & Ank. & Shi. & Kne. & Thi. & Abd. & Ank. & Shi. & Kne. & Thi. & Abd. \\
\hline \multirow[t]{2}{*}{ Model } & $\begin{array}{l}\text { S2 (Ank.) } \\
\text { S6 (Abd.) }\end{array}$ & $\begin{array}{l}\text { S3 (Shi.) } \\
\text { S2 (Ank.) }\end{array}$ & $\begin{array}{l}\text { S3 (Shi.) } \\
\text { S4 (Kne.) }\end{array}$ & $\begin{array}{l}\text { S4 (Kne.) } \\
\text { S5 (Thi.) }\end{array}$ & $\begin{array}{l}\text { S6 (Abd.) } \\
\text { S5 (Thi.) }\end{array}$ & $\begin{array}{l}\text { S2 (Ank.) } \\
\text { S3 (Shi.) }\end{array}$ & $\begin{array}{l}\text { S3 (Shi.) } \\
\text { S4 (Kne.) }\end{array}$ & $\begin{array}{l}\text { S4 (Kne.) } \\
\text { S3 (Shi.) }\end{array}$ & $\begin{array}{l}\text { S5 (Thi.) } \\
\text { S6 (Abd.) }\end{array}$ & $\begin{array}{l}\text { S6 (Abd.) } \\
\text { S5 (Thi.) }\end{array}$ \\
\hline & $D_{w}=0.033$ & $D_{w}=0.035$ & $D_{w}=0.005$ & $D_{w}=0.001$ & $D_{w}=0.024$ & $D_{w}=0.099$ & $D_{w}=0.062$ & $D_{w}=0.032$ & $D_{w}=0.002$ & $D_{w}=0.001$ \\
\hline \multirow[t]{2}{*}{ P1 } & $\begin{array}{l}\text { S2 (Ank.) } \\
\text { S1 (Solo) }\end{array}$ & $\begin{array}{l}\text { S5 (Thi.) } \\
\text { S3 (Shi.) }\end{array}$ & $\begin{array}{l}\text { S5 (Thi.) } \\
\text { S4 (Kne.) }\end{array}$ & $\begin{array}{l}\text { S5 (Thi.) } \\
\text { S6 (Abd.) }\end{array}$ & $\begin{array}{l}\text { S6 (Abd.) } \\
\text { S5 (Thi.) }\end{array}$ & $\begin{array}{l}\text { S2 (Ank.) } \\
\text { S3 (Shi.) }\end{array}$ & $\begin{array}{l}\text { S4 (Kne.) } \\
\text { S3 (Shi.) }\end{array}$ & $\begin{array}{l}\text { S4 (Kne.) } \\
\text { S3 (Shi.) }\end{array}$ & $\begin{array}{l}\text { S5 (Thi.) } \\
\text { S6 (Abd.) }\end{array}$ & $\begin{array}{l}\text { S6 (Abd.) } \\
\text { S5 (Thi.) }\end{array}$ \\
\hline & $D_{w}=0.055$ & $D_{w}=0.003$ & $D_{w}=0.012$ & $D_{w}=0.022$ & $D_{w}=0.026$ & $D_{w}=0.283$ & $D_{w}=0.020$ & $D_{w}=0.089$ & $D_{w}=0.083$ & $D_{w}=0.001$ \\
\hline \multirow[t]{2}{*}{$\mathbf{P 2}$} & $\begin{array}{l}\text { S2 (Ank.) } \\
\text { S5 (Thi.) }\end{array}$ & $\begin{array}{l}\text { S2 (Ank.) } \\
\text { S3 (Shi.) }\end{array}$ & $\begin{array}{l}\text { S4 (Kne.) } \\
\text { S3 (Shi.) }\end{array}$ & $\begin{array}{l}\text { S3 (Shi.) } \\
\text { S4 (Kne.) }\end{array}$ & $\begin{array}{l}\text { S4 (Kne.) } \\
\text { S6 (Abd.) }\end{array}$ & $\begin{array}{l}\text { S2 (Ank.) } \\
\text { S4 (Kne.) }\end{array}$ & $\begin{array}{l}\text { S4 (Kne.) } \\
\text { S3 (Shi.) }\end{array}$ & $\begin{array}{l}\text { S4 (Kne.) } \\
\text { S3 (Shi.) }\end{array}$ & $\begin{array}{l}\text { S6 (Abd.) } \\
\text { S4 (Kne.) }\end{array}$ & $\begin{array}{l}\text { S5 (Thi.) } \\
\text { S6 (Abd.) }\end{array}$ \\
\hline & $D_{w}=0.021$ & $D_{w}=0.008$ & $D_{w}=0.141$ & $D_{w}=0.008$ & $D_{w}=0.017$ & $D_{w}=0.107$ & $D_{w}=0.014$ & $D_{w}=0.014$ & $D_{w}=0.183$ & $D_{w}=0.007$ \\
\hline \multirow[t]{2}{*}{$\mathbf{P 3}$} & $\begin{array}{l}\text { S2 (Ank.) } \\
\text { S3 (Shi.) }\end{array}$ & $\begin{array}{l}\text { S4 (Kne.) } \\
\text { S3 (Shi.) }\end{array}$ & $\begin{array}{l}\text { S3 (Shi.) } \\
\text { S4 (Kne.) }\end{array}$ & $\begin{array}{l}\text { S5 (Thi.) } \\
\text { S4 (Kne.) }\end{array}$ & $\begin{array}{l}\text { S5 (Thi.) } \\
\text { S6 (Abd.) }\end{array}$ & $\begin{array}{l}\text { S2 (Ank.) } \\
\text { S3 (Shi.) }\end{array}$ & $\begin{array}{l}\text { S3 (Shi.) } \\
\text { S4 (Kne.) }\end{array}$ & $\begin{array}{l}\text { S3 (Shi.) } \\
\text { S6 (Abd.) }\end{array}$ & $\begin{array}{l}\text { S5 (Thi.) } \\
\text { S6 (Abd.) }\end{array}$ & $\begin{array}{l}\text { S6 (Abd.) } \\
\text { S3 (Shi.) }\end{array}$ \\
\hline & $D_{w}=0.085$ & $D_{w}=0.002$ & $D_{w}=0.001$ & $D_{w}=0.156$ & $D_{w}=0.011$ & $D_{w}=0.229$ & $D_{w}=0.038$ & $D_{w}=0.024$ & $D_{w}=0.027$ & $\begin{array}{l}D_{w} \\
0.0002\end{array}$ \\
\hline $\begin{array}{l}\text { Accuracy } \\
\text { using only } \\
\text { highest } \\
\text { session }\end{array}$ & $100 \%$ & $25 \%$ & $25 \%$ & $50 \%$ & $50 \%$ & $100 \%$ & $50 \%$ & $75 \%$ & $75 \%$ & $75 \%$ \\
\hline $\begin{array}{l}\text { Accuracy } \\
\text { using } \\
\text { highest and } \\
2^{\text {nd }} \text { highest } \\
\text { sessions }\end{array}$ & $100 \%$ & $100 \%$ & $100 \%$ & $75 \%$ & $100 \%$ & $100 \%$ & $100 \%$ & $75 \%$ & $75 \%$ & $100 \%$ \\
\hline
\end{tabular}




\subsection{DisCuSSION}

Ideally, for each ROI, the highest pressure would occur during the session when the $600 \mathrm{~g}$ mass was added to the ROI with a large difference between the two highest pressures. It is also expected that the weighted difference between the two highest pressures will be larger in regions whose original mass was lower. For instance, the abdominal region is much heavier than the ankle region ( $14 \mathrm{~kg}$ vs $800 \mathrm{~g}[10])$. When adding $600 \mathrm{~g}$ to both regions, the relative impact of the addition will clearly be higher for the ankle and, therefore, one would expect this to be more clearly discernable. In agreement with this expectation, the weighted differences (a proxy for decision confidence) are generally lower at the thigh and abdominal regions when compared to the ankle, shin and knee regions.

For both technologies, we were able to always accurately identify mass addition to the ankle region. Additions to other body regions were more difficult to identify. It is important to note that the resistive PSM was physically smaller and potentially truncated the abdominal ROI if the participant's lower body was longer. Introducing a second resistive mat adjacent to the first one would be able to ensure that this was not the case in future studies. Overall, the fibre-optic PSM was better able to identify the correct session when only using the session of highest pressure for each ROI with an overall accuracy of $75 \%$. The overall accuracy using only the session with the highest pressure for the resistive PSM was 50\%. However, when including the sessions with the highest and second highest pressures the piezo-resistive technology performed better with an overall accuracy of $95 \%$ (fibre-optic overall accuracy was $90 \%$ ). Additionally, the $D_{w}$ values for incorrectly classified sessions for each region based on the highest pressure session were 
generally smaller than correctly identified sessions for each region based on the highest pressure.

For physically adjacent regions, mass additions were often observed to be distributed across the adjacent regions. This occurs more often in sessions associated with human participants rather than the model. It was predicted, and now confirmed, that the skeletal system would distribute mass additions from areas of minimal contact to areas in full contact with the mattress and thus PSM. For instance, the knee area while in the supine position has minimal contact with the surface of the mat, so any mass added to that location will be reflected either above or below at the shin (calf) or thigh (hamstring) regions respectively. When looking at the knee ROI, the response to mass addition at the knee, shin and thigh were very similar due to the aforementioned skeletal distribution. This led to incorrect identification of the session with the highest pressure for some ROIs. In this case, the correct session was usually identified as the second highest pressure with a small weighted difference between the highest and second highest.

\subsection{CONCLUSION}

This chapter presents an extension the work summarized in Chapter 5, published in IEEE MeMeA 2016 [12]. Here, spatial resolution issues and participant movement were addressed. The piezo-resistive measurement technology, with much improved spatial resolution, was introduced and proved that the algorithms developed here are able to estimate mass variation regardless of the underlying PSM technology used. Participant movement from session to session was addressed by the application of spatial averaging and semi-autonomous ROI selection. This allows for specific region comparison between sessions, even if the participant moved slightly between testing sessions. In addition to 
addressing these previously identified factors, the preprocessing methods have been updated here in order to include a new calibration procedure. A mattress was also introduced in order to recreate expected data collection conditions. Given its presence we were still able to detect changes in mass especially when looking at the ankle region, which is of particular relevance to $\mathrm{CHF}$.

Many of the health conditions that motivated this work are more prevalent in the older adult population. Therefore, future work may include the recruitment of more participants in the older adult age group in order to further characterize our methods, though testing procedure would follow those outlined in Chapter 7, as we are more interested in internal changes in fluid. 


\section{Contribution 4 - Evaluating Fluid Changes within the Human Body}

Some of the content of this chapter was originally published in EMBC 2016, and therefore contains some of the same content [14]. I was the lead author for this paper.

This chapter reports on two separate sets of experiments. Section 7.1 reports on the use of fibre-optic PSM and Section 7.2 reports on the use of a piezo-electric PSM for monitoring internal changes in fluid by introducing a series of bladder voiding and drinking events.

\subsection{Preliminary EXPERIMENTATION}

Preliminary experiments were conducted using the fibre-optic PSM to establish whether large fluid ingestion and bladder voiding events could be detected.

\subsubsection{METHODS}

\subsubsection{Measurement System}

The measurement system includes a pressure-sensitive mat, containing a fibre-optic pressure sensor grid of 216 equally spaced $(10 \times 10 \mathrm{~cm})$ emitter-sensor pairs. All sensors are recorded at $20 \mathrm{~Hz}$ sampling rate and saved to a CSV file for analysis.

\subsubsection{Testing Procedure}

A mixed density foam mattress, $15 \mathrm{~cm}$ thick with no springs, was placed directly on the three PSMs on the floor. The PSMs were aligned vertically so that the entire body length could be captured. The previously created 2D anthropomorphic body model [16], 
[17] was placed on the mattress, in order to achieve consistent body alignment for each testing session, as shown in Figure 17.

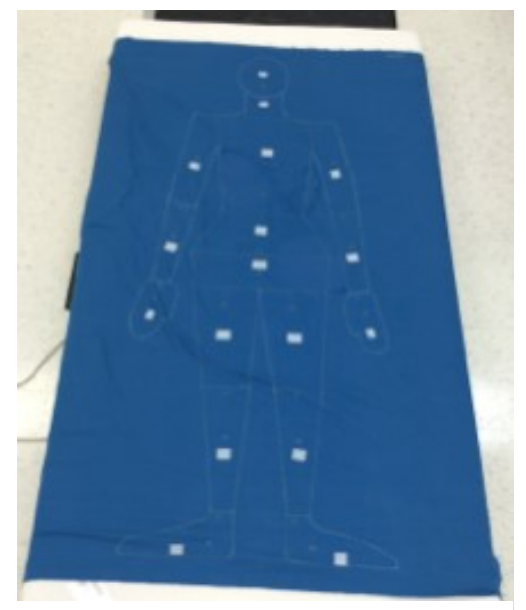

FIGURE 17. TEST INGSET UP

Data from all emitter-sensor pairs were collected over a two-minute calibration session while the mattress and 2D model were located directly on the PSMs. A healthy young adult female participant $(1.70 \mathrm{~m}, 60 \mathrm{~kg}, 23 \mathrm{yrs})$ was used for all further testing.

After the initial calibration session was recorded, the participant voided her bladder. Immediately after, she aligned herself with the top of the $2 \mathrm{D}$ model in a supine position and was asked to move as little as possible. Data were recorded for a period of three minutes, which included lying down and getting up. The first and last 30 seconds were later removed, resulting in a two-minute data set with the participant supine without motion.

To model typical fluid intake, the participant was asked to drink as much water as was comfortable, $700 \mathrm{~mL}$. The participant aligned herself with the top of the $2 \mathrm{D}$ model in a supine position and a 60 -minute data file was recorded. Every 30 minutes after the initial fluid intake, the participant was asked to remain motionless for a two-minute period. At all other times, the participant was asked to remain in a supine position, but there was no other restriction on movement. After one hour had passed, the participant again voided her 
bladder and repeated the three-minute measurement procedure. This resulted in four data files, the initial calibration file, the initial empty bladder file, the hour-long fluid intake file, and the final empty bladder file.

\subsubsection{Signal Processing}

The calibration data were used to identify the baseline activation state for each sensor and were used to reset the zero point for each testing file. As mentioned, the first and last 30 seconds were eliminated from each testing file to exclude the entrance and exit of the participant. Temporal filtering (averaging over the remaining two minutes) was completed for each empty bladder data file and to the three two-minute sessions from the 60-minute
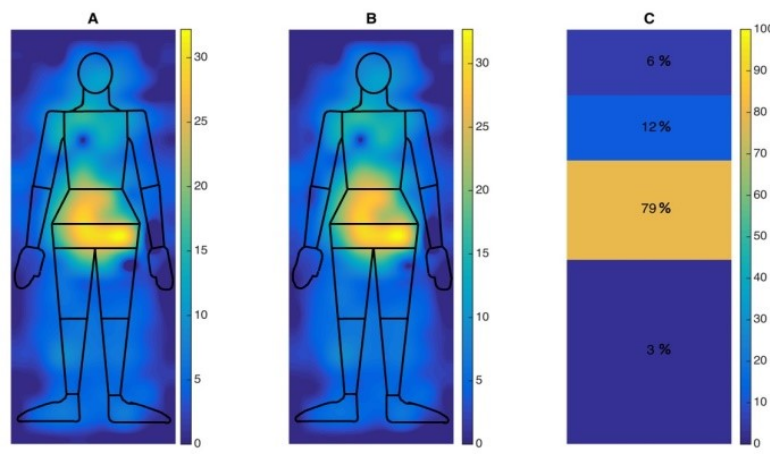

FIGURE 18. PARTICIPANT WITHINITIALEMPTY BLADDER (A), IMMEDIATELY AFTER 700ML FLUID INT AKE(B), AND PRESSURE DIFFERENCE (C)

TABLE 11. TEST ING SESSIONS

\begin{tabular}{|c|c|c|}
\hline \multirow{2}{*}{ Session } & \multicolumn{2}{|c|}{ Testing Pair } \\
\cline { 2 - 3 } & Initial & Comparison \\
\hline $\mathbf{1}$ & Initial Empty Bladder & $\begin{array}{c}\text { Immediately after } 700 \mathrm{~mL} \text { fluid } \\
\text { intake }\end{array}$ \\
\hline $\mathbf{2}$ & Initial Empty Bladder & 30 minutes after $700 \mathrm{~mL}$ fluid intake \\
\hline $\mathbf{3}$ & Initial Empty Bladder & 60 minutes after $700 \mathrm{~mL}$ fluid intake \\
\hline $\mathbf{4}$ & Initial Empty Bladder & $\begin{array}{c}\text { Immediately after second bladder } \\
\text { void }\end{array}$ \\
\hline $\mathbf{5}$ & $\begin{array}{c}\text { Immediately after second bladder } \\
\text { void }\end{array}$ & 60 minutes after $700 \mathrm{~mL}$ fluid intake \\
\hline
\end{tabular}



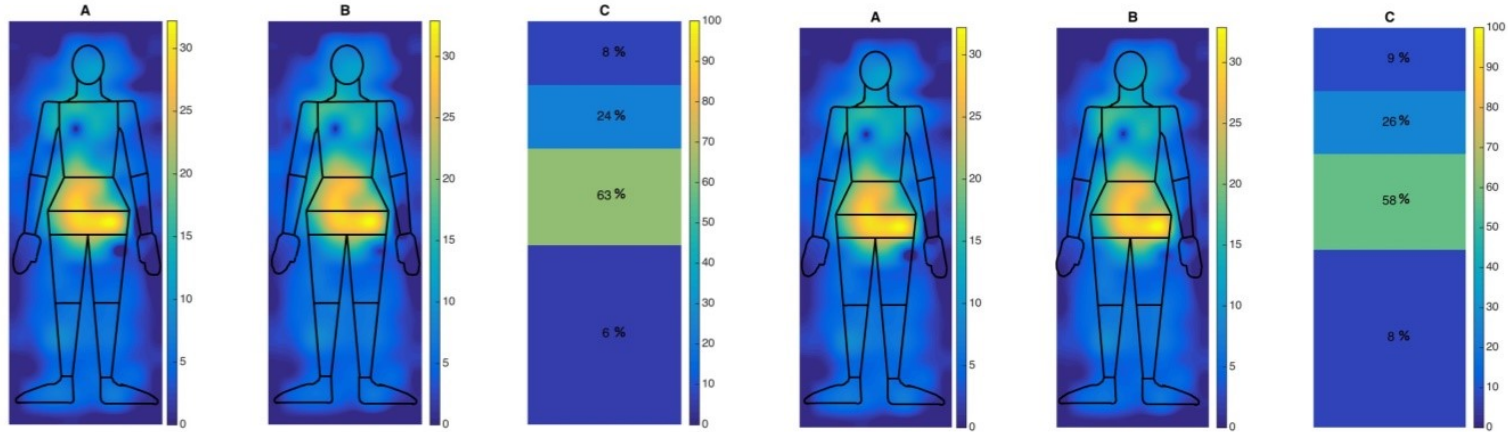

FIGURE 19. PARTICIPANT WITHINITIALEMPTY BLADDER(A) 30 MINUT ES AFT ER 700ML FLUID INT AKE (B), AND PRESSURE DIFFERENCE (C)
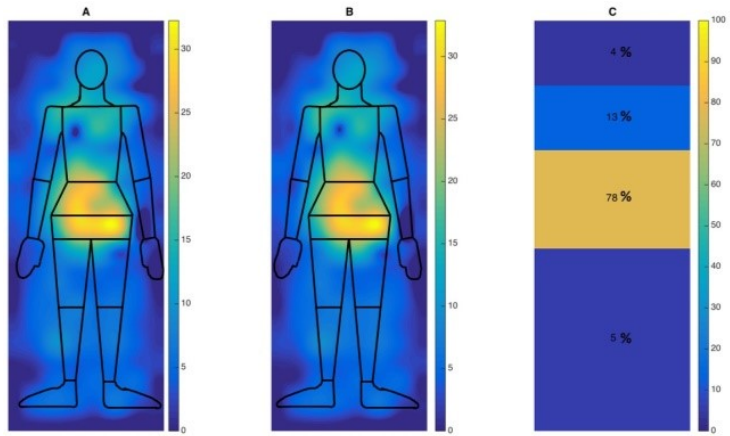

FIGURE 21. PART ICIPANT WITHFINAL EMPTY BLADDER (A), 60 MINUT ES AFT ER 700ML FLUID INT AKE IMMEDIATELY PRIOR TO EMPTYINGT HE BLADDER (B), AND PRESSURE DIFFERENCE (C).

FIGURE 20. PART ICIPANT WITHINITIALEMPTY BLADDER (A), 60 MINUTES AFT ER 700ML FLUID INT AKE (B) AND PRESSURE DIFFERENCE (C).
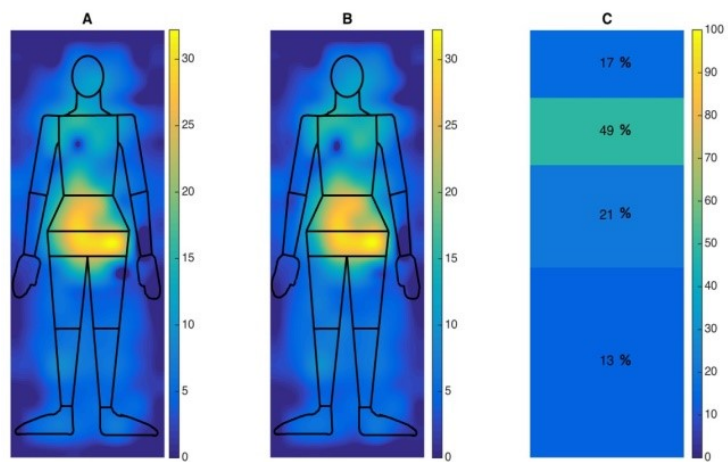

FIGURE 22. PART ICIPANT WITHINITIALEMPTY BLADDER (A), FINAL EMPTY BLADDER AFTER AN HOUR (B), AND PRESSURE DIFFERENCE (C).

file. Figure 18 illustrates the pressure responses from the initial voided bladder, the intake of $700 \mathrm{~mL}$ of water and the pressure differences between the two. This analysis was repeated for five pairs of data files as described in Table 11, resulting in Figure 18 through Figure 22.

The data were segmented into four body regions, based on the ROI segmentation method describe in Chapter 6, (head, chest, abdominal area, and lower body). The abdominal area was chosen to encompass both the stomach and the bladder regions. For each of these segments, the data from the Initial test condition (panel A from Figure 18 through Figure 22) were subtracted from the Comparison test condition (Panel B of same). 
Panel $\mathrm{C}$ of each figure illustrates the proportion of the total difference in pressure associated with each region, following Equation (13). The signal processing procedure for this experiment is summarized in Figure 23.

$$
P D_{i}=\frac{100}{\text { numCols }} \sum_{c=1}^{\text {numCols }} \frac{\sum_{r \in \text { Rows }_{i}} P D_{r, c}}{\sum_{r \in \text { AllRows }} P D_{r, c}}
$$

Where, numCols is the number of columns in the data (8), AllRows is the set of all rows (1..27), Rows $i$ is the set of rows belonging to body segment $i, P D_{r, c}$ is the pressure difference for row $r$ column $c$, and $P D_{i}$ is the percent difference for each body region calculated ( $i=$ head, chest, abdomen, lower body). The resulting percentage is displayed and assigned a color on a scale from 0 to 100 in the corresponding body regions (Figure 18C-Figure $22 \mathrm{C})$.

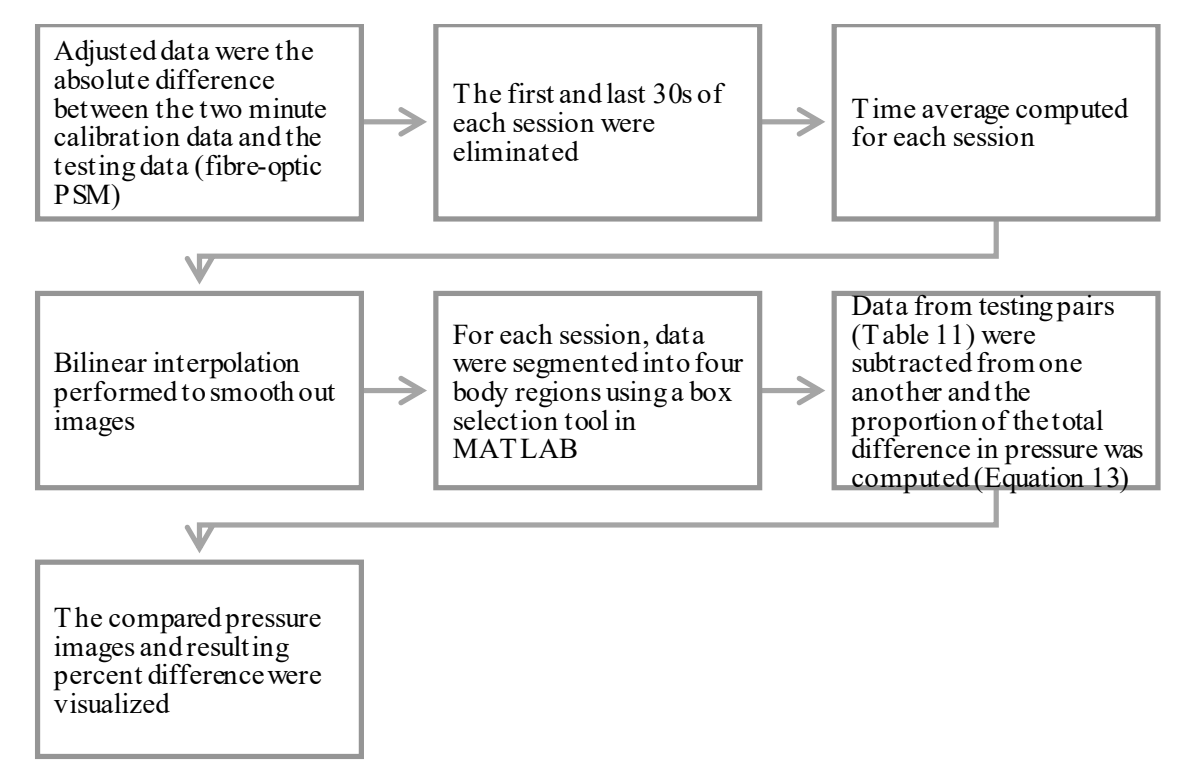

FIGURE 23. CONT RIBUT ION 4, PRELIMINARY SIGNAL PROCESSING SUMMARY

\subsubsection{RESULTS}

The physical locations of the stomach and bladder are very close with respect to total bodylength, making it more difficult to isolate each individually with the current resolution of 
the PSM. The bone structure of the back (spine and pelvis) when in a supine position also distributes the pressure caused by the bladder and the stomach to the same area. Therefore, the abdominal region discussed below includes both organs.

As can be seen in Figure 18, the additional $700 \mathrm{~mL}$ is visible in the difference image at the abdominal region when compared to the initially voided bladder. Figure 19 and Figure 20 have similar difference images; both indicating that there was an increase in abdominal pressure due to the ingested water after 30 and 60 minutes respectively when compared to the initial empty bladder. Comparing these figures with the initial pressure signature (Figure 21) suggests that the ingested fluid has begun to distribute throughout the body, with increasing proportions of the pressure increase observed in the torso and legs, in addition to some fluid likely beginning to accumulate in the bladder.

The difference between the data from one hour after ingestion and the final empty bladder session is largest in the abdominal area, reflecting the loss of fluid from the bladder during urination (Figure 21). The difference between the two empty bladder sessions (Figure 22) has percent differences of smaller magnitude than changes associated with the other sessions, indicating a more even distribution of weight difference. The largest difference is located in the torso, with the abdomen exhibiting the second highest difference. This can be explained by the fact that not all the ingested water was voided after an hour. Some of the water absorbed and dispersed throughout the body has yet to be filtered and gathered in the bladder. This process is discussed further in the following section. 


\subsubsection{DiscuSSION}

The increase in overall pressure is clearly visible when the initial $700 \mathrm{~mL}$ of water was ingested, where we see a $79 \%$ increase in pressure in the abdomen. Additionally, there is a similar decrease in pressure, 78\%, when comparing the final empty bladder to the 60 minutes post fluid intake at the abdomen. Therefore, PSMs are able to detect fluid intake and output events.

It is theorized that ingested water is absorbed through the stomach lining within 5 to 120 minutes [18]. How long it takes the body to recognize this additional fluid load depends on the previous hydration status. Therefore, no additional water would be filtered if the person were dehydrated prior to drinking the water. In this case the participant was normally hydrated and it appears as though the fluid was absorbed quickly, and the fluid load detected and the filtering process was in progress within 30 minutes [18]. Further absorption and filtration appears to have occurred between 30 minutes and 60 minutes post hydration, suggested by the redistribution of pressure at the abdomen from $63 \%$ after 30 minutes to $58 \%$ after 60 minutes.

When comparing the initial empty bladder to the final empty bladder 60 minutes post-water-intake, the difference in pressure is more evenly distributed throughout the body. The largest area of pressure difference is now located in the torso, followed by the abdomen, lower body and head. It is expected that not all the $700 \mathrm{~mL}$ of water would be absorbed, filtered and expelled within 60 minutes prior to the final empty bladder data set [18]. There should be more fluid distributed throughout the body after drinking water than before drinking. Figure $22 \mathrm{C}$ confirms this expectation with the percent pressure difference for each body region being more evenly distributed than any other testing session. 


\subsubsection{CONCLUSIONS}

This sub-chapter summarizes the proof of concept that it is possible to track fluid intake and output using PSMs. Experiments involved a young healthy female under idealized conditions, when drinking $700 \mathrm{~mL}$ of water. Pressure changes associated with both fluid intake and fluid output is distinguishable.

\subsection{FinAL EXPERIMENTATION}

This section summarizes the final experimentation procedure and results, which were summarized in Chapter 3. This procedure builds from the internal fluid monitoring system summarized in the previous section. The novel additions include: the introduction of two additional postures (prone and side), the adjustment of testing conditions to differentiate between getting up to (1) void, (2) drink or (3) do nothing over a longer testing period (approx. 2h), and the introduction of augmented algorithms for analysis. Furthermore, the higher density piezo-electric PSM is used here.

\subsubsection{METHODS}

\subsubsection{MEASUREMENT SYSTEM}

The measurement system utilized the piezo-resistive Tekscan ${ }^{\mathrm{TM}}$ HUGE MAT 5400N sensor and accompanying BPMS software. The PSM has a $22.76 \times 34.8 \times 0.012$ in sensing area that contains 1768 sensels $(0.39 \times 0.39$ in) 0.67 in apart on both the $\mathrm{x}$ and $\mathrm{y}$ axes. Therefore, the spatial resolution is $2.23 \mathrm{sensel} / \mathrm{in}^{2}$. The PSM was connected to a computer for data collection via a USB port using the Tekscan' ${ }^{\mathrm{TM}}$ data logger, 'Evolution Sensor Handle', Figure 24. All data collection was performed using the BPMSTM software at an 8 bit digital pressure resolution and sampled at $2 \mathrm{~Hz}$ [50]. 


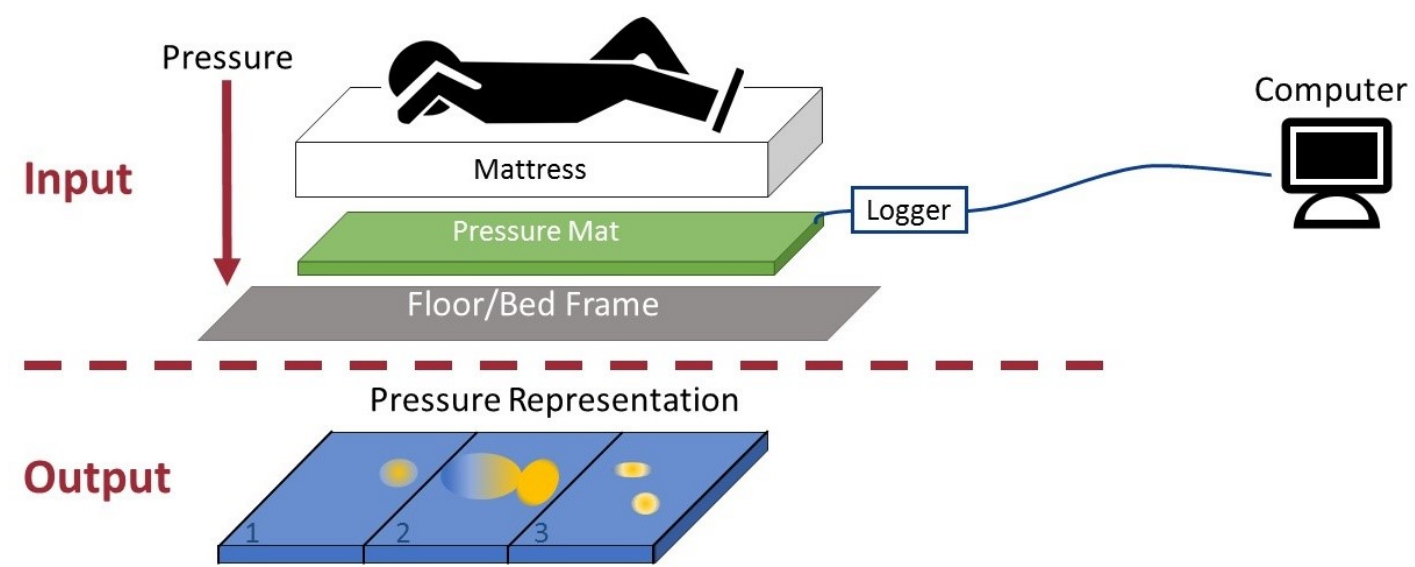

FiguRE 24. PiEZO-RESIST IVE PSM TEST ING SET UP

For a given testing session, each PSM was placed on a rigid support surface (floor) and a mixed density foam mattress, 5.9 in thick with no springs, was placed directly on top. A pillow was provided at the head of the mattress for the participant's comfort, which was not included in the sensing area. Due to the fact that the PSM was not long enough to cover the entire body, it was aligned so that the pressure sensing area covered from the participant's shoulders to their upper legs. Depending on the testing parameters (described in the following section), the participant was asked to lie down in either a supine, prone or side position.

\subsubsection{EXPerimental Procedure}

The built-in Tekscan BPMS calibration procedure was performed and applied prior to data collection. A healthy female participant (24 yrs, $5 \mathrm{ft} 7 \mathrm{inch}$, and $130 \mathrm{lbs})$ was asked to lie down on the mattress with her head on the pillow in a prone position. Data collection commenced at a $2 \mathrm{~Hz}$ sampling rate when the PSM identified an applied load and continued collection for a period of 135 minutes. A test protocol was developed to model bed entrances and exits associated with and without bladder voiding events, and with and 
without fluid intake events, as described in chapter 3. The experimental procedure was repeated for the other two postures (supine and side) under the same conditions.

\subsubsection{DATA ANALYSIS}

BPMS $^{\text {TM }}$ software was used to export pressure frame data for each testing session as a single CSV file. The file was transferred to MATLAB for all further processing. The average pressure response for each frame was calculated. Filtering was applied to both the average pressure response and each sensel's pressure response. The filtering procedure included a five point median filter, followed by a fifth-order Butterworth filter and a
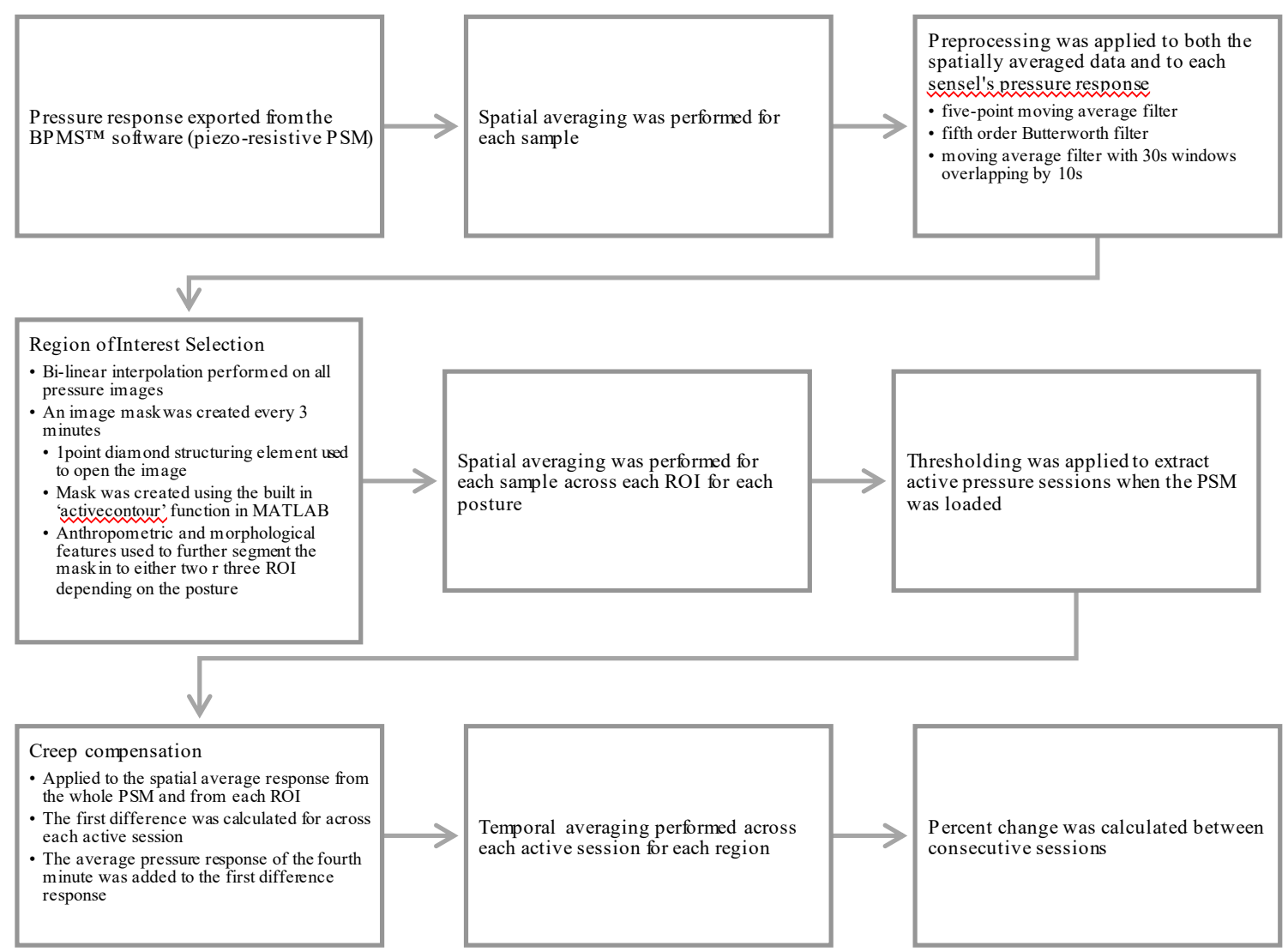

FIGURE 25. CONTRIBUT ION 4, FINAL RESULT SANALYSISPROCEDURE 
moving average filter with windows of 30 seconds each, overlapping by $10 \mathrm{~s}$. A summary of the entire data analysis procedure for the final experiment is displayed in the block diagram in Figure 25.

TABLE 12. TEST INGPARAMETERS

\begin{tabular}{|l|l|l|l|}
\hline $\begin{array}{l}\text { SESSION } \\
\text { NuMBER }\end{array}$ & $\begin{array}{l}\text { TIMING } \\
(\text { MIN) }\end{array}$ & $\begin{array}{l}\text { PARTICIPANT } \\
\text { STATUS }\end{array}$ & PURPOSE \\
\hline 1 & 10 & On & Initial baseline bladder volume \\
\hline 2 & 2 & Off & Stimulates bed exit with no changes \\
\hline 3 & 10 & On & Second empty bladder \\
\hline 4 & $\sim 5$ & Off & $\begin{array}{l}\text { Participant was asked to void their bladder } \\
\text { at the nearest facility to simulate night- } \\
\text { time bathroom visit. }\end{array}$ \\
\hline 5 & 10 & On & $\begin{array}{l}\text { Pressure response associated with small } \\
\text { bladder voiding event. }\end{array}$ \\
\hline 6 & $\sim 5$ & Off & $\begin{array}{l}\text { Participant was asked to drink as much } \\
\text { water as was comfortable ( 1L) }\end{array}$ \\
\hline 7 & 60 & On & $\begin{array}{l}\text { Pressure response associated with fluid } \\
\text { distribution after drinking. }\end{array}$ \\
\hline 8 & $\sim 5$ & Off & $\begin{array}{l}\text { Participant was asked to void their bladder } \\
\text { at the nearest facility to simulate night- } \\
\text { time bathroom visit. }\end{array}$ \\
\hline 9 & 10 & On & $\begin{array}{l}\text { Pressure response associated with large } \\
\text { bladder voiding event. }\end{array}$ \\
\hline 10 & 2 & Off & Simulates bed exit that has no changes \\
\hline 11 & 10 & On & $\begin{array}{l}\text { Second pressure response associated with } \\
\text { large bladder voiding event. }\end{array}$ \\
\hline Total & 130 minutes & \\
\hline
\end{tabular}




\subsubsection{REGION OF INTEREST SELECTION}

After data filtering, an automatic region of interest (ROI) selection tool was applied to each frame. Depending on the posture of the participant, either two or three RO Is were extracted (Table 13). Due to the skeletal structure of the human body, certain areas were not in contact with the mattress, resulting in slightly different ROIs defined for each pose. The
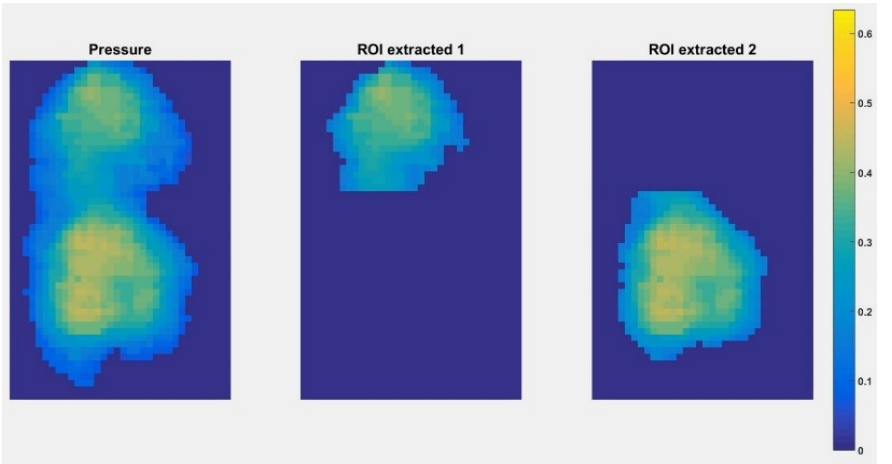

FIGURE 27 SUPINE ROI EXTRACTION RESULT

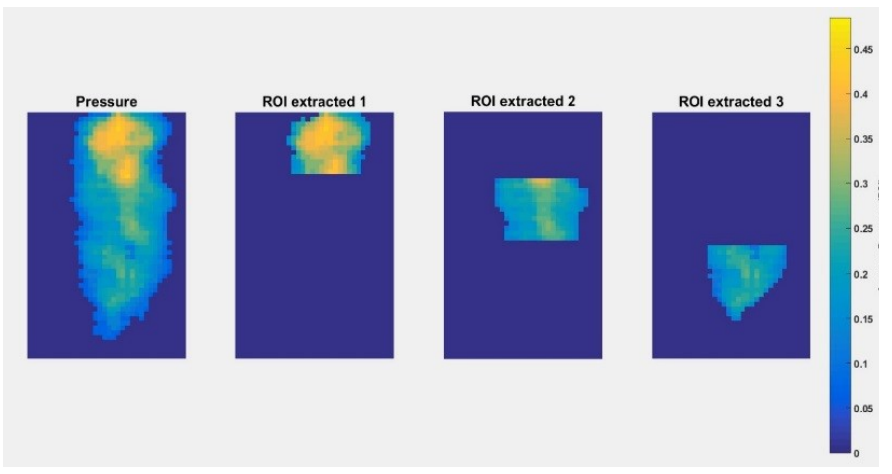

FIGURE 28 PRONE ROI EXTRACTION RESULT

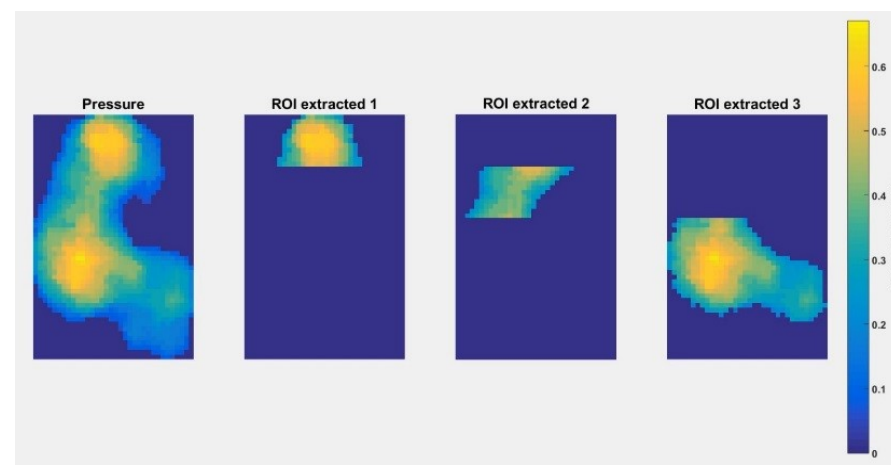

FIGURE 26 SIDE ROI EXTRACTION RESULT 
temporal average of each ROI was then calculated and passed through to the next algorithmic step. The ROI extraction was based on basic image processing methods to obtain a binary mask of the image (i.e. loaded vs. unloaded sensels). This mask was then segmented into specific ROIs defined by the position of the participant during testing. Figure 27 - Figure 26 show a sample ROI segmentation for a single frame for each position. TABLE 13. REGION OF INTEREST SEGMENTATION

\begin{tabular}{|l|l|l|}
\hline Posture & Number of Segments & Segment Descriptions \\
\hline Prone (Stomach) & 3 & $\begin{array}{l}\text { 1. Torso } \\
\text { 2. Hips } \\
\text { 3. Upper Legs }\end{array}$ \\
\hline Supine (Back) & 2 & $\begin{array}{l}\text { 1. Torso } \\
\text { 2. Hips }\end{array}$ \\
\hline Side & 3 & $\begin{array}{l}\text { 1. Torso } \\
\text { 2. Hips } \\
\text { 3. Lower Body }\end{array}$ \\
\hline
\end{tabular}

The mask was further cut vertically into segments based on the pose the participant was in. While prone, three segments were used. The segments were identified based on anthropomorphic body segment averages and morphological features, such as the narrowing of the image mask, to identify the waist and the junction of the thighs [73], [74]. The first segment, labeled as the torso, was defined from the top of the pressure sensing area to the location of the waist. The second segment was defined from the waist to the junction of the thighs and was labeled as the abdominal region. The final sub-segment while the participant was prone was from the junction of the thighs to the end of the sensing area and was labeled as the upper thigh region.

While supine, the mask was simply cut at the sensel row containing the narrowest pressure response. This point represents the waist region of the individual in question and 
does not rely on average anthropomorphic measurements, resulting in a more individualized segmentation method. The first ROI, the torso, was defined from the top of the PSM to the waist location. The second ROI, the lower abdomen and the hips, was defined from the waist location to the bottom of the PSM. While in this positon, there was very little contact between the participant's thighs and the mattress; thus, there is minimal upper leg pressure observed.

Finally, while lying on the left side, segmentation relied on a combination of the two aforementioned methods. First, the location of the hips/thighs was identified by finding the widest activated sensel row. From this location, the narrowest activated sensel row was then determined corresponding with the waist region. From this, the first sub-segment is defined from the top of the sensing area to the waist, the torso region. The second subsection, abdominal region, is defined from the waist to the largest active sensor row, representing the location of the hips/upper legs. The final sub-section is defined from the widest active region to the end of the PSM, representing the lower body region.

\subsubsection{CREEP COMPENSATION}

As defined in section 4.2, for the purposes of this thesis, we define drift as the tendency of the system output to fluctuate around continuous measurements caused by the fluctuation of the zero scale [76]. Creep refers to the systematic trend in observed pressure over time once the initial transient period ( $\sim$ two minutes for these sensors) has passed [76]. For the piezo-resistive sensors, the manufacture suggested that creep is characterized by a $\leq 5 \%$ increase in pressure response over log time. Our data roughly follows the quoted trend. A 
creep compensation algorithm was developed in order to (1) remove as much creep as possible and (2) to enable fair comparison between data recordings of different lengths.

After thresholding, to extract each sensor-occupied session, and data smoothing, the first difference between adjacent samples was calculated. This acts as a high-pass filter to de-trend the signal. To restore the DC offset, the de-trended data were then shifted by a factor corresponding to the average pressure response during the fourth minute from the filtered data and the $1^{\text {st }}$ difference response, which had a zero mean drift response. The adjusted data $(A d j)$ calculation is summarized in Equation (14) as seen in Figure 29.

$$
\operatorname{Adj}(i)=(D(i-1)-D(i))+s
$$

Where $s$ is

$$
s=D_{4}-A d j_{4}
$$

Where $D$ is either the average pressure response over the entire PSM or it is the average pressure response over each identified ROI. For each sample $i, D$ is adjusted individually by the previous sample, $\mathrm{D}(\mathrm{i}-1)$ and then adjusted by a shift factor, $s$. The shift factor is

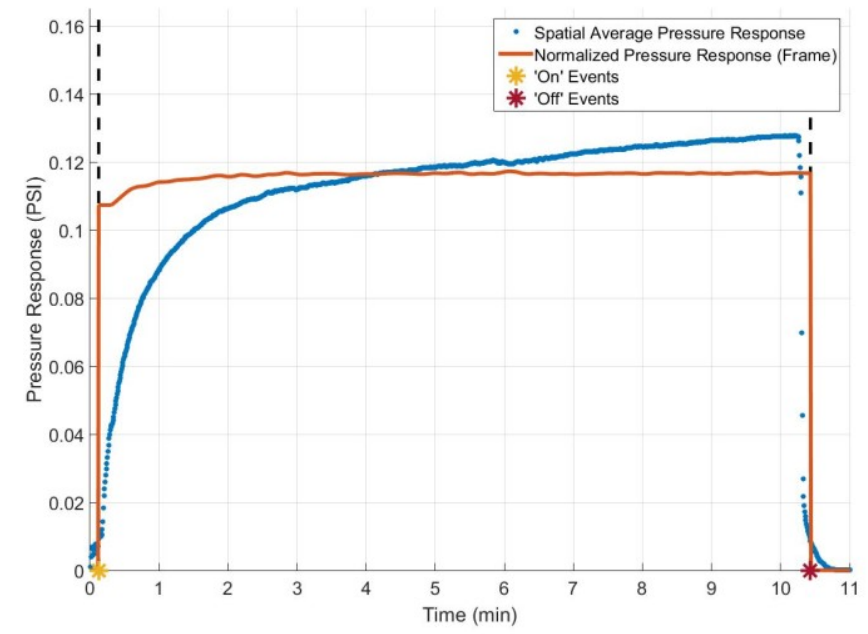

FIGURE 29. A SINGLE SENSEL LOADED 10 MINUTE SESSION WITHTHE FILTEREDPRESSURE RESPONSE (BLUE) AND T HE CREEP ADJUST ED RESPONSE (ORANGE) 
calculated based on the difference between the pressure response of the original data $\left(D_{4}\right)$ and that of the $1^{\text {st }}$ difference $\left(\operatorname{Adj}_{4}\right)$ response during the fourth minute of each session. The fourth minute was chosen because, (1) it was after the previously identified rise time [15] of each segment and (2) because it was within the time frame of the shortest loading segment. The resulting adjusted data (Adj) was then used as the pressure response at each sample. The creep-compensation was applied to the whole frame data and to each ROI segment under each posture conditions (prone, supine and side). The resulting creepcompensated pressure response, while the participant was in a prone position, can be seen in Figure 30

\subsubsection{RESULTS}

Average creep compensated pressure responses are detailed in Table 14 for each posture across each loading period. The percent change $(\% \Delta)$ between the current session and the previous session are calculated for each posture, Equation (16).

$$
\% \Delta=\frac{p(i)+p(i-1)}{p(i-1)} * 100 \%
$$

Where $p(i)$ is the average pressure of the whole frame or for each ROI segment for current sub-session and $p(i-1)$ is the average pressure of the whole frame or for each ROI segment for the previous sub-session as defined in Table 14. Positive percentages indicate

an increase in pressure between sessions and negative sessions indicate a decrease in pressure. 
The adjusted pressure response while the participant was in a prone, side and supine position for the ROI extracted pressure response can be seen in, Figure 30,Figure 32, and Figure 31, respectively. In all cases, it is very clear when the $1 \mathrm{~L}$ was imbibed at approximately 40 minutes. The large bladder void is also clear in both the prone and side positions. It is not as clear when the participant was in a supine position. Pressure responses become clearer after ROI extraction was applied.

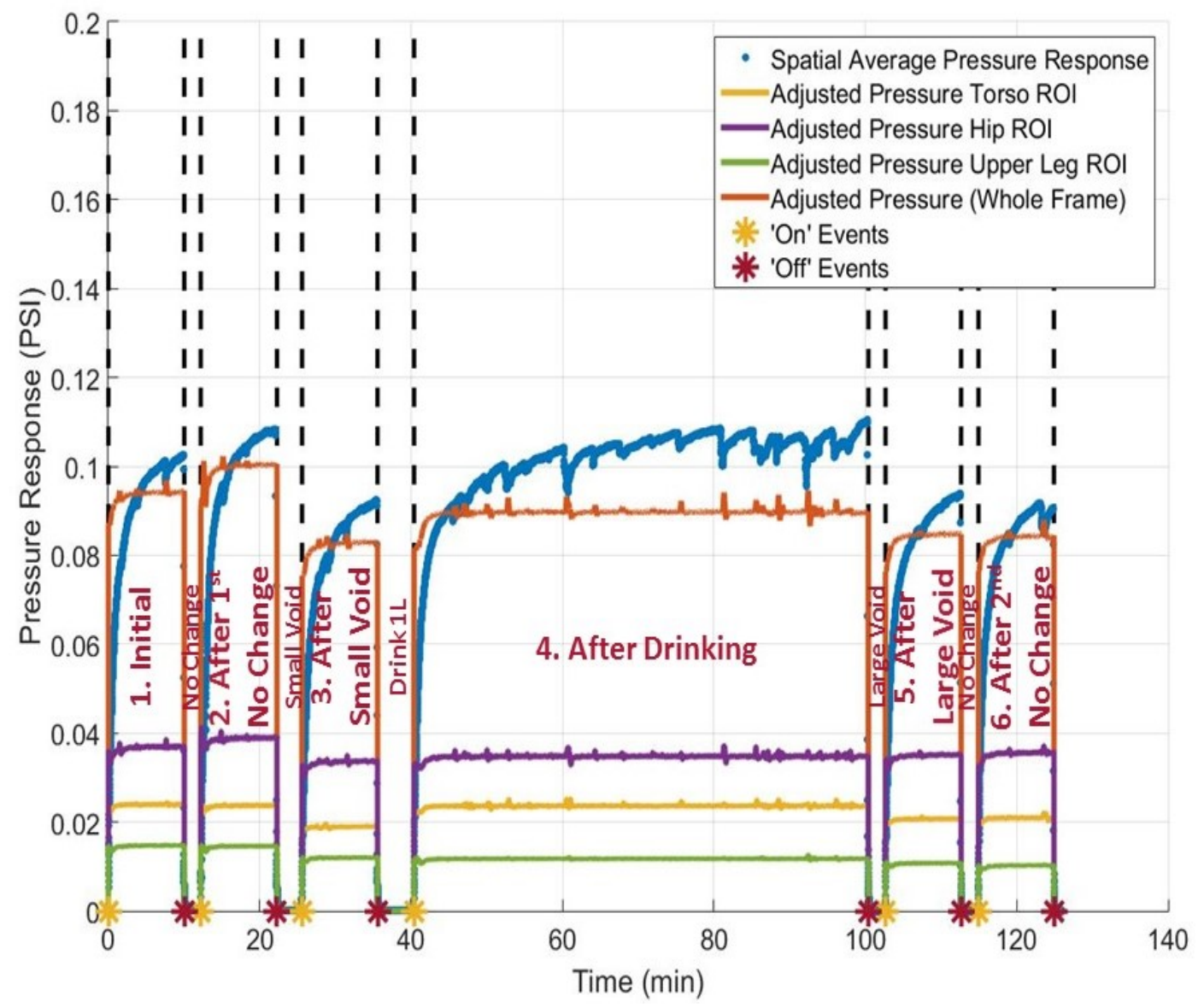

FIGURE 30. PRONE PRESSURE RESPONSE OF THE WHOLE PSM (BLUE), THE CREEP ADJUST ED PRESSURE RESP ONSE OF THE WHOLE PSM (ORANGE), THE TORSO(PURPLE), THE HIP ROI (YELLOW), AND THE UPPER LEG ROI (GREEN) 


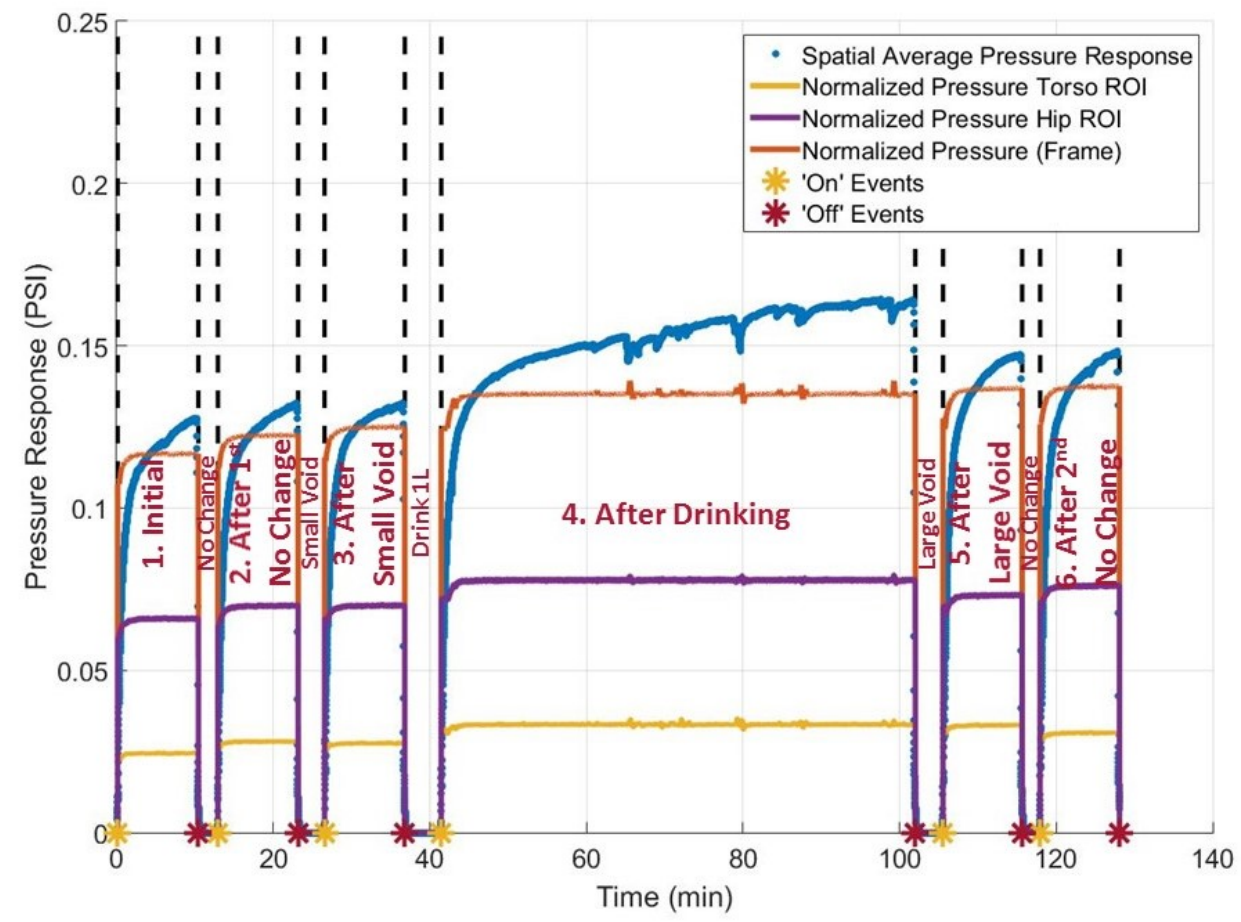

FIGURE 32. SUPINE PRESSURE RESP ONSE OF THE W HOLE PSM (BLUE), THE CREEP ADJUSTED PRESSURE RESP ONSE OF THE W HOLE PSM (ORANGE), THE TORSO ROI (PURPLE), THE HIP ROI(YELLOW), AND THE UPPER LEG ROI (GREEN)

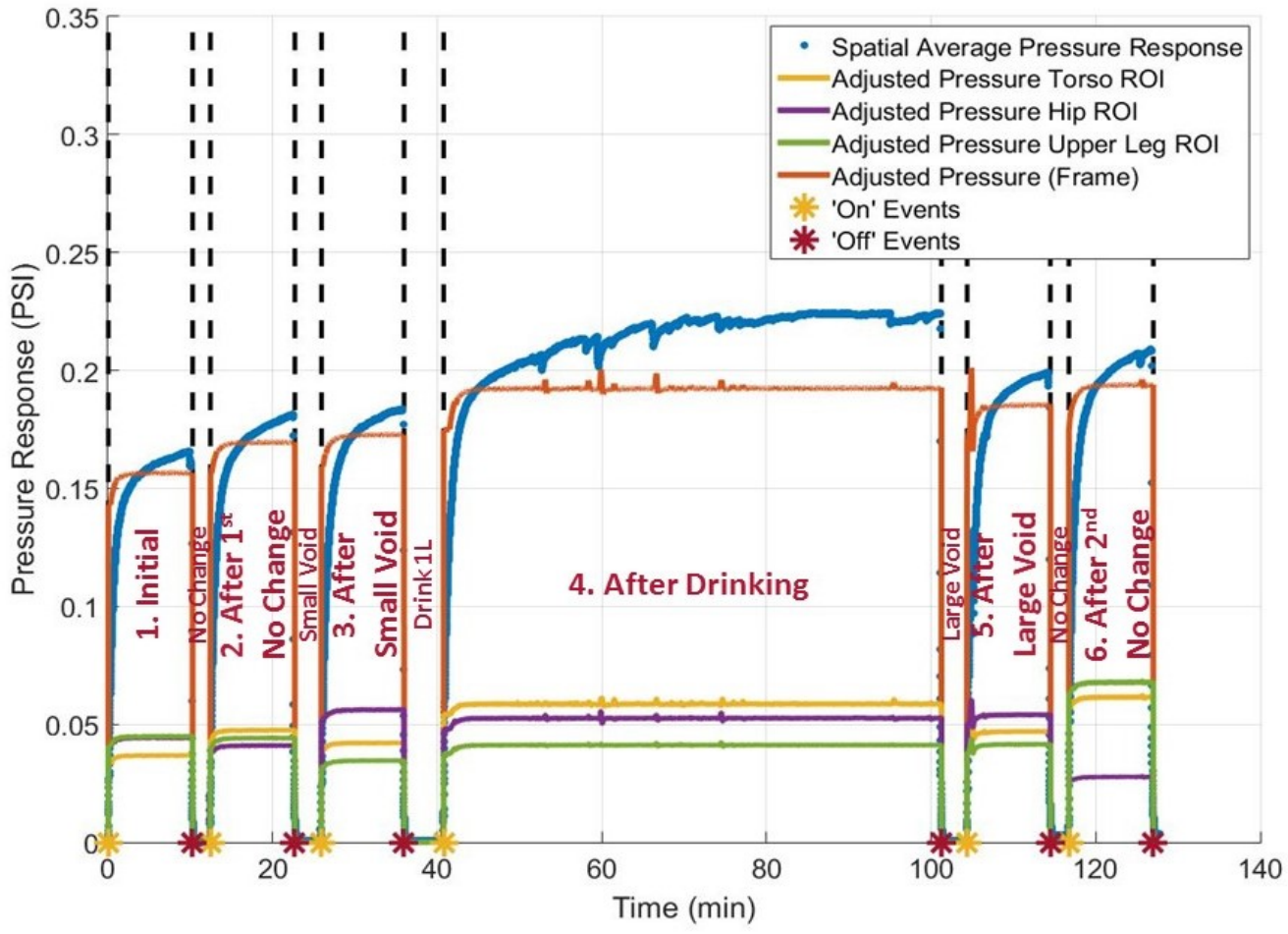

FIGURE 31. SIDE PRESSURE RESP ONSE OF T HE WHOLE PSM (BLUE), THE CREEP ADJUST ED PRESSURE RESPONSE OF T HE WHOLE PSM (ORANGE), THE TORSO ROI (PURPLE), THE HIP ROI (YELLOW), AND THE UPPER LEG ROI (GREEN) 
TABle 14. Average Pressure ReSPonse in PSI (Post URE \& REgion)

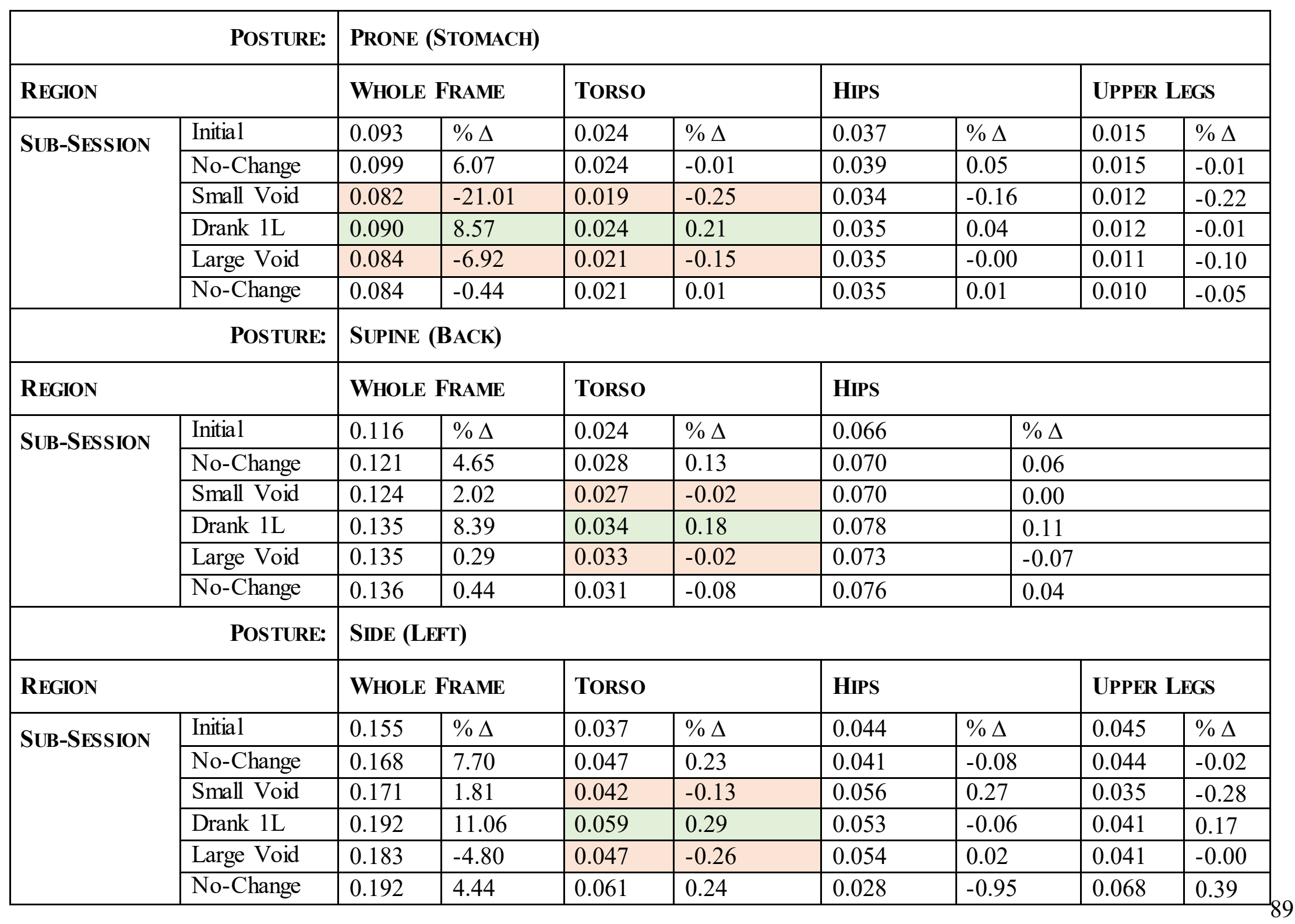


When looking at the prone position results in Figure 30, the torso region pressure response highlights the small bladder void at about 25 minutes. The large bladder void is also clear with a pressure decrease in all regions. The consecutive sessions with no changes in fluid distribution are similar in the overall pressure response as can be seen in Figure 30. Considering that this region contains both the bladder and stomach, this was not unexpected.

In Figure 30 the torso region (in yellow) exhibits a small pressure reduction after the small bladder voiding event at approximately 25 minutes as well as a pressure decrease after the large void after approximately 40 minutes. The pressure response due to consecutive sessions with no fluid changes is very similar in the overall pressure response and in the lower abdomen and hip ROI in Figure 30.

When the position is changed, and the stomach is no longer directly in contact with the mattress and thus the PSM, fluid changes become harder to differentiate. This is seen in both the frame pressure response and ROI segmentation for both the side position (Figure 31) and the supine position (Figure 32).

In order to determine if these percent changes between consecutive sessions were significant, random sampling was performed over each sensor-occupied session in order to perform an ANOVA statistical analysis with a null hypothesis that pressure response from each sensor-occupied session was the same. A piecewise comparison was then performed using MATLAB's built in function to determine if each loading period was statistically different from each other sensor-occupied session. The resulting multi-variable comparison is summarized in Table 15 -Table 17 for the torso segmented region while the participant was in a prone, supine and side position respectively. For each combination of sensor- 
occupied sessions, a p-value was calculated to define if their means were significantly different. The comparisons of consecutive sessions are highlighted to emphasize that corresponding sessions with no change were not statistically different $(p>0.05)$ and the corresponding sessions when fluid changes did occur are significantly different $(p<0.05)$. As expected, the differentiation between sub-samples when nothing changed and subsamples when changes did occur (drinking or voiding) are most clear while the participant was on their front in a prone position. This is due to the fact that the areas of interest (the stomach and bladder regions) are in direct contact with the mattress and thus the PSM (Table 15). When looking at the results from the supine and side positions, periods of change are significantly different from one another, however the periods of no change are sometimes also identified as significantly different (Table 16 and Table 17). This may be caused by the skeletal system distributing the pressure from the bladder to other regions of the body, and thus masking the signal. The statistical summary tables from all three positions for the whole PSM and the other regions are included in Table 6. 
TABLE 15. PIECEWISE COMPARISON BETWEEN EACH SUB-SESSION (PRONE - TORSO ROI)

\begin{tabular}{|c|c|c|c|c|c|}
\hline \multicolumn{6}{|c|}{ Prone - Torso ROI } \\
\hline 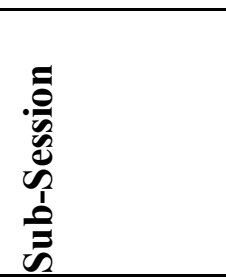 & 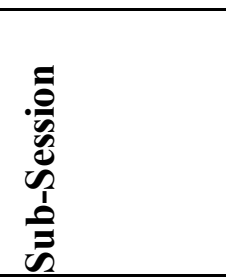 & 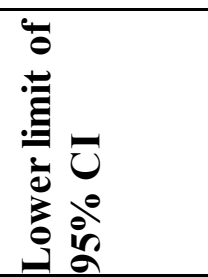 & 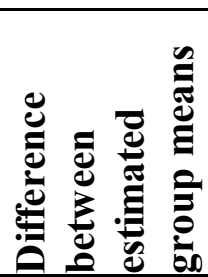 & 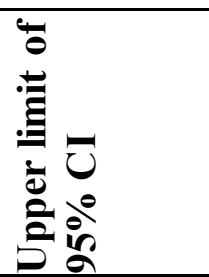 & 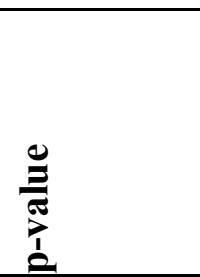 \\
\hline 1 - Initial & $\begin{array}{l}2-\text { After } 1^{\text {st }} \\
\text { No Change }\end{array}$ & -0.00 & 0.00 & 0.00 & 0.93 \\
\hline 1 & 3 & 0.00 & 0.01 & 0.01 & 0.00 \\
\hline 1 & 4 & -0.00 & 0.00 & 0.00 & 0.99 \\
\hline 1 & 5 & 0.00 & 0.00 & 0.00 & 0.00 \\
\hline 1 & 6 & 0.00 & 0.00 & 0.00 & 0.00 \\
\hline $\begin{array}{l}2 \text { - After 1st } \\
\text { No Change }\end{array}$ & $\begin{array}{l}3 \text { - After } \\
\text { Small Void }\end{array}$ & 0.00 & 0.00 & 0.01 & 0.00 \\
\hline 2 & 4 & -0.00 & -0.00 & 0.00 & 0.99 \\
\hline 2 & 5 & 0.00 & 0.00 & 0.00 & 0.00 \\
\hline 2 & 6 & 0.00 & 0.00 & 0.00 & 0.00 \\
\hline $\begin{array}{l}\text { 3- After } \\
\text { Small Void }\end{array}$ & $\begin{array}{l}4 \text { - After } \\
\text { Drinking }\end{array}$ & -0.01 & -0.00 & -0.00 & 0.00 \\
\hline 3 & 5 & -0.00 & -0.00 & -0.00 & 0.00 \\
\hline 3 & 6 & -0.00 & -0.00 & -0.00 & 0.00 \\
\hline $\begin{array}{l}4 \text { - After } \\
\text { Drinking }\end{array}$ & $\begin{array}{l}5 \text { - After } \\
\text { Large Void }\end{array}$ & 0.00 & 0.00 & 0.00 & 0.00 \\
\hline 4 & 6 & 0.00 & 0.00 & 0.00 & 0.00 \\
\hline $\begin{array}{l}5 \text { - After } \\
\text { Large Void }\end{array}$ & $\begin{array}{l}6 \text { - Affer } 2^{\text {nd }} \\
\text { No Change }\end{array}$ & -0.00 & -0.00 & 0.00 & 0.27 \\
\hline
\end{tabular}


TABLE 16. PIECEWISE COMPARISON BETWEEN EACH SUB-SESSION (SUPINE- TORSO ROI)

\begin{tabular}{|c|c|c|c|c|c|}
\hline \multicolumn{6}{|c|}{ Supine - Torso ROI } \\
\hline 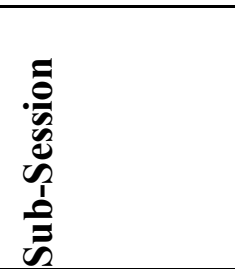 & 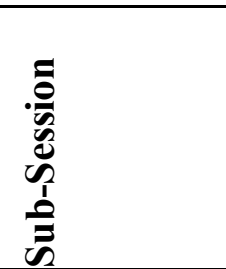 & 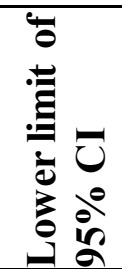 & 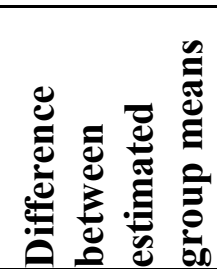 & 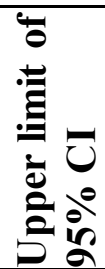 & 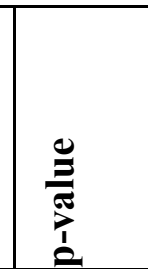 \\
\hline 1 - Initial & $\begin{array}{l}2 \text { - After } 1^{\text {st }} \\
\text { No Change }\end{array}$ & -0.00 & -0.00 & -0.00 & $2.1 \mathrm{E}-08$ \\
\hline 1 & 3 & -0.00 & -0.00 & -0.00 & $2.1 \mathrm{E}-08$ \\
\hline 1 & 4 & $\begin{array}{c}-0.01 \\
\end{array}$ & $\begin{array}{c}-0.01 \\
\end{array}$ & -0.01 & $2.1 \mathrm{E}-08$ \\
\hline 1 & 5 & -0.01 & -0.01 & -0.01 & $2.1 \mathrm{E}-08$ \\
\hline 1 & 6 & -0.01 & -0.01 & -0.01 & $2.1 \mathrm{E}-08$ \\
\hline $\begin{array}{l}2 \text { - After 1st } \\
\text { No Change }\end{array}$ & $\begin{array}{l}3 \text { - After } \\
\text { Small Void }\end{array}$ & 0.00 & 0.00 & 0.00 & $2.0 \mathrm{E}-03$ \\
\hline 2 & 4 & -0.01 & -0.01 & -0.00 & $2.1 \mathrm{E}-08$ \\
\hline 2 & 5 & -0.01 & -0.00 & -0.00 & $2.1 \mathrm{E}-08$ \\
\hline 2 & 6 & -0.00 & -0.00 & -0.00 & $2.1 \mathrm{E}-08$ \\
\hline $\begin{array}{l}3 \text { - After } \\
\text { Small Void }\end{array}$ & $\begin{array}{l}4-\text { After } \\
\text { Drinking }\end{array}$ & -0.01 & -0.01 & -0.01 & $2.1 \mathrm{E}-08$ \\
\hline 3 & 5 & -0.01 & $\begin{array}{l}-0.01 \\
\end{array}$ & -0.00 & $2.1 \mathrm{E}-08$ \\
\hline 3 & 6 & -0.00 & -0.00 & -0.00 & $2.1 \mathrm{E}-08$ \\
\hline $\begin{array}{l}4 \text { - After } \\
\text { Drinking }\end{array}$ & $\begin{array}{l}5 \text { - After } \\
\text { Large Void }\end{array}$ & 0.00 & 0.00 & 0.00 & $3.5 \mathrm{E}-02$ \\
\hline 4 & 6 & 0.00 & 0.00 & 0.00 & $2.1 \mathrm{E}-08$ \\
\hline $\begin{array}{l}5 \text { - After } \\
\text { Large Void }\end{array}$ & $\begin{array}{l}6-\text { After } 2^{\text {nd }} \\
\text { No Change }\end{array}$ & 0.00 & 0.00 & 0.00 & $2.1 \mathrm{E}-08$ \\
\hline
\end{tabular}


TABLE 17. PIECEWISE COMPARISON BETWEEN EACH SUB-SESSION (SIDE- TORSO ROI)

\begin{tabular}{|c|c|c|c|c|c|}
\hline \multicolumn{6}{|c|}{ Side - Torso ROI } \\
\hline 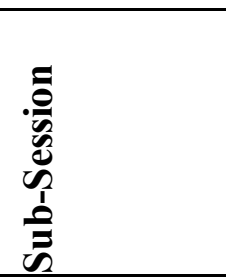 & 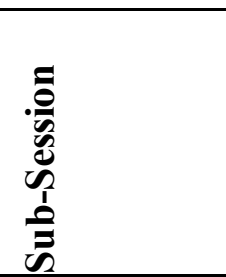 & 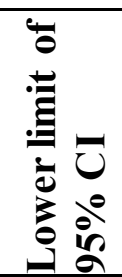 & 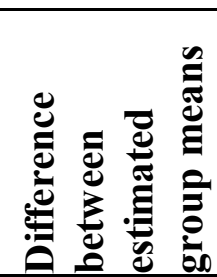 & 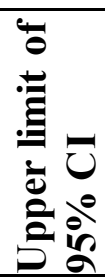 & 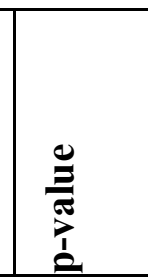 \\
\hline 1 - Initial & $\begin{array}{l}2-\text { After } 1^{\text {st }} \\
\text { No Change }\end{array}$ & -0.01 & -0.01 & -0.01 & $2 . \overline{\mathrm{E}}-08$ \\
\hline 1 & 3 & -0.01 & -0.01 & -0.00 & $2.1 \mathrm{E}-08$ \\
\hline 1 & 4 & -0.02 & -0.02 & -0.02 & $2.1 \mathrm{E}-08$ \\
\hline 1 & 5 & -0.01 & $\begin{array}{l}-0.01 \\
\end{array}$ & -0.01 & $2.1 \mathrm{E}-08$ \\
\hline 1 & 6 & -0.03 & -0.02 & -0.02 & $2.1 \mathrm{E}-08$ \\
\hline $\begin{array}{l}2 \text { - After 1st } \\
\text { No Change }\end{array}$ & $\begin{array}{l}3 \text { - After } \\
\text { Small Void }\end{array}$ & 0.00 & 0.01 & 0.01 & $2.1 \mathrm{E}-08$ \\
\hline 2 & 4 & -0.01 & $\begin{array}{l}-0.01 \\
\end{array}$ & -0.01 & $2.1 \mathrm{E}-08$ \\
\hline 2 & 5 & -0.00 & 0.00 & 0.00 & $8.9 \mathrm{E}-01$ \\
\hline 2 & 6 & -0.01 & -0.01 & -0.01 & $2.1 \mathrm{E}-08$ \\
\hline $\begin{array}{l}\text { 3- After } \\
\text { Small Void }\end{array}$ & $\begin{array}{l}4 \text { - After } \\
\text { Drinking }\end{array}$ & -0.02 & -0.02 & -0.02 & $2.1 \mathrm{E}-08$ \\
\hline 3 & 5 & -0.01 & -0.01 & -0.00 & $2.1 \mathrm{E}-08$ \\
\hline 3 & 6 & -0.02 & -0.02 & -0.02 & $2.1 \mathrm{E}-08$ \\
\hline $\begin{array}{l}4 \text { - After } \\
\text { Drinking }\end{array}$ & $\begin{array}{l}5 \text { - After } \\
\text { Large Void }\end{array}$ & 0.01 & 0.01 & 0.01 & $2.1 \mathrm{E}-08$ \\
\hline 4 & 6 & -0.00 & -0.00 & -0.00 & $5.5 \mathrm{E}-07$ \\
\hline $\begin{array}{l}5 \text { - After } \\
\text { Large Void }\end{array}$ & $\begin{array}{l}6 \text { - Affer } 2^{\text {nd }} \\
\text { No Change }\end{array}$ & -0.02 & -0.01 & -0.01 & $2.1 \mathrm{E}-08$ \\
\hline
\end{tabular}

\subsubsection{DisCUSSION}

As can be seen in Figure 30 through Figure 31, the pressure response increases when the participant drank $1 \mathrm{~L}$ of water. The pressure also decreases after the large bladder void in all positions. The small bladder void produces a corresponding reduced pressure 
decrease when looking at the whole frame response while the participant was in a prone position. When in a side or supine position the whole frame response is unable to identify this small decrease in pressures. However after the ROI segmentation, the small decrease in pressure associated with the small bladder void becomes clear in the abdominal ROIs for both the side (Figure 31) and supine (Figure 32) positions. The consecutive sessions of no fluid changes produce relatively consistent pressure responses the prone and supine positions of the whole frame pressure response. Additionally, the regions that did not overlap with the areas containing the stomach or the bladder presented with very consistent pressure responses when no changes were experienced (e.g. the upper leg ROI (yellow in Figure 30) when in a prone position).

The pose of the participant during testing had a large impact on fluid variation pressure detections. As mentioned, in some postures, pressure distributed from the stomach and/or bladder may not be in direct contact with the mattress, and hence the PSM. This effects the pressure response measurements for the side and supine positions the most. Some of the pressure from the addition or removal of fluid to the stomach or bladder is observed to be distributed to the adjacent ROIs.

In the case of the side position, some of this pressure is observed in the abdomen region with a small contact area, some is translated to the hip and upper leg ROI, and some is translated to the shoulder region (Figure 31). When an individual is lying in a supine position, there is very little pressure response in the abdominal region due to the curvature of the spine. The pressure associated with additions or removal of fluid to stomach or the bladder is therefore translated to the hip and to the torso ROIs (Figure 31). The pressure 
variations with fluid additions and removals are detectable when considering all the ROIs, however it is difficult to isolate a single ROI that contains all of the pertinent information.

We are able to detect the pressure response due to bladder voiding events and drinking events. This work has implications in the monitoring of nocturia. Being able to more consistently and accurately detect nighttime bathroom visits that included a voiding event can potentially surpass current unreliable self-reporting methods and provide important information for achieving better treatment plans. Better treatment and monitoring may also improve quality of life and reduce the occurrence of hospitalizations that are associated with some of the root conditions of nocturia.

Additionally, future work may include the use of a PSM that has a higher digital resolution ( $>8$ bit). The very small changes in pressure that are hypothesized to occur due to fluid absorption and distribution throughout the body are masked by the low digital resolution of this particular PSM. These minute pressure variations would be the most pertinent to CHF monitoring, specifically the identification of fluid edema. All algorithms developed for this study were designed to be compatible with any pressure input, therefore changing the underlying PSM technology is entirely possible.

\subsubsection{CONCLUSIONS}

This chapter described the results of the use of PSMs to monitor and detected internal fluid changes. Three postures (prone, supine and side) were considered when lying on a foam mattress placed directly on the Tekscan ${ }^{\mathrm{TM}}$ PSM. It has been observed that this PSM experiences a logarithmic creep over time, resulting in pressure responses that never truly settle when taking long term measurements such as these. A creep compensation 
algorithm was created and was applied to all spatially averaged data for the full PSM and for each of the extracted ROIs.

The pressure responses associated with drinking $1 \mathrm{~L}$ of water and then voiding one's bladder approximately one hour later were very clear across all positions. A ROI extraction algorithm was created to more specifically identify smaller internal fluid changes. Small bladder void events that occurred prior to drinking $1 \mathrm{~L}$ were detectable in the abdomen ROI and adjacent regions all postures. Finally, consecutive sessions when no fluid changes were performed, had consistent pressure responses when looking at the whole frame pressure or when looking at the pressure associated with the ROI.

The implications of theses results for monitoring nocturia were discussed and future work was proposed to extend this work to the other conditions known to be dependent of fluid distribution (CHF and kidney failure). Future work may also include monitoring the spatial pressure response associated with fluid distribution internally over the course of the testing sessions. Specifically, to investigate whether it is possible to monitor fluid absorption and distribution expected with CHF patients. More participants are needed to fully evaluate the current results and create a classification system that could be used either at home or in a hospital setting. 


\section{Conclusions and Future Work}

\subsection{Thesis CONCLUSIONS}

The main objective of this thesis was to evaluate if internal changes in fluid, that may be indicative of a variety of health conditions common amongst older adults, were detectable using PSMs. A series of four increasingly complex and realistic experiments were performed culminating in the final contribution where internal fluid changes, induced by drinking and voiding, were detectable. A system of algorithms was developed and updated throughout the thesis contributions that included a strategy for creep compensation, an automatic posture-specific ROI segmentation algorithm, and a mean pressure comparison between subsequent sensor-occupied sessions (as defined in the final experiment).

In the first iteration of the system, a simplistic 1:1 sensel subtraction comparison between two different loading testing sessions was employed. This algorithm was used to validate the anthropometric model and identify if external mass additions applied to the model at key locations on the lower body were detectable. The algorithm was then updated to include a semi-automatic ROI selection that permitted the user to create bounding rectangles around ROI during data analysis. This was done in conjunction with the introduction of human participants and the transition to a new higher-density PSM.

The final algorithm was developed with an updated testing procedure and evaluated in three different postures, where the participant was asked to lie down and get up and then return to the mattress multiple times. While the participant was off the mattress they were asked to either change their fluid distribution (drinking or voiding) or do nothing. An automatic ROI segmentation algorithm was created that was specific to each posture 
(prone, supine or side) using basic image processing techniques and known anthropometric measurements. The three PSM technologies considered in this thesis all exhibit some level of creep response under continuo us loading, leading to a signal that never truly settles. A creep compensation algorithm was also created to account for this continual increase in pressure by de-trending the signal and restoring the DC component. Finally ANOVA statistical analysis was performed based on these results. A piecewise variable comparison was conducted to identify if the means of each sensor-occupied session were significantly different.

As expected, the results for the prone posture produced the clearest pressure response, due to the bladder and stomach regions being in direct contact with the mattress and hence the PSM. In this position the consecutive sessions of no change were not significantly different, while the consecutive sessions where changes in fluid did occur were significantly different with a p-value $<0.05$. This was even clearer when looking at the torso ROI. While in a supine and side position, the participant's skeletal system distributed the mass from the bladder and stomach to other regions of the body, making detection more difficult. The introduction of more participants is essential in order to fully quantify the capabilities of this system. However, these results are quite promising.

Being able to accurately and non-invasively monitor minute changes in fluid distribution can lead to better monitoring procedures for conditions such as CHF and nocturia. This may lead to earlier identification of health decompensations, reducing the number of long term hospital visits and allowing older adults to live at home safely and comfortably for longer. 


\subsection{CONTRibutions}

This thesis has provided four main contributions. The first contribution being the preliminary work used to reduce the confounding factors associated with PSM testing by creating an anthropometric human body model to eliminate noise introduced by human participants [10], [15]. The second contribution was identifying that it was indeed possible to track external mass application (modeling fluid retention) under idealized conditions using PSM [12]. The third contribution included the first iteration of a ROI extraction algorithm in conjunction with the introduction of human participants. External mass was applied to key regions of the lower body over a series of experiments and the increase in pressure associated with the addition of mass was observed. Finally, the fourth contribution was the final set of algorithms containing the automatic ROI segmentation based on image processing techniques and creep compensation [14]. This work also demonstrated that we were able to use PSMs to track, not only external mass applications, but internal changes in fluid that were induced by asking a participant to drink fluid and subsequently void their bladder. Particularly in the prone position, statistically significant changes in observed pressure were observed for drinking and voiding events.

\subsection{Limitations}

\subsubsection{HUMAN MOVEMENT}

The human body is in constant motion, from very small muscle tremors and blood flow to the constant breathing movement. Additionally, dynamic movement experienced during some stages of sleep will influence the pressure response and may lead false indications of mass change [35], [66]. 


\subsubsection{POSTURE}

Patient posture during data recording must also be accounted for. Work conducted in our lab has previously demonstrated that it is possible to detect patient posture under static conditions [32]. This thesis also demonstrates that fluid distribution is measureable using the PSM in the prone, supine, and side positions. The problem becomes more complex when dynamic conditions are introduced (e.g. restless sleep).

PSMs do not directly measure a patient's mass, but quantify the contact pressure and contact area. This means that, due to limited sensitivity and sensel saturation, and the relative location of the mass applied, multiple pressure values can be observed based on the same applied mass. This phenomenon may occur when an individual is lying in a supine position vs. when they are sitting up. Their mass remains consistent, but the pressure response will appear larger while sitting due to the mass transfer from the upper body. Therefore, a posture identification system is needed in order to identify when an individual is either prone or supine for an accurate comparison. Foubert et al. have developed a posture recognition system using pressure sensors that provided a $80-90 \%$ detection accuracy for eight distinct postures [32]. Adaptation of their classification system may be able to account for this confounding factor when tracking mass distribution changes.

\subsubsection{PARTial PSM COVERAGE}

While the transition to the piezo-electric mats represented an improvement in sensel density, unfortunately, these PSMs do not cover the entire mattress. Therefore, errors may be introduced when a person's mass is not entirely applied to the PSM [85]. When only part of the total body mass is applied to the PSM, false changes in mass may be identified. Shifting of mass while only partially on the pressure sensors may be falsely identified as a 
change in mass distribution. Using larger mats that cover the entire bed surface will help address this potential confounding factor.

\subsection{FUTURE WORK}

This section highlights some factors that must be addressed prior to real-world implementation of the algorithm described in this thesis. Some of these factors have been addressed or partially addressed by the introduction of ROI segmentation and creep compensation. Other factors may be addressed by implementing the work of previous students that have used PSMs to measure other health related signals.

For all participant experiments in this thesis, drinking/consumption events and bladder voiding events were approved under the ethics protocol (CUREB approval \#103430230). Future work may include an application to the ethics board to also include asking participants to fast prior to experimentation. It is suspected that the pressure response may be influenced by food consumption and digestion, which may confound fluid distribution detection. Asking participants to fast prior to experimentation may determine if this is an issue that needs to be addressed computationally during analysis.

Further testing is needed to track fluid as it is absorbed and distributed throughout the body, filtered by the kidneys and returned to the bladder in preparation for urination. A temporal comparison of the spatially average pressure response from data collected in the final experiment is planned to address this area of future work. Due to the creep response and low digital resolution of the piezo-resistive PSM, the introduction of a PSM that has both a high spatial resolution and a high digital resolution may be needed for future measurements because the changes we are interested in are very small. This may provide a more definitive explanation about how long it takes for fluid to travel through the body 
and how much is actually absorbed. The application of computer simulations (e.g. Comsol) to model scenarios associated with fluid intake, absorption, and distribution could allow for multiple conditions to be evaluated in a shorter period of time. Additionally, modeling the fluid distributional pattern that is expected in CHF patients may provide a baseline measurement for the identification of fluid in true cases.

It is proposed that the application of the PSM to peritoneal dialysis patients be investigated. While an individual is undergoing this treatment, the amount of fluid added to the blood and the amount of fluid filtered out is constantly recorded by the dialys is machine. This could be used as a gold standard measurement to directly relate pressure response to fluid input and output.

This work was a preliminary investigation into the PSM's ability to track fluid changes. The introduction of more participants is necessary to fully evaluate this method of fluid tracking and is planned for future work. Additionally, a more thorough investigation is needed with more participants in order to fully characterize the fluid cycle. Measurements of the amount of fluid expelled would also allow for the computation of how much fluid is being absorbed over a defined period of time.

As mentioned, the algorithm developed here, can be applied to any PSM technology. The introduction of novel pressure sensors may lead to better fluid tracking results. There are a few novel pressure sensors being developed; including one being designed by a fellow graduate student here at Carleton University, the pressure sensitive bed sheet developed by studiollabs [39], and the pressure sensitive fabric being implemented in clothing at Google's Project Jacquard [38]. This work is ready to leverage improvements in sensor technologies. 


\section{Appendix A: Contribution 2 \& 3 Supplemental Materials}

\section{A.1 Model Results}
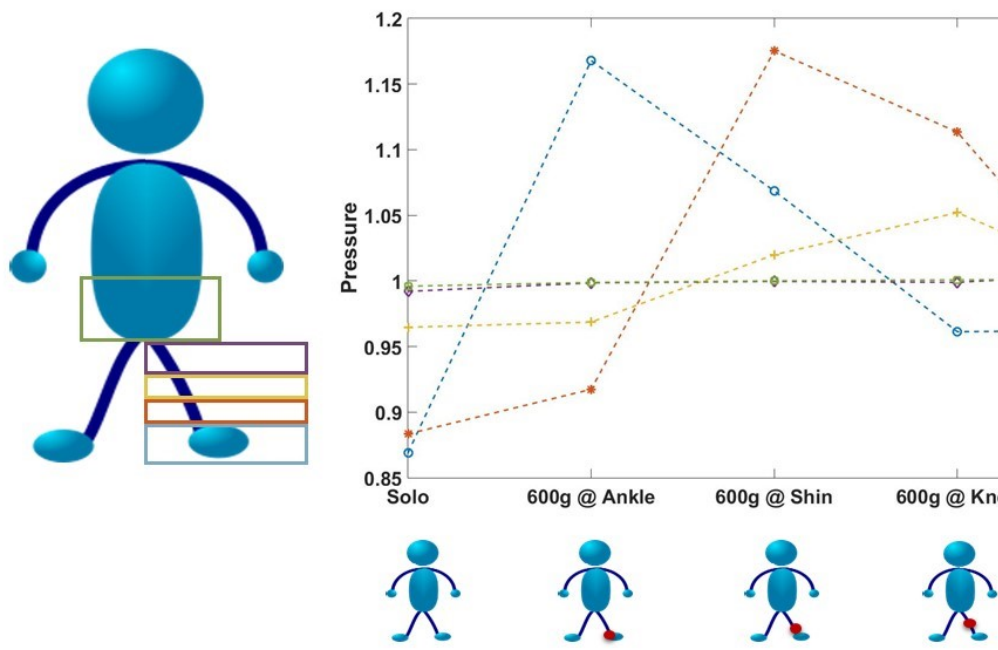

600g@ Thigh

600g@ Abdomen

FIGURE 33. MODEL PRESSURE VARIATION AT EACHREGION OVER ALL SESSIONS, WHILE USING THE FIBRE-OPTIC BASED MEASUREMENT TECHNOLOGY 

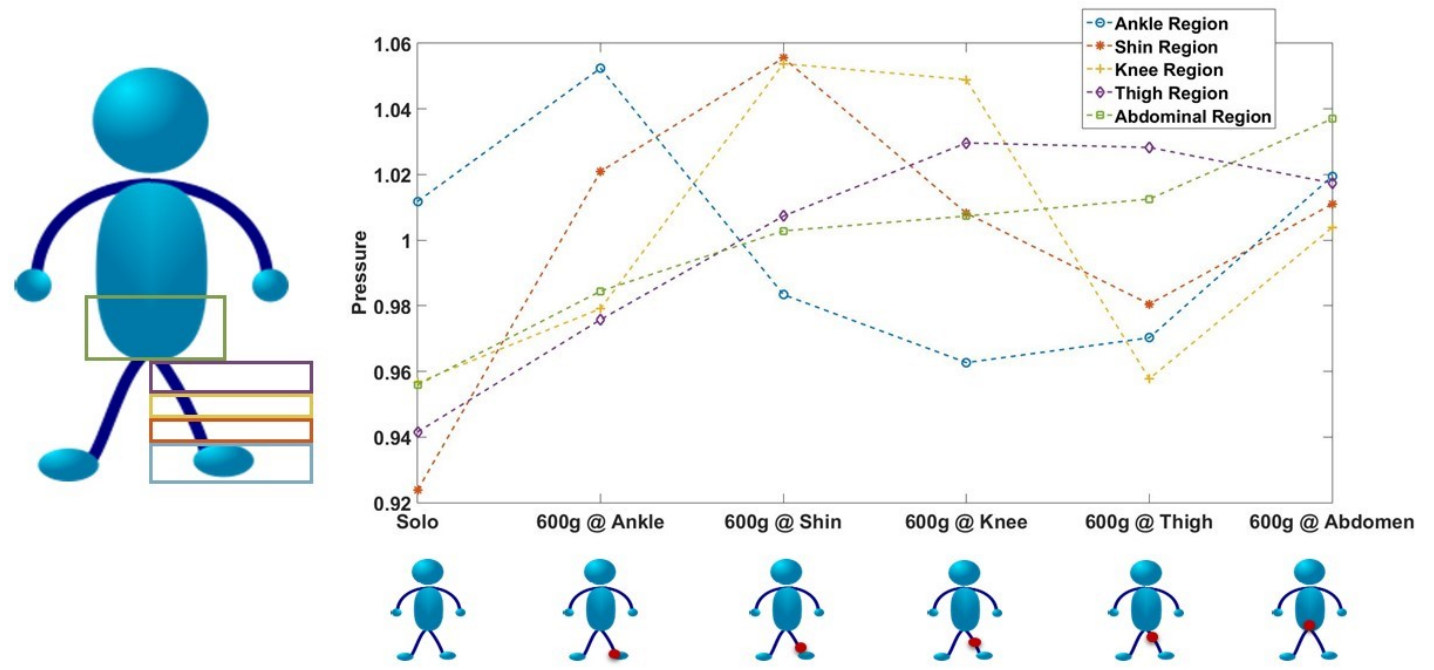

FigURE 34. MODEL PRESSURE VARIATION AT EACH REGION OVER ALL SESSIONS, WHILE USING THE PIEZORESIST IVE BASED MEASUREMENT TECHNOLOGY

\section{A.2 PARTICIPANT 2}
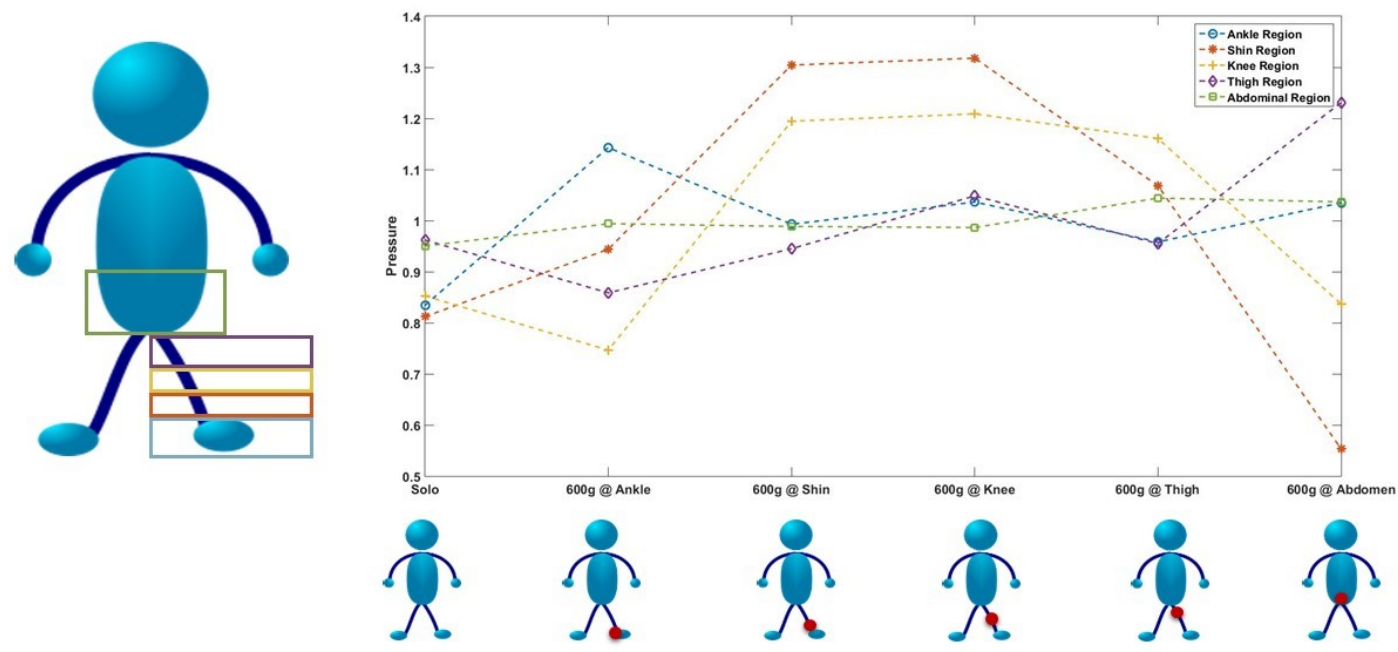

FIGURE 35. PARTICIPANT 2 PRESSURE VARIATION AT EACH REGION OVER ALL SESSIONS, WHILE USING THE FIBRE-OPT IC BASED MEASUREMENT TECHNOLOGY 

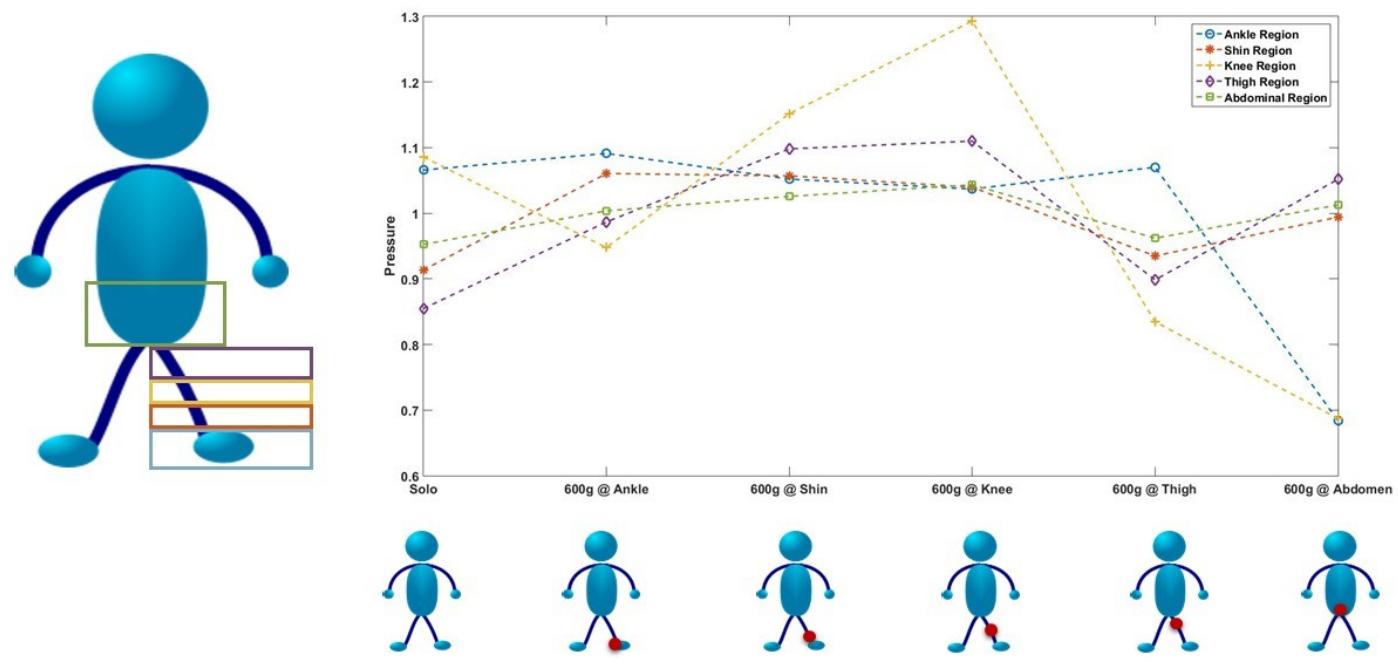

FIGURE 36. PARTICIPANT 2 PRESSURE VARIATION AT EACH REGION OVER ALL SESSIONS, WHILE USING THE PIEZO-RESIST IVE BASED MEASUREMENT TECHNOLOGY

\section{A.3 Participant 3}
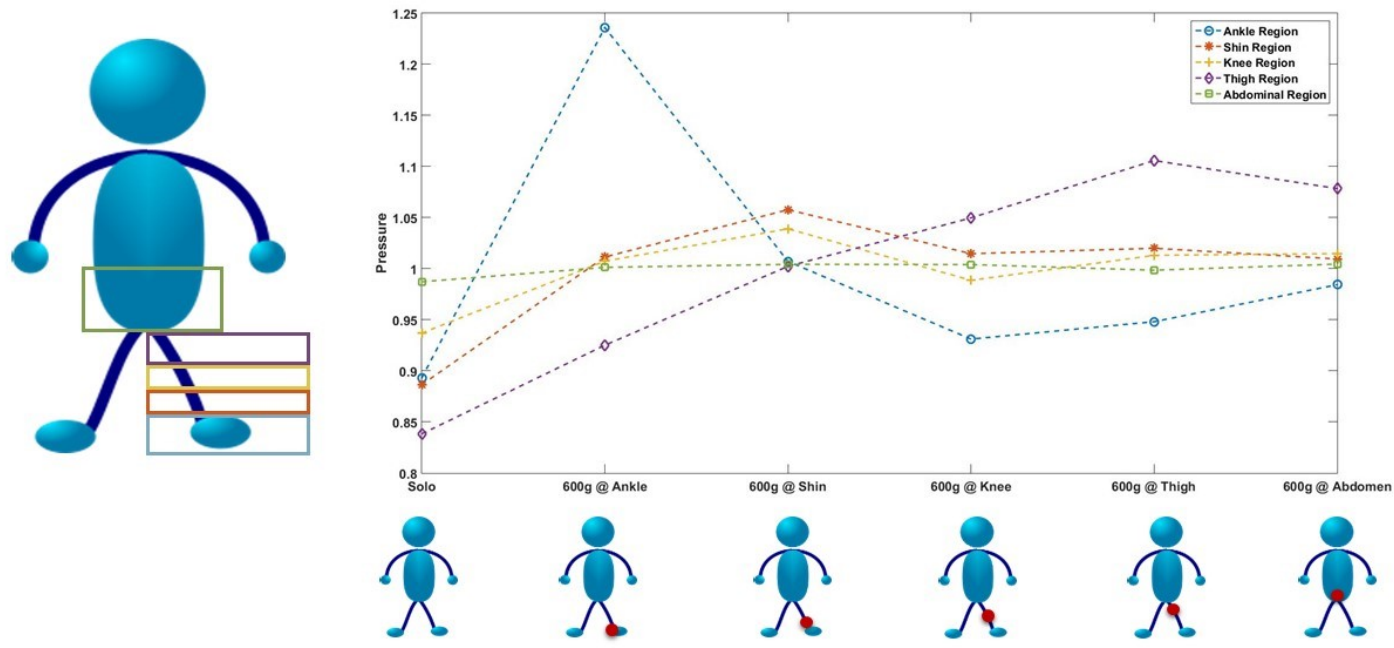

FIGURE 37. PARTICIPANT 3 PRESSURE VARIATION AT EACH REGION OVER ALL SESSIONS, WHILE USING THE FIBRE-OPT IC BASED MEASUREMENT TECHNOLOGY 

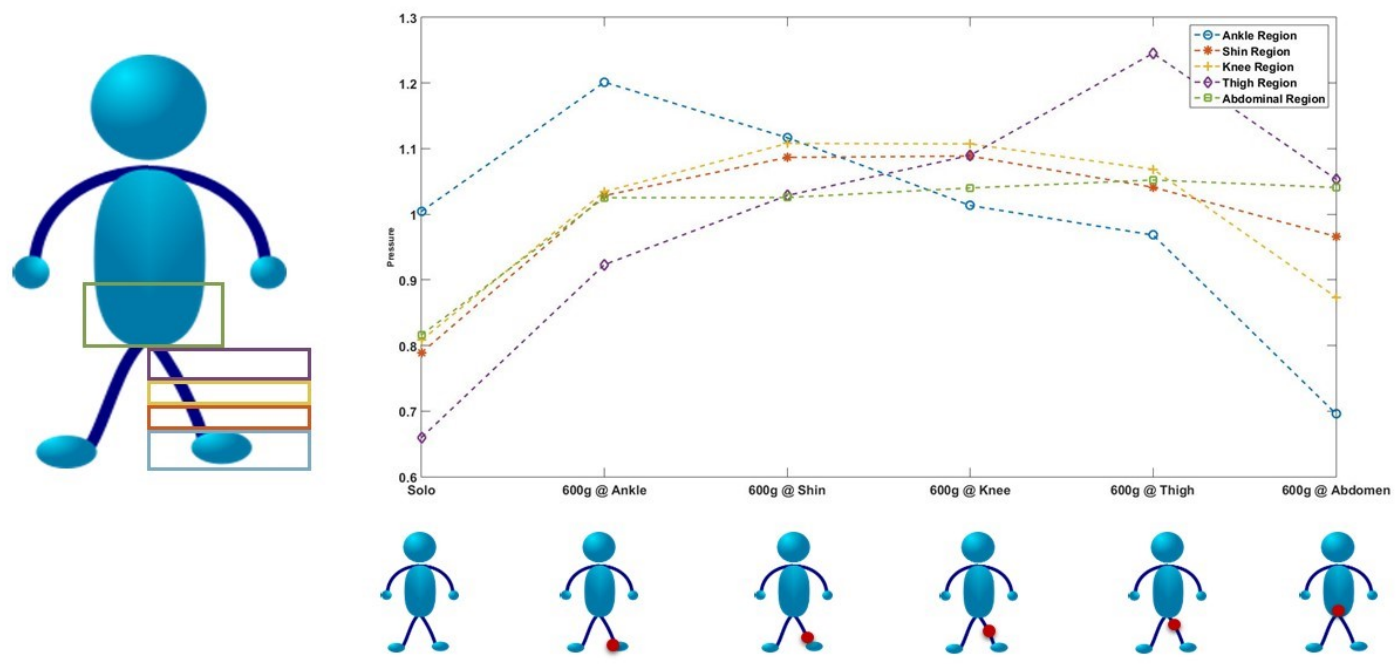

FIGURE 38. PARTICIPANT 3 PRESSURE VARIATION AT EACH REGION OVER ALL SESSIONS, WHILE USING THE PIEZO-RESIST IVE BASED MEASUREMENT TECHNOLOGY 


\section{Appendix B Contribution 4 Supplemental Materials}

\section{B.1. Prone}

\begin{tabular}{|c|c|c|c|c|c|}
\hline \multicolumn{6}{|c|}{ Prone - Whole PSM } \\
\hline 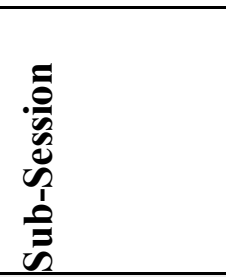 & 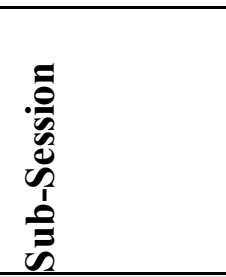 & 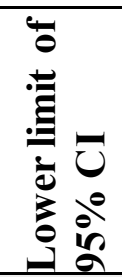 & 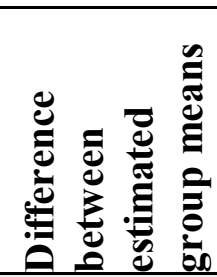 & 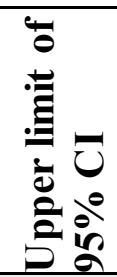 & 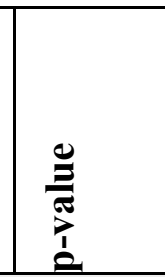 \\
\hline 1 - Initial & $\begin{array}{l}2 \text { - After } 1^{\text {st }} \\
\text { No Change }\end{array}$ & -0.01 & -0.01 & -0.00 & $2.1 \mathrm{E}-08$ \\
\hline 1 & 3 & 0.01 & 0.01 & 0.01 & $2.1 \mathrm{E}-08$ \\
\hline 1 & 4 & 0.00 & 0.00 & 0.01 & $2.1 \mathrm{E}-08$ \\
\hline 1 & 5 & 0.01 & 0.01 & 0.01 & $2.1 \mathrm{E}-08$ \\
\hline 1 & 6 & 0.01 & 0.01 & 0.01 & $2.1 \mathrm{E}-08$ \\
\hline $\begin{array}{l}2 \text { - After 1st } \\
\text { No Change }\end{array}$ & $\begin{array}{l}\text { - After } \\
\text { Small Void }\end{array}$ & 0.02 & 0.02 & 0.02 & $2.1 \mathrm{E}-08$ \\
\hline 2 & 4 & 0.01 & 0.01 & 0.01 & $2.1 \mathrm{E}-08$ \\
\hline 2 & 5 & 0.01 & 0.02 & 0.02 & $2.1 \mathrm{E}-08$ \\
\hline 2 & 6 & 0.01 & 0.02 & 0.02 & $2.1 \mathrm{E}-08$ \\
\hline $\begin{array}{l}\text { - After } \\
\text { Small Void }\end{array}$ & $\begin{array}{l}4 \text { - After } \\
\text { Drinking }\end{array}$ & -0.01 & -0.01 & -0.01 & $2.1 \mathrm{E}-08$ \\
\hline 3 & 5 & -0.00 & -0.00 & -0.00 & $4.7 \mathrm{E}-03$ \\
\hline 3 & 6 & -0.00 & -0.00 & -0.00 & $1.9 \mathrm{E}-02$ \\
\hline $\begin{array}{l}4 \text { - After } \\
\text { Drinking }\end{array}$ & $\begin{array}{l}5 \text { - After } \\
\text { Large Void }\end{array}$ & 0.00 & 0.01 & 0.01 & $2.1 \mathrm{E}-08$ \\
\hline 4 & 6 & 0.00 & 0.01 & 0.01 & $2.1 \mathrm{E}-08$ \\
\hline $\begin{array}{l}5 \text { - After } \\
\text { Large Void }\end{array}$ & $\begin{array}{l}6 \text { - After } 2^{\text {nd }} \\
\text { No Change }\end{array}$ & -0.00 & 0.00 & 0.00 & $10.0 \mathrm{E}-01$ \\
\hline
\end{tabular}




\begin{tabular}{|c|c|c|c|c|c|}
\hline \multicolumn{6}{|c|}{ Prone - Hip ROI } \\
\hline 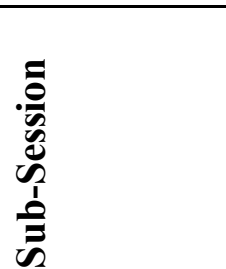 & 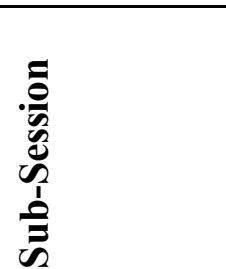 & 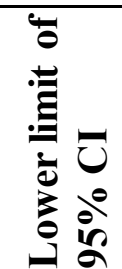 & 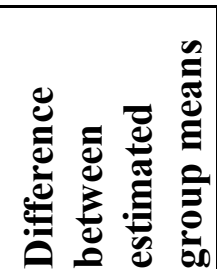 & 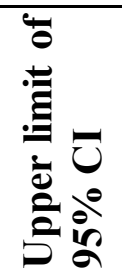 & 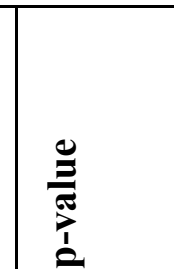 \\
\hline 1 - Initial & $\begin{array}{l}2 \text { - After } 1^{\text {st }} \\
\text { No Change }\end{array}$ & -0.00 & 0.00 & 0.00 & $9.3 \mathrm{E}-01$ \\
\hline 1 & 3 & 0.00 & 0.01 & 0.01 & $2.1 \mathrm{E}-08$ \\
\hline 1 & 4 & -0.00 & 0.00 & 0.00 & $10.0 \mathrm{E}-01$ \\
\hline$\overline{1}$ & 5 & 0.00 & 0.00 & 0.00 & $2.1 \mathrm{E}-08$ \\
\hline 1 & 6 & 0.00 & 0.00 & 0.00 & $2.1 \mathrm{E}-08$ \\
\hline $\begin{array}{l}2 \text { - After 1st } \\
\text { No Change }\end{array}$ & $\begin{array}{l}3 \text { - After } \\
\text { Small Void }\end{array}$ & 0.00 & 0.00 & 0.01 & $2.1 \mathrm{E}-08$ \\
\hline 2 & 4 & -0.00 & -0.00 & 0.00 & $10.0 \mathrm{E}-01$ \\
\hline 2 & 5 & 0.00 & 0.00 & 0.00 & $2.1 \mathrm{E}-08$ \\
\hline 2 & 6 & 0.00 & 0.00 & 0.00 & $2.1 \mathrm{E}-08$ \\
\hline $\begin{array}{l}\text { - After } \\
\text { Small Void }\end{array}$ & $\begin{array}{l}4 \text { - After } \\
\text { Drinking }\end{array}$ & $\begin{array}{l}-0.01 \\
\end{array}$ & -0.00 & -0.00 & $2.1 \mathrm{E}-08$ \\
\hline 3 & 5 & -0.00 & -0.00 & -0.00 & $2.1 \mathrm{E}-08$ \\
\hline 3 & 6 & -0.00 & -0.00 & -0.00 & $2.1 \mathrm{E}-08$ \\
\hline $\begin{array}{l}4 \text { - After } \\
\text { Drinking }\end{array}$ & $\begin{array}{l}5 \text { - After } \\
\text { Large Void }\end{array}$ & 0.00 & 0.00 & 0.00 & $2.1 \mathrm{E}-08$ \\
\hline 4 & 6 & 0.00 & 0.00 & 0.00 & $2.1 \mathrm{E}-08$ \\
\hline $\begin{array}{l}\text { - After } \\
\text { Large Void }\end{array}$ & $\begin{array}{l}6 \text { - After } 2^{\text {nd }} \\
\text { No Change }\end{array}$ & -0.00 & -0.00 & 0.00 & $2.7 \mathrm{E}-01$ \\
\hline
\end{tabular}




\begin{tabular}{|c|c|c|c|c|c|}
\hline \multicolumn{6}{|c|}{ Prone - Upper Leg ROI } \\
\hline 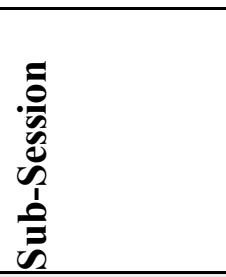 & $\begin{array}{l}5 \\
. \overline{0} \\
0 \\
0 \\
0 \\
1 \\
0 \\
\overline{0}\end{array}$ & 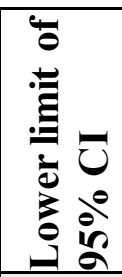 & 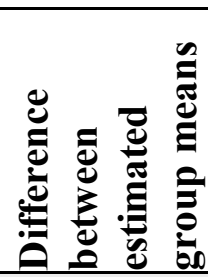 & 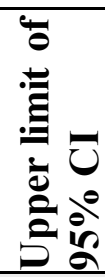 & 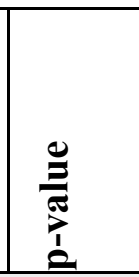 \\
\hline 1 - Initial & $\begin{array}{l}2 \text { - After } 1^{\text {st }} \\
\text { No Change }\end{array}$ & -0.00 & 0.00 & 0.00 & $1.9 \mathrm{E}-01$ \\
\hline 1 & 3 & 0.00 & 0.00 & 0.00 & $2.1 \mathrm{E}-08$ \\
\hline 1 & 4 & 0.00 & 0.00 & 0.00 & $2.1 \mathrm{E}-08$ \\
\hline 1 & 5 & 0.00 & 0.00 & 0.00 & $2.1 \mathrm{E}-08$ \\
\hline 1 & 6 & 0.00 & 0.00 & 0.00 & $2.1 \mathrm{E}-08$ \\
\hline $\begin{array}{l}2 \text { - After 1st } \\
\text { No Change }\end{array}$ & $\begin{array}{l}\text { - After } \\
\text { Small Void }\end{array}$ & 0.00 & 0.00 & 0.00 & $2.1 \mathrm{E}-08$ \\
\hline 2 & 4 & 0.00 & 0.00 & 0.00 & $2.1 \mathrm{E}-08$ \\
\hline 2 & 5 & 0.00 & 0.00 & 0.00 & $2.1 \mathrm{E}-08$ \\
\hline 2 & 6 & 0.00 & 0.00 & 0.00 & $2.1 \mathrm{E}-08$ \\
\hline $\begin{array}{l}3 \text { - After } \\
\text { Small Void }\end{array}$ & $\begin{array}{l}4 \text { - After } \\
\text { Drinking }\end{array}$ & -0.00 & 0.00 & 0.00 & $4.0 \mathrm{E}-01$ \\
\hline 3 & 5 & 0.00 & 0.00 & 0.00 & $2.1 \mathrm{E}-08$ \\
\hline 3 & 6 & 0.00 & 0.00 & 0.00 & $2.1 \mathrm{E}-08$ \\
\hline $\begin{array}{l}4 \text { - After } \\
\text { Drinking }\end{array}$ & $\begin{array}{l}5 \text { - After } \\
\text { Large Void }\end{array}$ & 0.00 & 0.00 & 0.00 & $2.1 \mathrm{E}-08$ \\
\hline 4 & 6 & 0.00 & 0.00 & 0.00 & $2.1 \mathrm{E}-08$ \\
\hline $\begin{array}{l}5 \text { - After } \\
\text { Large Void }\end{array}$ & $\begin{array}{l}6 \text { - After } 2^{\text {nd }} \\
\text { No Change }\end{array}$ & 0.00 & 0.00 & 0.00 & $9.1 \mathrm{E}-03$ \\
\hline
\end{tabular}




\section{B.2. Supine}

\begin{tabular}{|c|c|c|c|c|c|}
\hline \multicolumn{6}{|c|}{ Supine - Whole PSM } \\
\hline 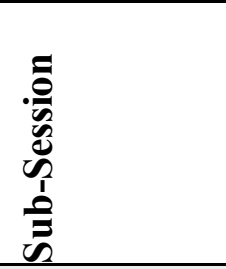 & 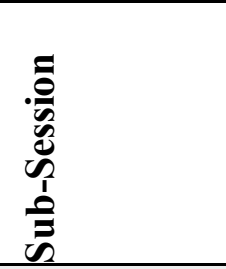 & 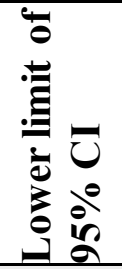 & 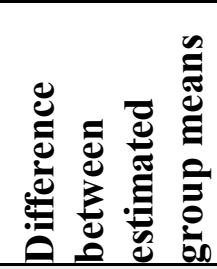 & 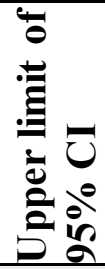 & 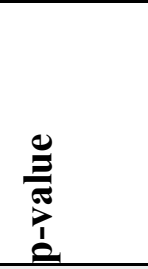 \\
\hline 1 - Initial & $\begin{array}{l}2 \text { - After } 1^{\text {st }} \\
\text { No Change }\end{array}$ & -0.01 & -0.01 & -0.00 & $2.1 \mathrm{E}-08$ \\
\hline 1 & 3 & -0.01 & -0.01 & -0.01 & $2.1 \mathrm{E}-08$ \\
\hline 1 & 4 & -0.02 & -0.02 & -0.02 & $2.1 \mathrm{E}-08$ \\
\hline 1 & 5 & -0.02 & -0.02 & -0.02 & $2.1 \mathrm{E}-08$ \\
\hline 1 & 6 & -0.02 & -0.02 & -0.02 & $2.1 \mathrm{E}-08$ \\
\hline $\begin{array}{l}2 \text { - After 1st } \\
\text { No Change }\end{array}$ & $\begin{array}{l}3 \text { - After } \\
\text { Small Void }\end{array}$ & -0.00 & -0.00 & 0.00 & $4.8 \mathrm{E}-02$ \\
\hline 2 & 4 & -0.01 & -0.01 & -0.01 & $2.1 \mathrm{E}-08$ \\
\hline 2 & 5 & -0.02 & -0.01 & -0.01 & $2.1 \mathrm{E}-08$ \\
\hline 2 & 6 & -0.02 & -0.01 & -0.01 & $2.1 \mathrm{E}-08$ \\
\hline $\begin{array}{l}3 \text { - After } \\
\text { Small Void }\end{array}$ & $\begin{array}{l}4 \text { - After } \\
\text { Drinking }\end{array}$ & -0.01 & -0.01 & -0.01 & $2.1 \mathrm{E}-08$ \\
\hline 3 & 5 & -0.01 & -0.01 & -0.01 & $2.1 \mathrm{E}-08$ \\
\hline 3 & 6 & -0.01 & -0.01 & -0.01 & $2.1 \mathrm{E}-08$ \\
\hline $\begin{array}{l}4 \text { - After } \\
\text { Drinking }\end{array}$ & $\begin{array}{l}5 \text { - After } \\
\text { Large Void }\end{array}$ & -0.00 & -0.00 & 0.00 & $6.8 \mathrm{E}-01$ \\
\hline 4 & 6 & -0.00 & -0.00 & 0.00 & $3.1 \mathrm{E}-01$ \\
\hline $\begin{array}{l}5 \text { - After } \\
\text { Large Void }\end{array}$ & $\begin{array}{l}6 \text { - After } 2^{\text {nd }} \\
\text { No Change }\end{array}$ & -0.00 & -0.00 & 0.00 & $9.9 \mathrm{E}-01$ \\
\hline
\end{tabular}




\begin{tabular}{|c|c|c|c|c|c|}
\hline \multicolumn{6}{|c|}{ Supine - Hip ROI } \\
\hline 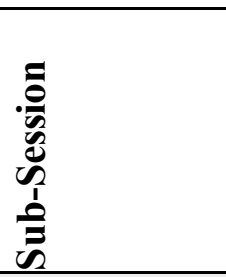 & 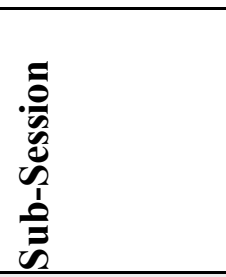 & 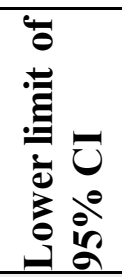 & 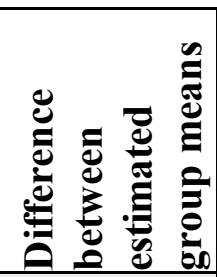 & 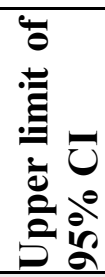 & 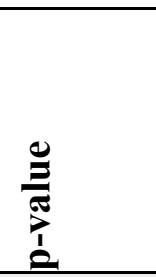 \\
\hline 1 - Initial & $\begin{array}{l}2 \text { - After } 1^{\text {st }} \\
\text { No Change }\end{array}$ & -0.01 & -0.00 & -0.00 & $2.1 \mathrm{E}-08$ \\
\hline 1 & 3 & -0.00 & -0.00 & -0.00 & $5.0 \mathrm{E}-06$ \\
\hline 1 & 4 & -0.01 & -0.01 & -0.01 & $2.1 \mathrm{E}-08$ \\
\hline 1 & 5 & -0.01 & -0.01 & -0.01 & $2.1 \mathrm{E}-08$ \\
\hline 1 & 6 & -0.01 & -0.01 & -0.01 & $2.1 \mathrm{E}-08$ \\
\hline $\begin{array}{l}2 \text { - After 1st } \\
\text { No Change }\end{array}$ & $\begin{array}{l}\text { - After } \\
\text { Small Void }\end{array}$ & -0.00 & 0.00 & 0.00 & $3.3 \mathrm{E}-01$ \\
\hline 2 & 4 & $\begin{array}{c}-0.01 \\
\end{array}$ & $\begin{array}{l}-0.01 \\
\end{array}$ & -0.01 & $2.1 \mathrm{E}-08$ \\
\hline 2 & 5 & -0.00 & -0.00 & -0.00 & $4.6 \mathrm{E}-06$ \\
\hline 2 & 6 & -0.01 & -0.01 & -0.00 & $2.1 \mathrm{E}-08$ \\
\hline $\begin{array}{l}3 \text { - After } \\
\text { Small Void }\end{array}$ & $\begin{array}{l}4 \text { - After } \\
\text { Drinking }\end{array}$ & $\begin{array}{l}-0.01 \\
\end{array}$ & $\begin{array}{l}-0.01 \\
\end{array}$ & -0.01 & $2.1 \mathrm{E}-08$ \\
\hline 3 & 5 & -0.01 & -0.00 & -0.00 & $2.1 \mathrm{E}-08$ \\
\hline 3 & 6 & -0.01 & -0.01 & -0.01 & $2.1 \mathrm{E}-08$ \\
\hline $\begin{array}{l}4 \text { - After } \\
\text { Drinking }\end{array}$ & $\begin{array}{l}5 \text { - After } \\
\text { Large Void }\end{array}$ & 0.00 & 0.01 & 0.01 & $2.1 \mathrm{E}-08$ \\
\hline 4 & 6 & 0.00 & 0.00 & 0.00 & $2.6 \mathrm{E}-06$ \\
\hline $\begin{array}{l}5 \text { - After } \\
\text { Large Void }\end{array}$ & $\begin{array}{l}6 \text { - After } 2^{\text {nd }} \\
\text { No Change }\end{array}$ & -0.00 & -0.00 & -0.00 & $3.2 \mathrm{E}-05$ \\
\hline
\end{tabular}




\section{B.3. Side}

\begin{tabular}{|c|c|c|c|c|c|}
\hline \multicolumn{6}{|c|}{ Side - Whole PSM } \\
\hline 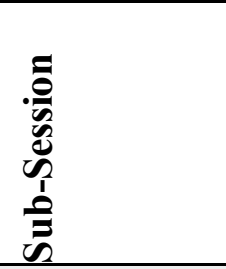 & 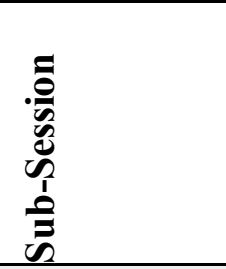 & 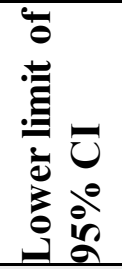 & 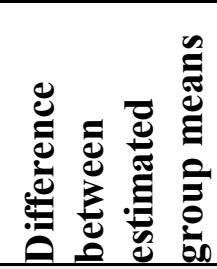 & 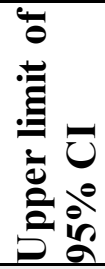 & 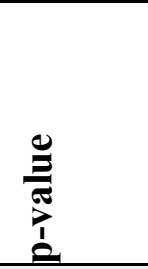 \\
\hline 1 - Initial & $\begin{array}{l}2 \text { - After } 1^{\text {st }} \\
\text { No Change }\end{array}$ & -0.02 & -0.01 & -0.01 & $2.2 \mathrm{E}-08$ \\
\hline 1 & 3 & -0.02 & -0.01 & -0.01 & $2.1 \mathrm{E}-08$ \\
\hline 1 & 4 & -0.04 & -0.04 & -0.03 & $2.1 \mathrm{E}-08$ \\
\hline 1 & 5 & -0.03 & -0.03 & -0.02 & $2.1 \mathrm{E}-08$ \\
\hline 1 & 6 & -0.04 & -0.03 & -0.03 & $2.1 \mathrm{E}-08$ \\
\hline $\begin{array}{l}2 \text { - After 1st } \\
\text { No Change }\end{array}$ & $\begin{array}{l}3 \text { - After } \\
\text { Small Void }\end{array}$ & -0.01 & -0.00 & 0.00 & $5.4 \mathrm{E}-01$ \\
\hline 2 & 4 & -0.03 & -0.02 & -0.01 & $2.1 \mathrm{E}-08$ \\
\hline 2 & 5 & -0.02 & -0.01 & -0.01 & $2.1 \mathrm{E}-08$ \\
\hline 2 & 6 & -0.03 & -0.02 & -0.02 & $2.1 \mathrm{E}-08$ \\
\hline $\begin{array}{l}3 \text { - After } \\
\text { Small Void }\end{array}$ & $\begin{array}{l}4 \text { - After } \\
\text { Drinking }\end{array}$ & -0.03 & -0.02 & -0.02 & $2.1 \mathrm{E}-08$ \\
\hline 3 & 5 & -0.02 & -0.01 & -0.01 & $2.1 \mathrm{E}-08$ \\
\hline 3 & 6 & -0.02 & -0.02 & -0.02 & $2.1 \mathrm{E}-08$ \\
\hline $\begin{array}{l}4 \text { - After } \\
\text { Drinking }\end{array}$ & $\begin{array}{l}5 \text { - After } \\
\text { Large Void }\end{array}$ & 0.00 & 0.01 & 0.01 & $1.5 \mathrm{E}-06$ \\
\hline 4 & 6 & -0.00 & 0.00 & 0.01 & $9.6 \mathrm{E}-01$ \\
\hline $\begin{array}{l}5 \text { - After } \\
\text { Large Void }\end{array}$ & $\begin{array}{l}6 \text { - After } 2^{\text {nd }} \\
\text { No Change }\end{array}$ & -0.01 & -0.01 & -0.00 & $5.2 \mathrm{E}-05$ \\
\hline
\end{tabular}




\begin{tabular}{|c|c|c|c|c|c|}
\hline \multicolumn{6}{|c|}{ Side - Hip ROI } \\
\hline 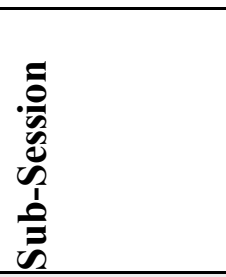 & 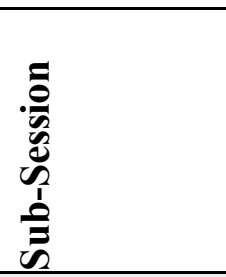 & 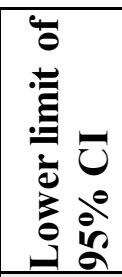 & 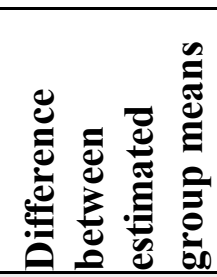 & 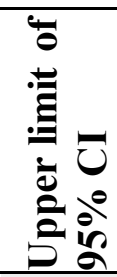 & 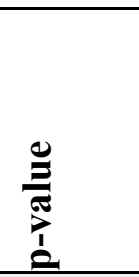 \\
\hline 1 - Initial & $\begin{array}{l}2 \text { - After } 1^{\text {st }} \\
\text { No Change }\end{array}$ & 0.00 & 0.00 & 0.00 & $2.1 \mathrm{E}-08$ \\
\hline 1 & 3 & -0.01 & -0.01 & -0.01 & $2.1 \mathrm{E}-08$ \\
\hline 1 & 4 & -0.01 & -0.01 & -0.01 & $2.1 \mathrm{E}-08$ \\
\hline 1 & 5 & -0.01 & -0.01 & -0.01 & $2.1 \mathrm{E}-08$ \\
\hline 1 & 6 & 0.02 & 0.02 & 0.02 & $2.1 \mathrm{E}-08$ \\
\hline $\begin{array}{l}2 \text { - After 1st } \\
\text { No Change }\end{array}$ & $\begin{array}{l}\text { - After } \\
\text { Small Void }\end{array}$ & -0.02 & -0.02 & -0.01 & $2.1 \mathrm{E}-08$ \\
\hline 2 & 4 & -0.01 & -0.01 & -0.01 & $2.1 \mathrm{E}-08$ \\
\hline 2 & 5 & -0.01 & -0.01 & -0.01 & $2.1 \mathrm{E}-08$ \\
\hline 2 & 6 & 0.01 & 0.01 & 0.01 & $2.1 \mathrm{E}-08$ \\
\hline $\begin{array}{l}\text { 3- After } \\
\text { Small Void }\end{array}$ & $\begin{array}{l}4 \text { - After } \\
\text { Drinking }\end{array}$ & 0.00 & 0.00 & 0.00 & $2.1 \mathrm{E}-08$ \\
\hline 3 & 5 & 0.00 & 0.00 & 0.00 & $3.1 \mathrm{E}-04$ \\
\hline 3 & 6 & 0.03 & 0.03 & 0.03 & $2.1 \mathrm{E}-08$ \\
\hline $\begin{array}{l}4 \text { - After } \\
\text { Drinking }\end{array}$ & $\begin{array}{l}5 \text { - After } \\
\text { Large Void }\end{array}$ & -0.00 & -0.00 & -0.00 & $1.3 \mathrm{E}-02$ \\
\hline 4 & 6 & 0.02 & 0.03 & 0.03 & $2.1 \mathrm{E}-08$ \\
\hline $\begin{array}{l}5 \text { - After } \\
\text { Large Void }\end{array}$ & $\begin{array}{l}6 \text { - After } 2^{\text {nd }} \\
\text { No Change }\end{array}$ & 0.03 & 0.03 & 0.03 & $2.1 \mathrm{E}-08$ \\
\hline
\end{tabular}




\begin{tabular}{|c|c|c|c|c|c|}
\hline \multicolumn{6}{|c|}{ Side - Upper Leg ROI } \\
\hline 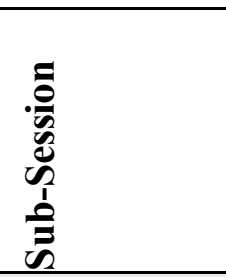 & 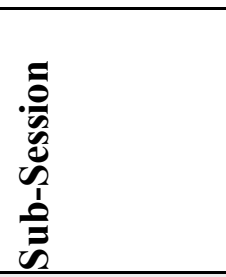 & 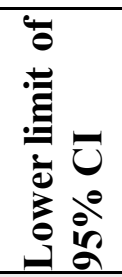 & 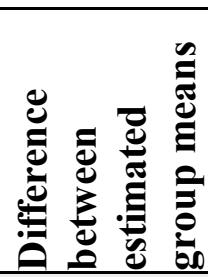 & 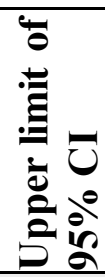 & 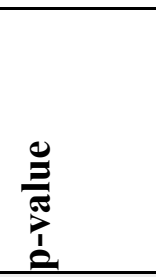 \\
\hline 1 - Initial & $\begin{array}{l}2 \text { - After } 1^{\text {st }} \\
\text { No Change }\end{array}$ & -0.00 & 0.00 & 0.00 & $6.2 \mathrm{E}-01$ \\
\hline 1 & 3 & 0.01 & 0.01 & 0.01 & $2.1 \mathrm{E}-08$ \\
\hline 1 & 4 & 0.00 & 0.00 & 0.00 & $2.1 \mathrm{E}-08$ \\
\hline 1 & 5 & 0.00 & 0.00 & 0.00 & $2.1 \mathrm{E}-08$ \\
\hline 1 & 6 & -0.02 & -0.02 & -0.02 & $2.1 \mathrm{E}-08$ \\
\hline $\begin{array}{l}2 \text { - After 1st } \\
\text { No Change }\end{array}$ & $\begin{array}{l}\text { - After } \\
\text { Small Void }\end{array}$ & 0.01 & 0.01 & 0.01 & $2.1 \mathrm{E}-08$ \\
\hline 2 & 4 & 0.00 & 0.00 & 0.00 & $2.4 \mathrm{E}-08$ \\
\hline 2 & 5 & 0.00 & 0.00 & 0.00 & $2.6 \mathrm{E}-08$ \\
\hline 2 & 6 & -0.02 & -0.02 & -0.02 & $2.1 \mathrm{E}-08$ \\
\hline $\begin{array}{l}3 \text { - After } \\
\text { Small Void }\end{array}$ & $\begin{array}{l}4 \text { - After } \\
\text { Drinking }\end{array}$ & $\begin{array}{c}-0.01 \\
\end{array}$ & -0.01 & -0.01 & $2.1 \mathrm{E}-08$ \\
\hline 3 & 5 & -0.01 & -0.01 & -0.01 & $2.1 \mathrm{E}-08$ \\
\hline 3 & 6 & -0.03 & -0.03 & -0.03 & $2.1 \mathrm{E}-08$ \\
\hline $\begin{array}{l}4 \text { - After } \\
\text { Drinking }\end{array}$ & $\begin{array}{l}5 \text { - After } \\
\text { Large Void }\end{array}$ & -0.00 & 0.00 & 0.00 & $1.0 \mathrm{E}+00$ \\
\hline 4 & 6 & -0.03 & -0.03 & -0.02 & $2.1 \mathrm{E}-08$ \\
\hline $\begin{array}{l}\text { - After } \\
\text { Large Void }\end{array}$ & $\begin{array}{l}6 \text { - After } 2^{\text {nd }} \\
\text { No Change }\end{array}$ & -0.03 & -0.03 & -0.02 & $2.1 \mathrm{E}-08$ \\
\hline
\end{tabular}




\section{References}

[1] Statistics Canada, "The Canadian Population in 2011: Age and Sex," Ottawa, Canada, 2011.

[2] United Nations Department of Economic and Socail Affairs Populations Division, "World Population Ageing," 2015.

[3] P. Arora, P. Vasa, D. Brenner, K. Iglar, P. McFarlane, H. Morrison, and A. Badawi, "Prevalence Estimates of Chronic Kidney Disease in Canada: Results of a Nationally Representative Survey," Can. Med. Assoc., vol. 185, no. 9, pp. E417-23, 2013.

[4] R. Schrier and W. Wang, "Acute Renal Failure: Definitions, Diagnosis, Pathogenesis, and Therapy," J. Clin. Invest., vol. 114, no. 1, pp. 5-14, 2004.

[5] Public Health Agency of Canada, "Tracking Heart Disease," 2009.

[6] M. S. Figueroa and J. I. Peters, "Congestive Heart Failure: Diagnosis, Pathophysiology, Therapy, and Implications for Respiratory Care.," Respir. Care, vol. 51, pp. 403-412, 2006.

[7] V. Huppert, J. Paulus, U. Paulsen, M. Burkart, B. Wullich, and B. Eskofier, "Quantification of Nighttime Micturition with an Ambulatory Sensor-Based System,” IEEE J. Biomed. Heal. Inform., vol. PP, no. 99, pp. 1-1, 2015.

[8] S. Boongird, N. Shah, T. D. Nolin, and M. L. Unruh, "Nocturia and Aging: Diagnosis and Treatment," Adv. Chronic Kidney Dis., vol. 17, no. 4, pp. e27-e40, 2010.

[9] R. Steele, C. Secombe, and W. Brookes, "Using Wireless Sensor Networks for Aged 
Care: The Patient's Perspective," in Proc. 2006 Pervasive Health Conference and Workshops, 2006, pp. 1-10.

[10] M. Cohen-McFarlane, J. R. Green, R. Goubran, and F. Knoefel, "Characterization of Measurements from Pressure Sensitive Mats using an Anthropomorphic Body Model," in Proc. IEEE Int. Instrum. Meas. Technol. Conf. (I2MTC), 2016, pp. 1-4.

[11] M. Cohen-McFarlane, J. R. Green, F. Knoefel, and R. Goubran, "Characterization of Fibre-Optic Pressure Mats for Long Term Patient Monitoring.” Bruyere Research Institue, Ottawa, 2015.

[12] M. Cohen-McFarlane, J. R. Green, R. Goubran, and F. Knoefel, "Monitoring Congestive Heart Failure using Pressure-Sensitive Mats," in Proc. IEEE Int. Symp. Med. Meas. Appl. (MeMeA), 2016, pp. 1-6.

[13] M. Cohen-McFarlane, R. Goubran, F. Knoefel, and J. R. Green, 'Unobtrusive Monitoring of Congestive Heart Failure.” AGE-WELL AGM, Montreal, 2016.

[14] M. Cohen-McFarlane, J. R. Green, R. A. Goubran, and F. Knoefel, "Smart Monitoring of Fluid Intake and Bladder Voiding using Pressure Sensitive Mats," Proc. IEEE Eng. Med. Biol. Soc, pp. 4921-4924, 2016.

[15] S. Nizami, M. Cohen-McFarlane, J. R. Green, and R. Goubran, "Comparing Metrological Properties of Pressure-Sensitive Mats for Continuous Patient Monitoring," in Proc. IEEE Sensors Applications Symp. (SAS), 2017, pp. 1-6.

[16] United Nations, "World Population Ageing 2013," 2013.

[17] N. N. Aronson and A. Yannarell, "Portrait of Seniors in Canada," Biochim. Biophys. Acta, vol. 413, no. 1, pp. 135-42, 1975.

[18] Canadian Institute for Health Information (CIHI), "Health Care in Canada , 2011 A 
Focus on Seniors and Aging," p. 162, 2011.

[19] Statistics Canada, "Causes of Death, Canada." CANSIM, 2014.

[20] M. S. Figueroa and J. I. Peters, "Congestive Heart Failure: Diagnosis, Pathophysiology, Therapy, and Implications for Respiratory Care," Respir. Care , vol. 51, no. 4, pp. 403-412, Apr. 2006.

[21] C. D. Kemp and J. V. Conte, "The Pathophysiology of Heart Failure," Cardiovasc. Pathol., vol. 21, no. 5, pp. 365-371, 2012.

[22] K. Gudmundsson, P. Lyngå, M. Rosenqvist, and F. Braunschweig, "Monitoring of Daily Body Weight and Intrathoracic Impedance in Heart Failure Patients With a High Risk of Volume Overload Decompensation," Clin. Cardiol., vol. 452, pp. 446$452,2016$.

[23] G. Sergi, L. Lupoli, G. Enzi, S. Volpato, E. Perissinotto, R. Bertani, E. M. Inelmen, P. Bonometto, L. Busetto, a Berton, and a Coin, "Reliability of bioelectrical impedance methods in detecting body fluids in elderly patients with congestive heart failure.," Scand. J. Clin. Lab. Invest., vol. 66, no. 1, pp. 19-30, 2006.

[24] S. Siegel, K. Noblett, J. Mangel, T. Giebling, S. E. Sutherland, and E. T. Bird, "Results of a Prospective, Randomized, Multicenter Study Evaluating Sacral Neuromodulation with Interstim Therapy Compared to Standard Medical Therapy at 6 Months in Subjects with Mild Symptoms of Overactive Bladder," Neurourol. Urodyn., vol. 34, no. 3, pp. 224-230, 2015.

[25] B. M. Eskofier, J. Paulus, U. Paulsen, M. Burkart, B. Wullich, and V. Huppert, "An Ambulatroy Sensor-Based System for Quantification of Nighttime Micturition for Accurate Nocturia Assesment," in Proc. IEEE Eng. Med. Biol. Soc. (EMBC), 2014, 
pp. 566-569.

[26] C. Palnæs Hansen and P. Klarskov, "The accuracy of the frequency-volume chart: Comparison of self-reported and measured volumes," Br. J. Urol., vol. 81, no. 5, pp. 709-711, 1998.

[27] S. Sakar, "Continuous Renal Replacement Therapy (CRRT).," Nat.Rev. Nephrol., vol. 6, pp. 521-529, 2010.

[28] J. C. Y. Lai, Y. Xu, E. Gunawan, E. C. P. Chua, A. Maskooki, Y. L. Guan, K. S. Low, C. B. Soh, and C. L. Poh, "Wireless sensing of human respiratory parameters by low-power ultrawideband impulse radio radar," IEEE Trans. Instrum. Meas., vol. 60, no. 3, pp. 928-938, 2011.

[29] A. M. Chan, N. Selvaraj, N. Ferdosi, and R. Narasimhan, "Wireless Patch Sensor For Remote Monitoring of Heart Rate, Respiration, Activity, and Falls," in Proc. IEEE Eng. Med. Biol. Soc. (EMBC), 2013, pp. 6115-6118.

[30] L. Fanucci, S. Saponara, T. Bacchillone, M. Donati, P. Barba, I. Sanchez-Tato, and C. Carmona, "Sensing Devices and Sensor Signal Processing for Remote Monitoring of Vital Signs in CHF Patients," IEEE. Trans. Instrum. Meas., vol. 62, no. 3, pp. 553-569, 2013.

[31] R. A. Clark, S. C. Inglis, F. A. McAlister, J. G. F. Cleland, and S. Stewart, "Telemonitoring or Structured Telephone Support Programmes for Patients with Chronic Heart Failure: Systematic Review and Meta-Analysis," BMJ, vol. 334, no. 7600, pp. 942-942, 2007.

[32] N. Foubert, A. M. McKee, R. A. Goubran, and F. Knoefel, "Lying and Sitting Posture Recognition and Transition Detection using a Pressure Sensor Array," in 
Proc. IEEE Int. Symp. Med. Meas. Appl. (MeMeA), 2012, pp. 1-6.

[33] E. Marenzi, G. M. Bertolotti, and A. Cristiani, "Design and development of a monitoring system for the interface pressure measurement of seated people," IEEE Trans. Instrum. Meas., vol. 62, no. 3, pp. 570-577, 2013.

[34] S. Cruz, D. Dias, J. C. Viana, and L. A. Rocha, "Inkjet Printed Pressure Sensing Platform for Postural Imbalance Monitoring," IEEE Trans. Instrum. Meas., vol. 64, no. 10, pp. 2813-2820, 2015.

[35] S. Bennett, Z. Ren, R. Goubran, K. Rockwood, and F. Knoefel, "In-Bed Mobility Monitoring Using Pressure Sensors," IEEE Tras. Instrum. Meas., vol. 64, no. 8, pp. 2110-2120, 2015.

[36] O. Salehi-Abari, F. Alaca, J. R. Green, and R. Goubran, "Application of Sensor Networks in a Smart Apartment," in Proc. Can. Med. and Biol. Eng. Soc. (CMBEC), 2010, pp. 15-18.

[37] C. F. Babbs, J. D. Bourland, G. P. Graber, J. T. Jones, and W. E. Schoenlein, "A Pressure-Sensitive Mat for Measureing Contact Pressure Distributions of Patients Lying on Hospital Beds," Biomed. Instrum. Technol., vol. 24, no. 5, pp. 363-370, 1990.

[38] D. I. Townsend, M. Holtzman, R. Goubran, M. Frize, and F. Knoefel, "Simulated Central Apnea Detection using the Pressure Variance," in Proc. IEEE Eng. Med. Biol. Soc. (EMBC), 2009, pp. 3917-3920.

[39] M. B. Pouyan, M. Nourani, and M. Pompeo, "Sleep State Classification using Pressure Sensor Mats," in Proc. IEEE Eng. Med. Biol. Soc. (EMBC), 2015, pp. $1207-1210$. 
[40] G. Guerrero Mora, J. M. Kortelainen, E. R. Palacios Hernandez, M. Tenhunen, A. M. Bianchi, and M. O. Mendez, "Evaluation of Pressure Bed Sensor for Automatic SAHS Screening,” IEEE Trans. Instrum. Meas., vol. 64, no. 7, pp. 1935-1943, 2015.

[41] M. Pouliot, V. Joshi, R. Goubran, and F. Knoefel, "Bed Occupancy Monitoring: Data Processing and Clinician User Interface Design," in Proc. IEEE Eng. Med. Biol. Soc. (EMBC), 2012, pp. 5810-5814.

[42] Z. Ren, T. Grant, R. Goubran, I. Fellow, M. El-tanany, I. Member, H. Sveistrup, M. Bilodeau, and J. Jutai, "Analyzing Center of Pressure Progression During Bed Exits," in Proc. IEEE Eng. Med. Biol. Soc. (EMBC), 2014, pp. 1786-1789.

[43] Google, "Project Jacquard," 2016. [Online]. Available: https:/atap.google.com/jacquard/.

[44] I. Poupyre and Google Inc., "Two-Layer Interactive Textiles," 14/959,730, 2015.

[45] Studio 1 Labs, "Pressure Sensitive Bed-Sheetes," 2017. [Online]. Available: http://www.studio1 labs.com/. [Accessed: 31-Jan-2017].

[46] C. M. A. Ashruf, "Thin Flexible Pressure Sensors," Sens. Rev., vol. 22, no. 4, pp. $322-327,2002$.

[47] E. L. Morin, J. T. Bryant, S. A. Reid, and R. A. Whiteside, "Calibration Issues of Tekscan Systems for Human Pressure Assessment," Soldier Mobil. Innov. Load Carriage Syst. Des. Eval., p. 24.1-24.7, 2000.

[48] Tekscan, "How the Tekscan Pressure Sensor is Made," 2016. [Online]. Available: https $/ /$ www.youtube.com/watch? v=q6_iZwuK3cU.

[49] Tekscan, "How the Tekscan Pressure Sensor is Made." .

[50] Tekscan, "BPMS TM User Manual 7.6x," South Boston, MA, 2016. 
[51] C. M. a. Ashruf, "Thin flexible pressure sensors," Sens. Rev., vol. 22, no. 4, pp. 322 $327,2002$.

[52] R. Cork, "XSENSOR technology: a pressure imaging overview," Sens. Rev., vol. 27, no. 1, pp. 24-28, 2007.

[53] XSensor (R) Technology Corporation, "Test \& Measurement Product Catalog."

[54] Y. Tanimoto, K. Nanba, A. Tokuhiro, H. Ukida, and H. Yamamoto, "Measurement system of transfer motion for patients with spinal cord injuries," IEEE Trans. Instrum. Meas., vol. 57, no. 1, pp. 213-219, 2008.

[55] M. Pouliot, V. Joshi, J. Chauvin, R. Goubran, and F. Knoefel, "Differentiating assisted and unassisted bed exits using ultrasonic sensor," in IEEE I2MTC International Instrumentation and Measurement Technology Conference, Proceedings, 2012, pp. 1104-1108.

[56] S. L. Bennett, "Measurements of Change in Thermal Images Due to Applied Pressure," pp. 3-8, 2015.

[57] S. Boughorbel, F. Bruekers, and J. Breebaart, "Baby-posture classification from pressure-sensor data," Proc. - Int. Conf. Pattern Recognit., pp. 556-559, 2010.

[58] A. Nag, S. Member, and S. C. Mukhopadhyay, "Occupancy Detection at Smart Home Using Real-Time Dynamic Thresholding of Flexiforce Sensor," IEEE Sens. J., vol. 15 , no. 8, pp. 4457-4463, 2015.

[59] E. Marenzi, G. M. Bertolotti, and A. Cristiani, "Design and Development of a Monitoring System for the Interface Pressure Measurement of Seated People," IEEE Trans. Instrum. Meas., vol. 62, no. 3, pp. 570-577, 2013.

[60] Y. Tanimoto, H. Takechi, H. Nagahata, and H. Yamamoto, "Pressure measurement 
of air cushions for patients," IMTC/99. Proc. 16th IEEE Instrum. Meas. Technol. Conf. (Cat. No.99CH36309), vol. 2, no. 3, pp. 666-670, 1999.

[61] A. Arcelus, I. Veledar, R. Goubran, F. Knoefel, H. Sveistrup, and M. Bilodeau, "Measurements of Sit-to-Stand Timing and Symmetry from Bed Pressure Sensors," IEEE Trans. Instrum. Meas., vol. 60, no. 5, pp. 1732-1740, 2011.

[62] S. L. Bennett, R. Goubran, K. Rockwood, and F. Knoefel, "Distinguishing between Stable and Unstable Sit-to-Stand Transfers using Pressure Sensors," in Proc. IEEE Int. Symp. Med. Meas. Appl. (MeMeA), 2014, pp. 1-4.

[63] S. L. Bennett, R. Goubran, A. Arcelus, K. Rockwood, and F. Knoefel, "Pressure Signal Feature Extraction for the Differentiation of Clinical Mobility Assessments," in Proc. IEEE Int. Symp. Med. Meas. Appl. (MeMeA), 2012, pp. 1-5.

[64] D. Townsend, M. Holtzman, R. Goubran, M. Frize, and F. Knoefel, "Relative thresholding with under-mattress pressure sensors to detect central apnea," IEEE Trans. Instrum. Meas., vol. 60, no. 10, pp. 3281-3289, 2011.

[65] D. Townsend, R. Goubran, F. Knoefel, and J. Leech, "Validation of Unobtrusive Pressure Sensor Array for Central Sleep Apnea Screening," IEEE Trans. Instrum. Meas., vol. 61, no. 7, pp. 1857-1865, 2012.

[66] D. I. Townsend, M. Holtzman, R. Goubran, M. Frize, and F. Knoefel, "Measurement of Torso Movement with Delay Mapping using an Unobtrusive Pressure-Sensor Array,” IEEE Trans. Instrum. Meas., vol. 60, no. 5, pp. 1751-1760, 2011.

[67] G. G. Mora, J. M. Kortelainen, E. Ruth, P. Hernández, M. Tenhunen, A. M. Bianchi, and M. O. Méndez, "Evaluation of Pressure Bed Sensor for Automatic SAHS Screening," IEEE Trans. Instrum. Meas., vol. 64, no. 7, pp. 1935-1943, 2015. 
[68] R. Bayford and A. Tizzard, "Bioimpedance imaging: an overview of potential clinical applications," Analyst, vol. 137, no. 20, p. 4635, 2012.

[69] S. Lee, G. Squillace, C. Smeets, M. Vandecasteele, L. Grieten, R. De Francisco, and C. Van Hoof, "Congestive Heart Failure Patient Monitoring using Wearable Bioimpedance Sensor Technology,” pp. 438-441, 2015.

[70] H. I. Choi, "Injury risk prediction using elderly digital human body model," Int. J. Automot. Technol., vol. 16, no. 3, pp. 465-469, 2015.

[71] S. Diego and L. Jolla, "Human Body Model Acquisition and Tracking Using Voxel Data '," Int. J. Comput. Vis., vol. 53, no. 3, pp. 199-223, 2003.

[72] A. Carlsson, F. Chang, P. Lemmen, A. Kullgren, K.-U. Schmitt, A. Linder, and M. Svensson, "Anthropometric Specifications, Development, and Evaluation of EvaRID-A 50(th) Percentile Female Rear Impact Finite Element Dummy Model.," Traffic Inj. Prev., pp. 855-865, 2014.

[73] S. of A. R. Project, "Anthropometric Source Book, Volume I: Anthropmetry for Designers," vol. I, 1978.

[74] M. J. Pavol, T. M. Owings, and M. D. Grabiner, 'Body segment inertial parameter estimation for the general population of older adults," J. Biomech., vol. 35, no. 5, pp. 707-712, 2002.

[75] H. K. Huang and S. C. Wu, "The evaluation of mass densities of the human body in vivi from CT Scans,” Comput. Biol. Med., vol. 6, no. 4, pp. 337-343, 1976.

[76] F. Shelton and J. W. Lott, "Conducting and interpreting interface pressure evaluations of clinical support surfaces," Geriatr. Nurs. (Minneap)., vol. 24, no. 4, pp. 222-227, 2003. 
[77] K. Bethe, D. Baumgarten, and J. Frank, "Creep of sensor's elastic elements: Metals versus non-metals," Sensors Actuators A. Phys., vol. 23, no. 1-3, pp. 844-849, 1990.

[78] Z. R. Dey, N. R. Nair, and N. Shapcott, "Evaluation of the Force Sensing Application pressure mapping system.," J. Med. Eng. Technol., vol. 37, no. 3, pp. 213-9, 2013.

[79] J. G. Dabling, A. Filatov, and J. W. Wheeler, "Static and cyclic performance evaluation of sensors for human interface pressure measurement," $2012 \mathrm{Annu}$. Int. Conf. IEEE Eng. Med. Biol. Soc., pp. 162-165, 2012.

[80] M. Ferguson-Pell, S. Hagisawa, and D. Bain, "Evaluation of a sensor for low interface pressure applications," Med. Eng. Phys., vol. 22, no. 9, pp. 657-663, 2001.

[81] A. A. Polliack, R. C. Sieh, D. D. Craig, S. Landsberger, D. R. McNeil, and E. Ayyappa, "Scientific validation of two commercial pressure sensor systems for prosthetic socket fit," Prosthet. Orthot. Int., vol. 24, pp. 63-73, 2000.

[82] J. McMurray, S. Adamopoulos, S. Anker, A. Auricchio, M. Bohm, K. Dickstein, V. Falk, G. Filippatos, C. Fonseca, M. Gomez-Sanchez, T. Jaarsma, L. Kober, G. Lip, A. Maggioni, A. Parkhomenko, B. Pieske, B. Popescu, P. Ronnevik, F. Rutten, J. Schwitter, P. Seferovic, J. Stepinska, P. Trindade, A. Voors, F. Zannad, and A. Zeiher, "ESC Guidelines for the diagnosis and treatment of acute and chronic heart failure 2012: The Task Force for the Diagnosis and Treatment of Acute and Chronic Heart Failure 2012 of the European Society of Cardiology," Eur. Heart J., vol. 33, pp. 1787-1847, 2012.

[83] A. Arcelus, I. Veledar, R. Goubran, F. Knoefel, H. Sveistrup, and M. Bilodeau, "Measurements of Sit-to-Stand Timing and Symmetry from Bed Pressure Sensors," 
IEEE Trans. Instrum. Meas., vol. 60, no. 5, pp. 1732-1740, 2011.

[84] D. Townsend, R. Goubran, F. Knoefel, and J. Leech, "Validation of Unobtrusive Pressure Sensor Array for Central Sleep Apnea Screening," IEEE Trans. Instrum. Meas., vol. 61, no. 7, pp. 1857-1865, 2012.

[85] M. Holtzman, A. Arcelus, I. Veledar, R. Goubran, H. Sveistrup, and P. Guitard, "Force Estimation with a Non-Uniform Pressure Sensor Array," in Proc. IEEE Int. Instrum. Meas. Technol. Conf. (I2MTC), 2008, pp. 1974-1979. 